\title{
Thermal Safety Analyses for the Production of Plutonium-238 at the High Flux Isotope Reactor
}

Approved for public release.

Distribution is unlimited.
C.J. Hurt James D. Freels Randy W. Hobbs Prashant K. Jain G. Ivan Maldonado

August 2016 


\title{
DOCUMENT AVAILABILITY
}

Reports produced after January 1, 1996, are generally available free via US Department of Energy (DOE) SciTech Connect.

\section{Website http://www.osti.gov/scitech/}

Reports produced before January 1, 1996, may be purchased by members of the public from the following source:

\author{
National Technical Information Service \\ 5285 Port Royal Road \\ Springfield, VA 22161 \\ Telephone 703-605-6000 (1-800-553-6847) \\ TDD 703-487-4639 \\ Fax 703-605-6900 \\ E-mail info@ ntis.gov \\ Website http://www.ntis.gov/help/ordermethods.aspx
}

Reports are available to DOE employees, DOE contractors, Energy Technology Data Exchange

representatives, and International Nuclear Information System representatives from the following source:

Office of Scientific and Technical Information

PO Box 62

Oak Ridge, TN 37831

Telephone 865-576-8401

Fax 865-576-5728

E-mail reports@osti.gov

Website http://www.osti.gov/contact.html

This report was prepared as an account of work sponsored by an agency of the United States Government. Neither the United States Government nor any agency thereof, nor any of their employees, makes any warranty, express or implied, or assumes any legal liability or responsibility for the accuracy, completeness, or usefulness of any information, apparatus, product, or process disclosed, or represents that its use would not infringe privately owned rights. Reference herein to any specific commercial product, process, or service by trade name, trademark, manufacturer, or otherwise, does not necessarily constitute or imply its endorsement, recommendation, or favoring by the United States Government or any agency thereof. The views and opinions of authors expressed herein do not necessarily state or reflect those of the United States Government or any agency thereof. 
Research Reactors Division

Thermal Safety Analyses for the Production of Plutonium-238 at the High Flux Isotope Reactor

\author{
Christopher J. Hurt \\ James D. Freels \\ Randy W. Hobbs \\ Prashant K. Jain \\ G. Ivan Maldonado
}

Date Published: August 2016

Prepared by

OAK RIDGE NATIONAL LABORATORY

Oak Ridge, TN 37831-6283

managed by

UT-BATTELLE, LLC

for the

US DEPARTMENT OF ENERGY

under contract DE-AC05-00OR22725 



\section{CONTENTS}

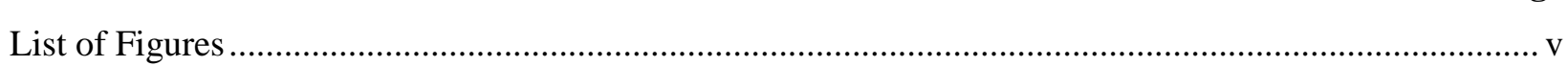

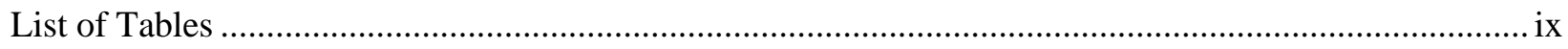

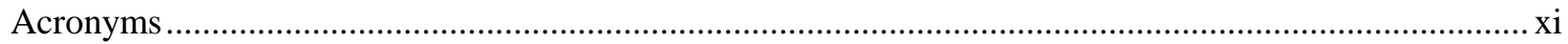

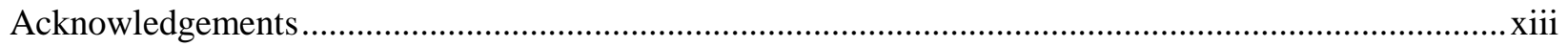

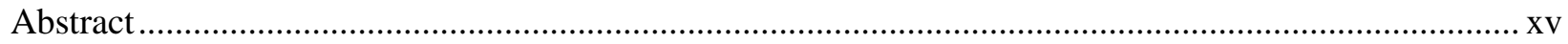

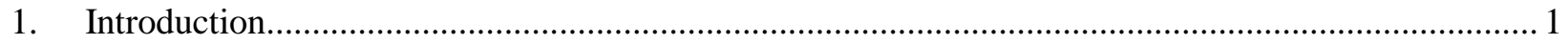

2. Overview of the Plutonium-238 Supply Project ........................................................................... 3

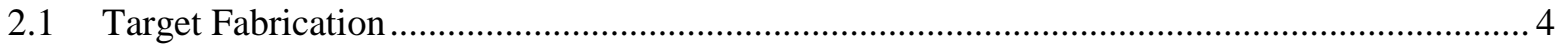

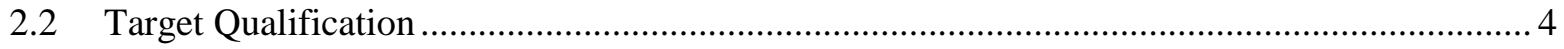

2.2.1 Experiment Safety Analysis Review........................................................................ 5

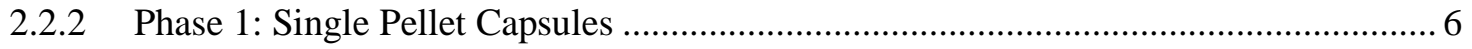

2.2.3 Phase 2: Partially Loaded Targets............................................................................. 7

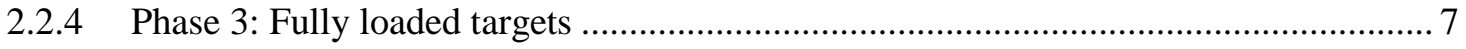

2.2.5 Phase 4: Production and optimization of targets ....................................................... 8

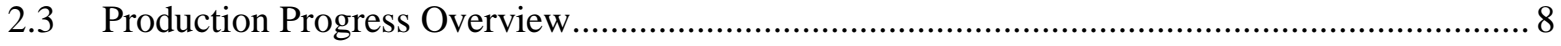

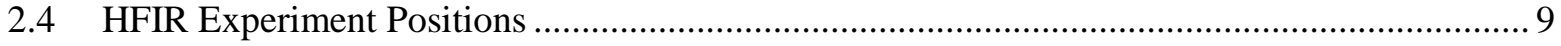

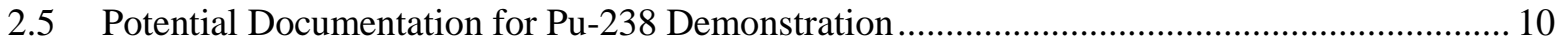

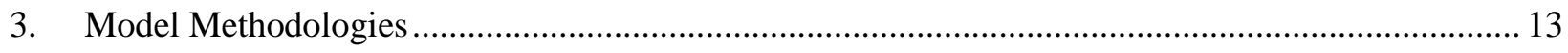

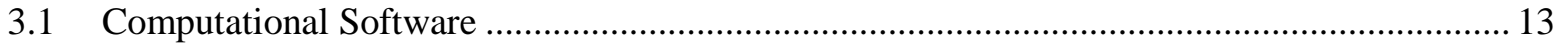

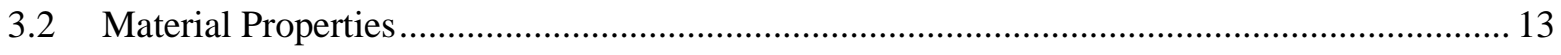

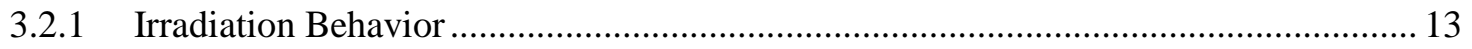

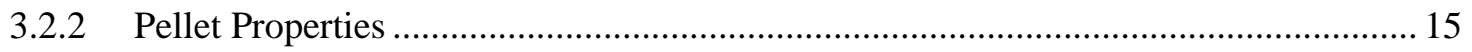

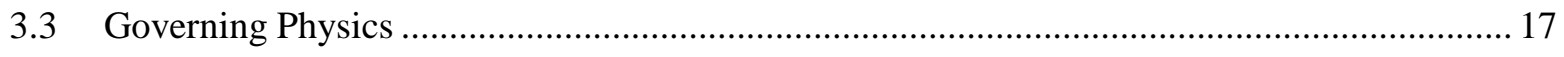

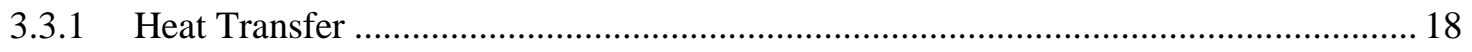

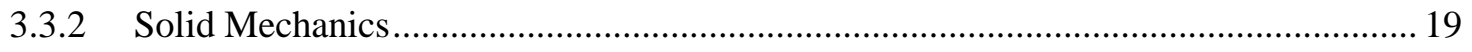

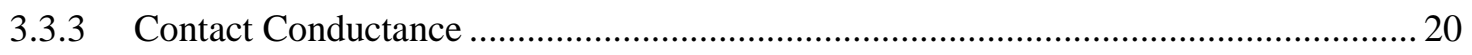

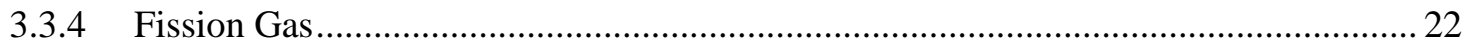

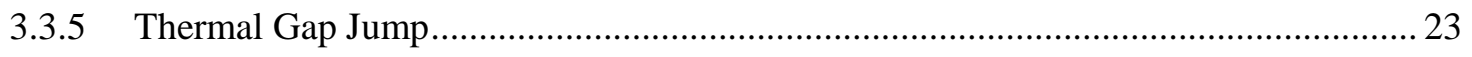

3.3.6 Target Surface: Heat Transfer Coefficient, Bulk Temperature, and Oxide Layer ....... 26

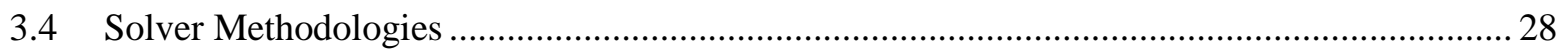

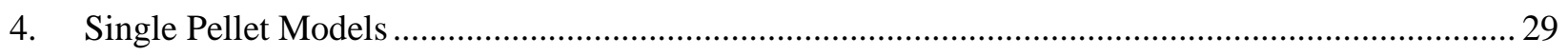

4.1 Single Pellet Mesh ........................................................................................................... 29 


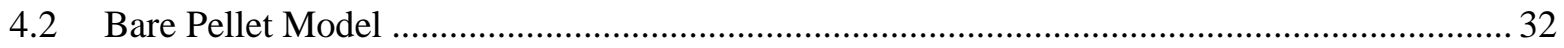

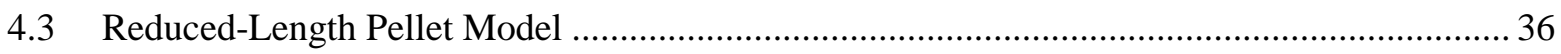

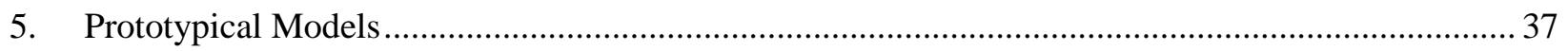

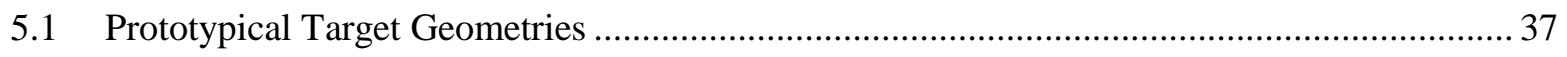

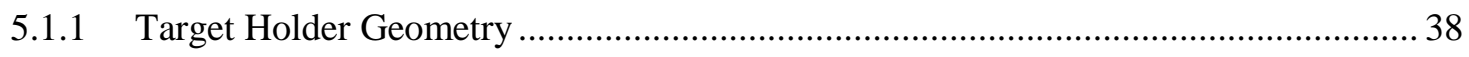

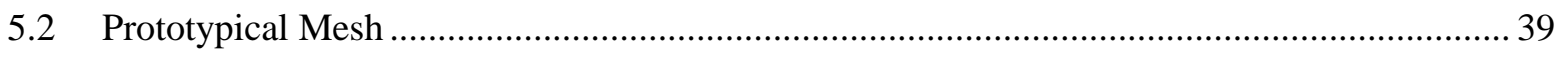

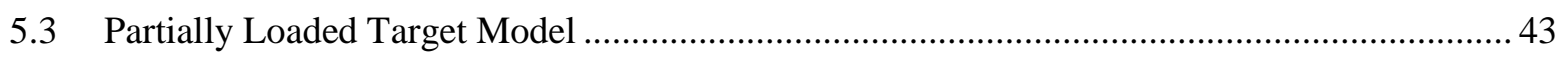

5.3.1 Partially Loaded Model Analysis.......................................................................... 43

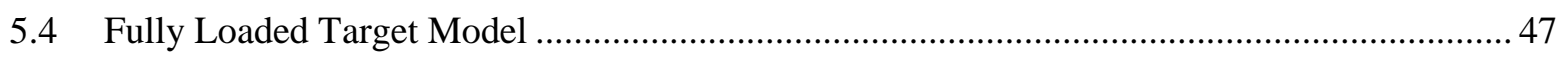

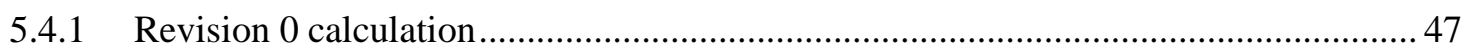

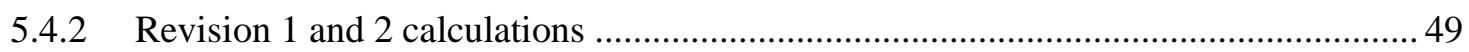

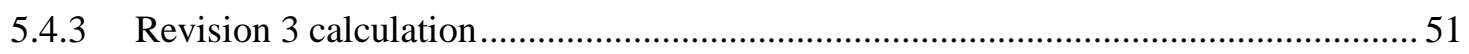

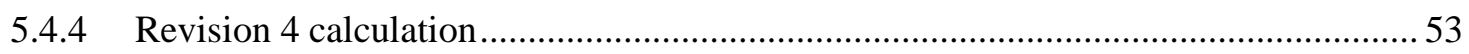

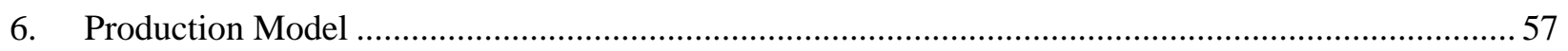

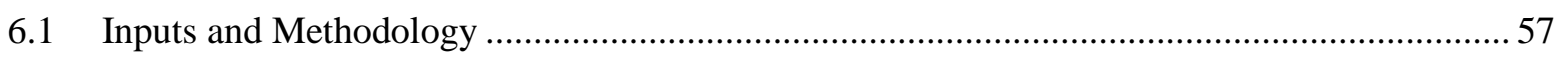

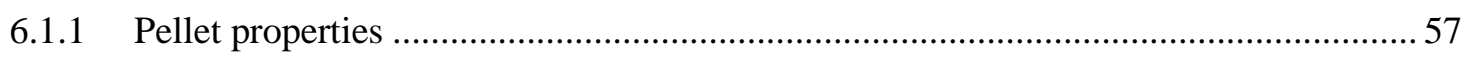

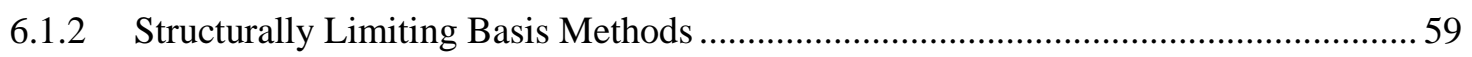

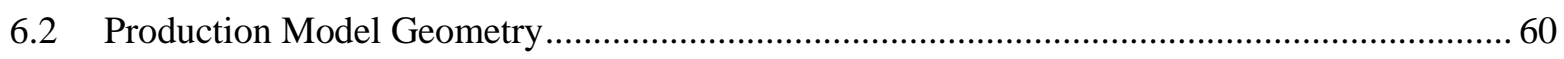

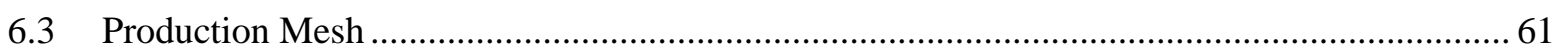

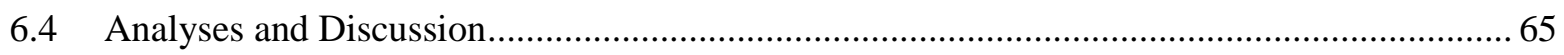

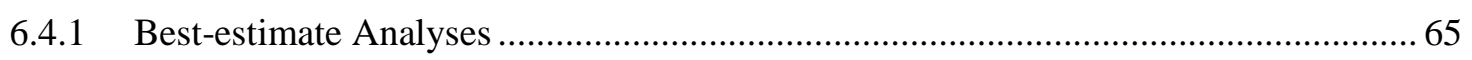

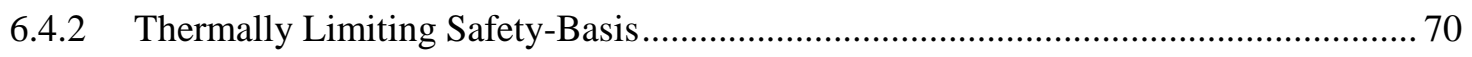

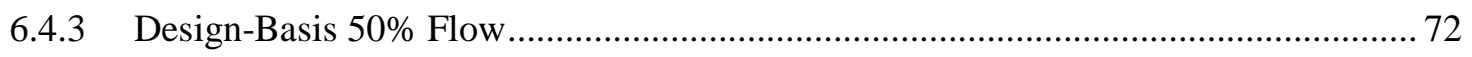

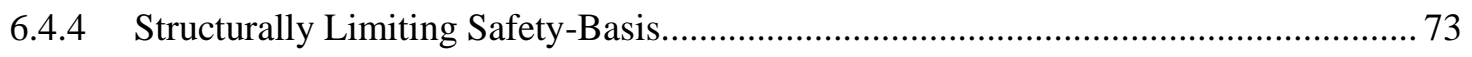

6.4.5 Summary of Production Target Analyses ............................................................ 75

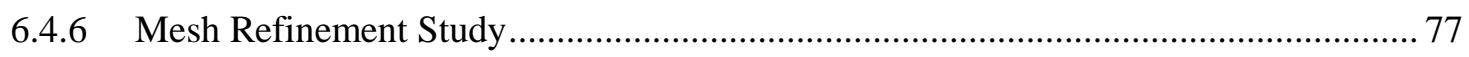

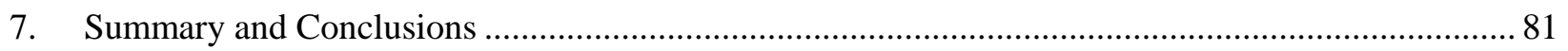

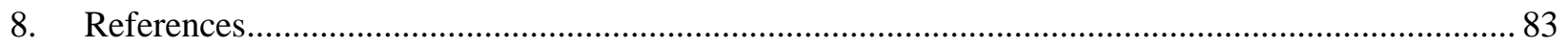




\section{LIST OF FIGURES}

Figure Page

Fig. 2.1: Important reaction and decay pathways in neutron irradiation of ${ }^{237} \mathrm{~Np}$.................................. 3

Fig. 2.2: Overview graphic of the ${ }^{238} \mathrm{Pu}$ supply project...................................................................... 4

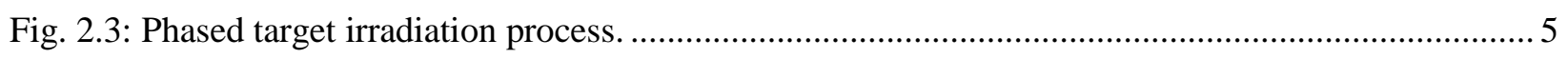

Fig. 2.4: Simple diagram of the experiment safety review process at the HFIR. .................................... 5

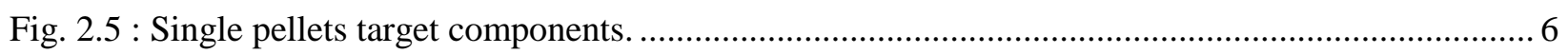

Fig. 2.6 : Partially loaded test targets with holder prior to irradiation. ........................................................ 7

Fig. 2.7: Irradiated target designs and ${ }^{238} \mathrm{Pu}$ production by HFIR operating cycle through cycle

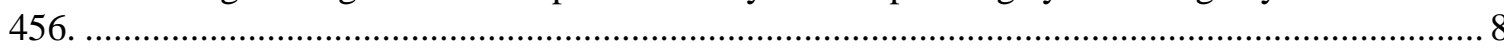

Fig. 2.8: Irradiated target designs and ${ }^{238} \mathrm{Pu}$ production by HFIR operating cycle through cycle

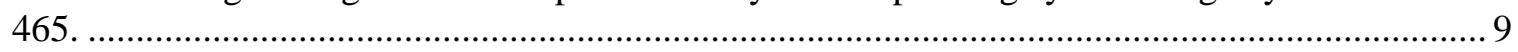

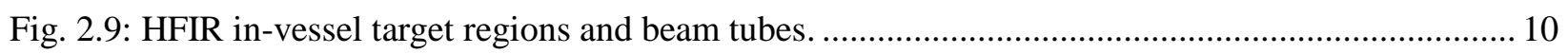

Fig. 2.10: Areas of the ${ }^{238} \mathrm{Pu}$ supply project demonstration efforts identified as amenable to

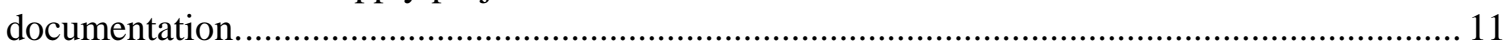

Fig. 3.1: General trend and contributions to pellet dimensional irradiation behavior. ............................. 14

Fig. 3.2: Example radial temperature profile taken from the fully loaded target model........................... 15

Fig. 3.3: Pellet thermal expansion for varying heat-treatment temperatures as a function of

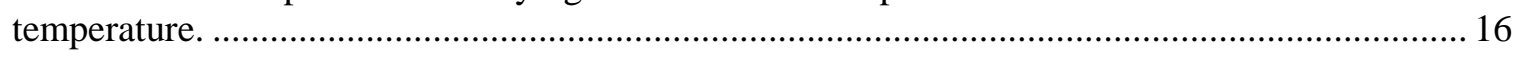

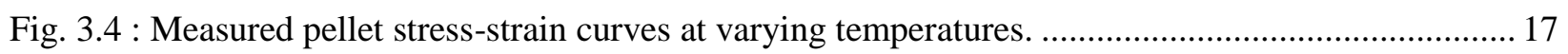

Fig. 3.5: Pellet heating rate vs. axial position for the polynomial fits and input data at $0,5,10,15$,

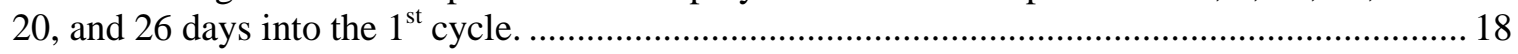

Fig. 4.1: Bare pellet mesh for the extra-coarse and normal mesh cases at the pellet domain.................... 30

Fig. 4.2: Reduced-length pellet mesh for mesh 3 case at the pellet domain with surrounding LHS. ......... 30

Fig. 4.3: Bare pellet meshes for capsule components and the entire capsule for the coarse mesh case

Fig. 4.4: Maximum pellet temperature as a function of fractional reactor power and initial cold radial gap size.

Fig. 4.5: Minimum pellet side gap size as a function of fractional reactor power and initial cold radial gap size.

Fig. 4.6: Temperature contour of the $1 / 4$-pie slice modeled bare pellet capsule for the 1.1 mil cold-

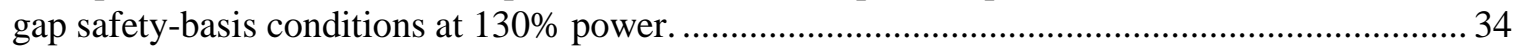

Fig. 4.7: Temperature contour of the pellet domain with thermal expansion deformation $\mathrm{x} 100$ for

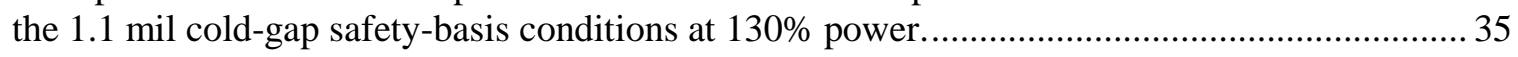

Fig. 4.8: Temperature height profile for an X-Y cut plane at location of maximum pellet temperature for the 1.1 mil cold-gap safety-basis conditions at $130 \%$ power.

Fig. 4.9: Temperature profile along the axial centerline for 130\% SB conditions with mesh-1 quadratic solution. 
Fig. 5.1 : Representation of partially loaded model target pin components............................................. 37

Fig. 5.2 : Representation of fully loaded model target pin components. ................................................. 38

Fig. 5.3: Radial cut-view of prototypical target holder with seven prototypical target "pins". .................. 39

Fig. 5.4: Extremely-coarse and extra-coarse mesh at the pellet domain that serve as the primary mesh for the fully and partially loaded targets, respectively. ...................................................... 40

Fig. 5.5: Coarse, normal, and fine mesh at the pellet domain................................................................. 41

Fig. 5.6: Extremely-coarse, extra-coarse, and fine mesh at the pellet and housing adjacent domains.

Fig. 5.7: Extra-coarse mesh at the TEC/UST/housing and TEC/UST/WBT/housing domains for the partially loaded and fully loaded target models, respectively.

Fig. 5.8: Extra-coarse mesh at the BEC/LST/housing domains for the partially loaded and fully loaded target models.

Fig. 5.9: Allowable pellet shrinkage vs. fabrication gas gap for safety-basis of a 1 Cycle Irradiation.

Fig. 5.10: Allowable pellet shrinkage vs. fabrication gas gap for safety-basis of a 2 Cycle Irradiation.

Fig. 5.11: 3-D rotated temperature contour of the 2-D axisymmetric modeled volume of the partially loaded target assembly for the $900^{\circ} \mathrm{C}$ Pellet EOC-1 DB conditions at $50 \%$ flow and $100 \%$ power.

Fig. 5.12: Temperature contour with deformation of the 2-D axisymmetric modeled volume of the zoomed-in pellet stack/housing gas gap for the $900^{\circ} \mathrm{C}$ Pellet EOC-1 SB conditions at $130 \%$ power.

Fig. 5.13: Temperature vs. axial position along the axial centerline for the $900^{\circ} \mathrm{C}$ Pellet EOC-1 SB conditions at $130 \%$ power.

Fig. 5.14: The limiting pellet diametrical shrinkage for 0.1-0.3 mil fabrication gap against the measured PIE shrinkages for each pellet heat-treatment.

Fig. 5.15: Allowable pellet shrinkage vs. fabrication gas gap for safety-basis of a 1 cycle irradiation.

Fig. 5.16: 3-D rotated temperature contour for an undistorted and distorted view at VXF-15 EOC$1 \mathrm{SB}$ conditions at $130 \%$ power.

Fig. 5.17: 3-D rotated stress contour with 10000x deformation of the 2-D axisymmetric modeled volume of the hot pellet for the VXF-15 EOC-1 SB conditions at $130 \%$ power.

Fig. 5.18: Temperature vs. position along the axial centerline for the VXF-15 EOC-1 SB conditions at $130 \%$ power.

Fig. 5.19: Allowable pellet shrinkage vs. maximum pellet heating for safety-basis of a 2 cycle irradiation.

Fig. 5.20: Calculated allowable pellet shrinkage with respect to fully loaded target temperatures along with partially loaded PIE data as a function of pellet heat generation. 50

Fig. 5.21: PIE data and fitted curves for pellet shrinkage vs. fission density.

Fig. 5.22: Temperature profile along the pellet centerline at 100\% power for 5, 10, 15, 20, and 26 days into the $2^{\text {nd }}$ cycle for VXF-3 position. 
Fig. 5.23: Day 26 of $2^{\text {nd }}$ cycle at VXF-3 temperature profile along the pellet axial centerline at $130 \%$ power.

Fig. 5.24: COMSOL data-fitted temperature profiles along the pellet centerline at $100 \%$ power for $5,10,15,20$, and 26 days into the second cycle at position VXF-15.

Fig. 5.25: COMSOL data-fitted pellet centerline temperature profiles at $100 \%$ power for second cycle times at VXF15 as well as EOC-1 for positions VXF-3 and VXF-15.

Fig. 5.26: Pellet stack temperature profiles for day 0,5 , and 10 into the $2^{\text {nd }}$ cycle, not to same scale.

Fig. 5.27: Pellet stack temperature profiles for day 15,20 and 26 into the $2^{\text {nd }}$ cycle, not to same scale.

Fig. 5.28: Mesh refinement for best estimate (primary) and cold case (no structural mechanics) models for the fully loaded target.

Fig. 6.1: Non-simultaneous observation confidence intervals and their curve fits along with the raw PIE data.

Fig. 6.2: Thermal expansion measurement data, averaged data, and the COMSOL probe results. 59

Fig. 6.3 : Representation of production model target pin components.

Fig. 6.4 : Extra coarse mesh in the pellet/cladding region. .62

Fig. 6.5 : Normal, finer and extra fine meshes in the pellet/cladding region. .

Fig. 6.6: Extremely fine mesh in the pellet/cladding region.

Fig. 6.7: Extra coarse and extremely fine meshes in the upper region near the WBT.

Fig. 6.8: Extra coarse and extremely fine meshes in the lower region near the BEC, LST, lower expansion spacers and housing.

Fig. 6.9: Maximum target temperatures over 3 irradiation cycles ( 78 days) for all 7 pins in VXF15 and pin 1 in VXF-3 ("Pin 8").

Fig. 6.10: Maximum side pressure over 3 irradiation cycles (78 days) for pin 1 in VXF-15.

Fig. 6.11: 2-D R-Z (distorted) VXF-15 pin 1 pellet temperature profiles $\left({ }^{\circ} \mathrm{C}\right)$ for EOC-1, 2, and 3 .

Fig. 6.12: 2-D R-Z (distorted) VXF-15 pin 1 pellet temperature profiles $\left({ }^{\circ} \mathrm{C}\right)$ showing radial gap for EOC-1, 2, and 3 where gap width shown is approximately 1 mil.

Fig. 6.13: Pin 1, cycle 1 pellet centerline temperatures as a function of axial position. 68

Fig. 6.14: Pin 1, cycle 2 pellet centerline temperatures as a function of axial position. 68

Fig. 6.15: Pin 1, cycle 3 pellet centerline temperatures as a function of axial position.

Fig. 6.16: Pin 1, cycle 3 pellet side temperatures as a function of axial position.

Fig. 6.17: Pin 1, cycle 3 pellet side pressures as a function of axial position. .70

Fig. 6.18: Pin 1 maximum material region temperatures as a function of irradiation days over 3 cycles. 71

Fig. 6.19: 3-D center pellet von Mises stress profile at TLB EOC-2 and 3 with 100x deformation. ......... 71

Fig. 6.20: EOC-3 bulk coolant temperature as a function of axial position for all cases.......................... 72

Fig. 6.21: EOC-3 target surface temperature as a function of axial position for all cases. .73 
It is important to note the changing scales (on the right of each plot) in Fig. 6.22 and Fig. 6.23, which if unnoticed could lead to misleading interpretations of the results. These plots are therefore best used for comparing differing behavioral trends in the different cases, and only cautiously for comparisons of magnitude.

Fig. 6.22: 3-D center pellet von Mises stress profile at EOC-3 for TLB, SLB-1 and SLB-2 cases with $100 x$ deformation.

Fig. 6.23: 3-D pellet stack von Mises stress profile at EOC-3 for SLB-1 and SLB-2 cases with 100x deformation and 20x distortion in $\mathrm{R}$ direction.

Fig. 6.24: EOC-3 maximum target temperature as a function of the power/volume factor for the BE, SLB, and TLB cases.

Fig. 6.25: EOC-3 pellet radial side pressure as a function of the power/volume factor for the BE, SLB, and TLB cases.

Fig. 6.26: Mesh refinement results for EOC1/EOC3 and linear/quadratic bases using an averaged error norm.

Fig. 6.27: Mesh refinement results for EOC1/EOC3 and linear/quadratic bases using the maximum temperature error norm. 


\section{LIST OF TABLES}

\section{Table}

Table 5.1: Mesh cases for partially and fully loaded target analyses................................................... 39

Table 6.1: Summary of safety limit results for the production target analyses...................................... 76

Table 7.1: Summary of solution scopes for all models .......................................................................... 81 



\section{ACRONYMS}

\begin{tabular}{|c|c|}
\hline 2-D & two-dimensional \\
\hline $3-\mathrm{D}$ & three-dimensional \\
\hline Al-6061-t6 & aluminum alloy type 6061 with T6 temper \\
\hline BEC & bottom end cap \\
\hline DB & design basis \\
\hline DOE & Department of Energy \\
\hline EOC & end-of-cycle \\
\hline HFIR & High Flux Isotope Reactor \\
\hline INL & Idaho National Laboratory \\
\hline LHS & lower heat sink \\
\hline LST & lower support tube \\
\hline NASA & National Aeronautics and Space Administration \\
\hline NEUP & Nuclear Energy University Program \\
\hline $\mathrm{NpO}_{2} / \mathrm{Al}$ & neptunium dioxide in aluminum cermet \\
\hline ORNL & Oak Ridge National Laboratory \\
\hline PIE & post irradiation examination \\
\hline PB & permanent beryllium reflector \\
\hline QA & quality assurance \\
\hline REDC & Radiochemical Energy Development Center \\
\hline RRD & Research Reactors Division \\
\hline RTG & radioisotope thermoelectric generators \\
\hline SB & safety basis \\
\hline SLB & structurally limiting safety basis \\
\hline SST & stainless steel \\
\hline TEC & top end cap \\
\hline TLB & thermally limiting safety basis \\
\hline $\mathrm{UO}_{2}$ & uranium dioxide \\
\hline US & United States \\
\hline UST & upper support tube \\
\hline WBT & weld backing/support tube \\
\hline VXF & vertical experiment facility \\
\hline
\end{tabular}





\section{ACKNOWLEDGEMENTS}

The authors would like to acknowledge the support of this work provided by the US Department of Energy as well as the Research Reactors Division, and additional support from the Reactor and Nuclear Systems Division and Nuclear Security and Isotope Technology Division at Oak Ridge National Laboratory. The primary author would also like to acknowledge the support of the Department of Energy Office of Nuclear Energy through the Nuclear Energy University Program fellowship. 



\begin{abstract}
There has been a considerable effort over the previous few years to demonstrate and optimize the production of plutonium-238 $\left({ }^{238} \mathrm{Pu}\right)$ at the High Flux Isotope Reactor (HFIR). This effort has involved resources from multiple divisions and facilities at the Oak Ridge National Laboratory (ORNL) to demonstrate the fabrication, irradiation, and chemical processing of targets containing neptunium-237 $\left({ }^{237} \mathrm{~Np}\right)$ dioxide $\left(\mathrm{NpO}_{2}\right) /$ aluminum $(\mathrm{Al})$ cermet pellets. A critical preliminary step to irradiation at the HFIR is to demonstrate the safety of the target under irradiation via documented experiment safety analyses.
\end{abstract}

The steady-state thermal safety analyses of the target are simulated in a finite element model with the COMSOL Multiphysics code that determines, among other crucial parameters, the limiting maximum temperature in the target. Safety analysis efforts for this model discussed in the present report include: (1) initial modeling of single and reduced-length pellet capsules in order to generate an experimental knowledge base that incorporate initial non-linear contact heat transfer and fission gas equations, (2) modeling efforts for prototypical designs of partially loaded and fully loaded targets using limited available knowledge of fabrication and irradiation characteristics, and (3) the most recent and comprehensive modeling effort of a fully coupled thermo-mechanical approach over the entire fully loaded target domain incorporating burn-up dependent irradiation behavior and measured target and pellet properties, hereafter referred to as the "production" model.

These models are used to conservatively determine several important steady-state parameters including target stresses and temperatures, the limiting condition of which is the maximum temperature with respect to the melting point. The single pellet model results provide a basis for the safety of the irradiations, followed by parametric analyses in the initial prototypical designs that were necessary due to the limiting fabrication and irradiation data available. The calculated parameters in the final production target model are the most accurate and comprehensive, while still conservative. Over 210 permutations in irradiation time and position were evaluated, and are supported by the most recent inputs and highest fidelity methodology. The results of these analyses show that the models presented in this report provide a robust and reliable basis for previous, current and future experiment safety analyses. In addition, they reveal an evolving knowledge of the steady-state behavior of the $\mathrm{NpO}_{2} / \mathrm{Al}$ pellets under irradiation for a variety of target encapsulations and potential conditions. 



\section{INTRODUCTION}

The domestic production of plutonium-238 $\left({ }^{238} \mathrm{Pu}\right)$ dioxide $\left(\mathrm{PuO}_{2}\right)$ is an effort undertaken currently by the US Department of Energy (DOE) to supply the National Aeronautics and Space Administration (NASA) with a radioisotope fuel source for deep space missions. The production of ${ }^{238} \mathrm{Pu}$ at DOE research reactors is a critical component in the intended re-established supply chain [1],[2] and the first step in that function is the pilot demonstration of the fabrication, irradiation and chemical processing of targets containing neptunium-237 $\left({ }^{237} \mathrm{~Np}\right)$ dioxide $\left(\mathrm{NpO}_{2}\right)$ at the Oak Ridge National Laboratory (ORNL). The targets are irradiated at the High Flux Isotope Reactor (HFIR) at ORNL before being chemically processed at the ORNL Radiochemical Engineering Development Center (REDC).

The HFIR is a high-enriched uranium (HEU) fuel reactor that, in its function as a high neutron flux reactor, supports such scientific missions as neutron scattering experiments, materials irradiation research, neutron activation analysis, and isotope production. A variety of target positions exist for experiment irradiation, including positions in its permanent beryllium (PB) reflector that are used for the experiments discussed in this report. In order for an experiment to be qualified for irradiation at the HFIR, a safety review must be conducted to ensure safe operation of the HFIR [3]. This commonly includes steady-state thermal-structure safety analyses [4] in finite element codes like ANSYS, ABAQUS, and, as is used for the models in this report, the commercial code COMSOL Multiphysics. The fission heat generation from these targets provides a unique modeling challenge in terms of the nonlinear contact heat transfer, strongly coupled thermal-structural feedbacks, and pellet irradiation behavior.

The steady-state safety analysis has been simulated through multiple model versions corresponding with the phased approach of the target irradiation plan, each of which underwent its own revisions as necessary to incorporate improvements or changes in input data including target fabrication parameters or measured post-irradiation data, and/or accommodate changes in the scope of the simulations including the target irradiation time or burnup or the irradiation position. The following five models were created in sequential order: (1) a "bare pellet" or single pellet capsule model simulated for two irradiation cycles [5],[6], (2) the reduced-length pellet model built to accommodate the need for further post-irradiation data while reducing the necessary cooling requirements [7], (3) the partially loaded target model which contained an eight (8) pellet stack and was simulated for two irradiation cycles [8], (4) the fully loaded target model which contained a fifty-two (52) pellet stack and was qualified for two cycles [9], and (5) the comprehensive updated fully loaded or production target model intended for three irradiation cycles and with detailed input and fully coupled thermo-mechanical physics throughout the target domain [10]. The two single pellet models and the first two prototypical target models are grouped together, respectively, in this report due to their similarities in modeling including dimensions, input, authors, and scope.

Section 2 of this report serves as a background overview of the ${ }^{238} \mathrm{Pu}$ supply project in an overall DOE scope, an ORNL scope, and more narrowly a safety analysis scope at the HFIR. Section 3 details the methodology of these models, including inputs, equations, and computational tools utilized. The two single pellet models and their results are discussed in section 4, while the first two prototypical design targets' (partially loaded and the initial fully loaded) models and their results are discussed in section 5. Section 6 gives an overview of the current production target model and the results to date. A summary of the model results and the conclusions drawn from them is given in section 7. 



\section{OVERVIEW OF THE PLUTONIUM-238 SUPPLY PROJECT}

A campaign is underway to provide a new supply of plutonium-238 using existing nuclear research reactors at the ORNL and Idaho National Laboratory (INL) and existing chemical recovery facilities at ORNL. Validation and testing activities for new irradiation target designs have been conducted in four phases over a 3-4 year period to provide data to support an increased throughput toward a production phase. Design, qualification, fabrication, and irradiation of targets over the first three project phases have been completed. Data from post-irradiation examination (PIE) has been extracted to support safety analysis and irradiation of future target designs.

Plutonium-238 oxide pellets fuel the radioisotope thermoelectric generators (RTGs) that are the established power sources for deep space missions where solar power is not viable. The DOE has been tasked to re-establish the domestic production of ${ }^{238} \mathrm{Pu}$ in support of ${ }^{238} \mathrm{Pu}$-powered spacecraft utilized by NASA.

The technology demonstration activities described here are focused on supporting future production capability; specifically background information on the target design, qualification and irradiation studies that have taken place to date is discussed in this chapter. The intended infrastructure for full-scale production includes multiple DOE facilities and target irradiation at research reactors at both ORNL and INL, however the focus of this chapter is on target design, qualification and irradiation studies that have taken place at ORNL.

The neutron irradiation of ${ }^{237} \mathrm{~Np}$ in a nuclear reactor yields ${ }^{238} \mathrm{Pu}$ as shown in the reaction and decay pathway in Fig. 2.1 as well as other by-products including undesirable isotopes such as ${ }^{236} \mathrm{Pu}$. It is anticipated that the HFIR at ORNL and the Advanced Test Reactor (ATR) at INL, together will irradiate sufficient neptunium oxide $\left(\mathrm{NpO}_{2}\right)$ to produce an estimated $1.5 \mathrm{~kg}$ of plutonium product per year.

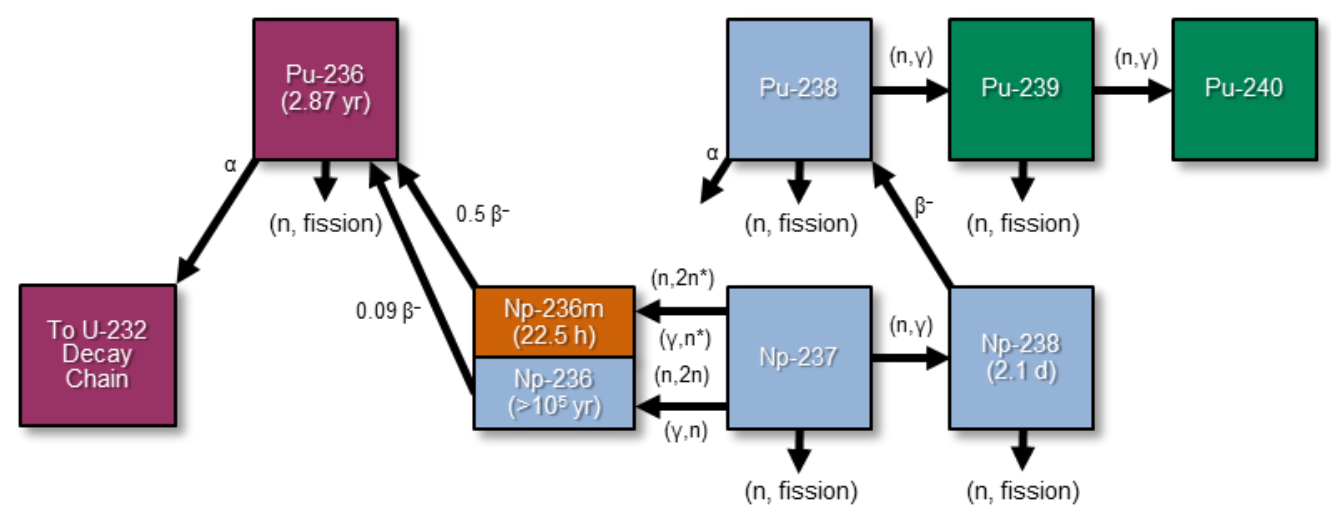

Fig. 2.1: Important reaction and decay pathways in neutron irradiation of ${ }^{237} \mathrm{~Np}$.

The overview of the planned domestic supply chain is shown in Fig. 2.2 [1], where the irradiation efforts at HFIR are highlighted. The stored neptunium oxide is located at INL, from there it will be transferred to its fabrication location (ORNL), with some chemical processing to remove impurities before pellet pressing and target fabrication. Irradiations will then take place as previously discussed before chemical processing to extract the ${ }^{238} \mathrm{Pu}$ stock and remaining ${ }^{237} \mathrm{~Np}$ feedstock for recycling before delivering the final product to Los Alamos National Laboratory, where it will be used in the powdered form of $\mathrm{PuO}_{2}$. 


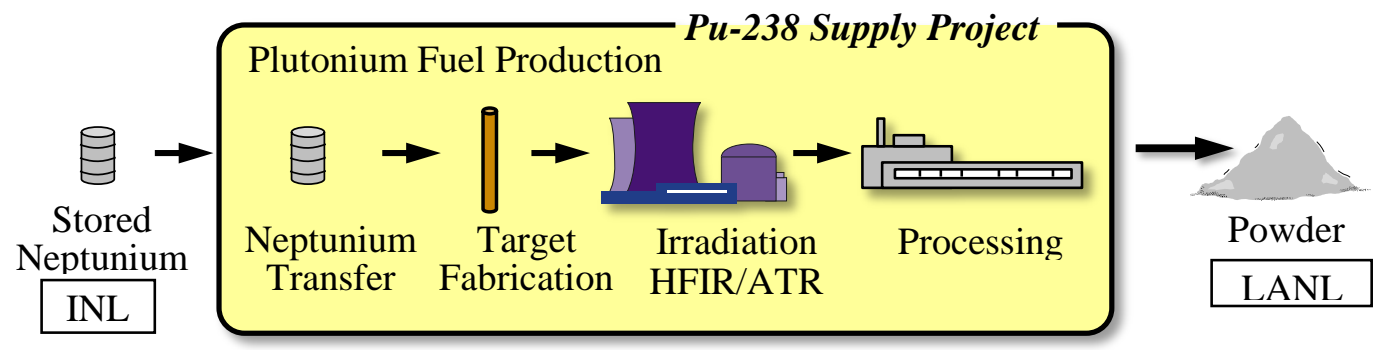

Fig. 2.2: Overview graphic of the ${ }^{238} \mathrm{Pu}$ supply project.

Before ${ }^{238} \mathrm{Pu}$ can be produced, a series of irradiation and processing tests are required to develop and validate the designs, procedures, process flow sheets, and specifications required during the production process.

Initial tests were conducted in the HFIR in order to expedite development of the knowledge base necessary for target design and are highlighted below. A series of target irradiations and post-irradiation examinations (PIEs) have provided a body of knowledge necessary to qualify prototypical, or productionstyle, targets. By the end of the project, production targets will be irradiated in HFIR. The use of existing hot cell facilities in the ORNL REDC to conduct chemical processing and recovery scale-up tests is not discussed in any detail here.

\subsection{TARGET FABRICATION}

Target fabrication requires several steps to prepare for irradiation:

- preparing neptunium feedstock for fabrication into pellet form, including the removal of ${ }^{233} \mathrm{~Pa}$, conversion to $\mathrm{NpO}_{2}$, and characterizing the resulting oxide powder to develop a material specification for $\mathrm{NpO}_{2}$,

- blending the $\mathrm{NpO}_{2}$ powder with aluminum powder, pressing them into pellets, verifying the composition through testing and analysis,

- loading the pressed pellets into an aluminum clad and then transferring the target to a welding glove box,

- $\quad$ seal-welding, leak testing, and radiographing the target, and

- hydrostatic compression of the target and radiographic inspection as necessary.

All of the above steps have been demonstrated on significant $\left(\sim 500\right.$ gm) quantities of $\mathrm{NpO}_{2}$. The current target design to be used consists of $\mathrm{NpO}_{2} / \mathrm{Al}$ pellets $(\sim 1 / 4$ " diameter by $\sim 3 / 8$ " length) loaded into a sealed thin walled 6061 aluminum (Al-6061) containment housing tube [11].

\subsection{TARGET QUALIFICATION}

The irradiation test program consists of four phases (these four phases are color coded in Fig. 2.3) that provide an incremental approach intended to reduce the risk of target failure during testing. Additionally, PIE results from each phase serve as a hold point and are used to guide the course of the subsequent irradiations. The irradiation characteristics of ${ }^{238} \mathrm{Pu}$ production in the HFIR of particular interest are:

- pellet dimensional changes

- fission gas release fractions

- heat generation rates
- pellet clad interaction (PCI)

- ${ }^{236} \mathrm{Pu}$ production

- product yields 
Fig. 2.3 illustrates how several irradiation cycles have been used in the testing:

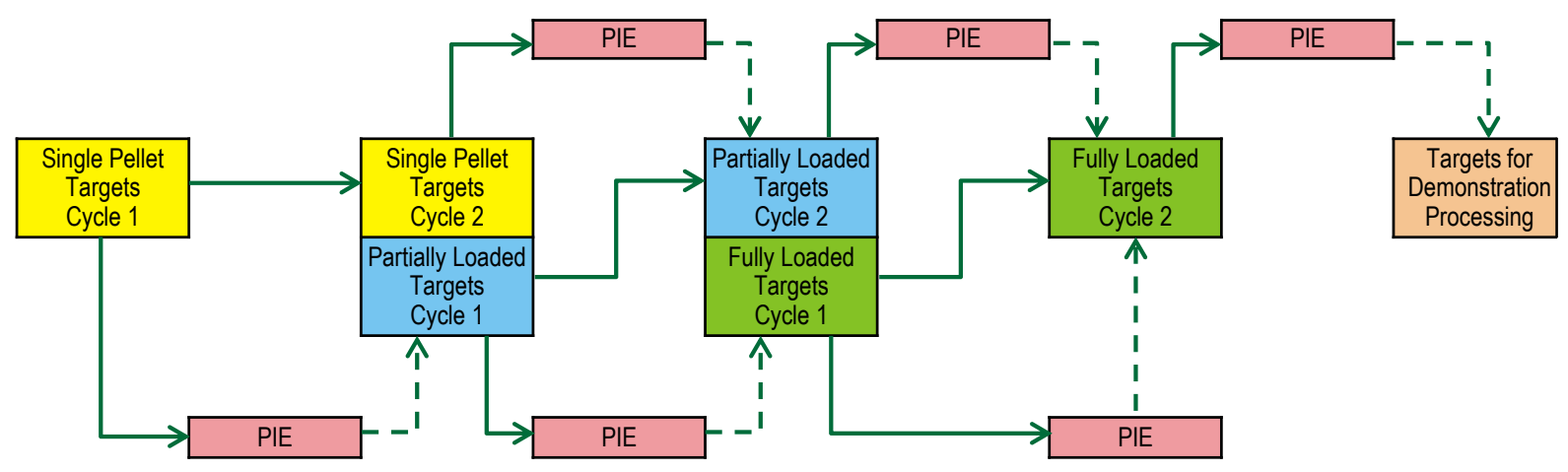

Fig. 2.3: Phased target irradiation process.

\subsubsection{Experiment Safety Analysis Review}

Final target qualification requires an experiment authorization basis document supported by safety review references including calculations that assure target cooling in off-normal and nominal reactor operating conditions that do not result in either reactor fuel damage or damage to the experiment target as defined in the HFIR SAR [12]. The process to generate a comprehensive experiment authorization basis document is shown in Fig. 2.4 below.

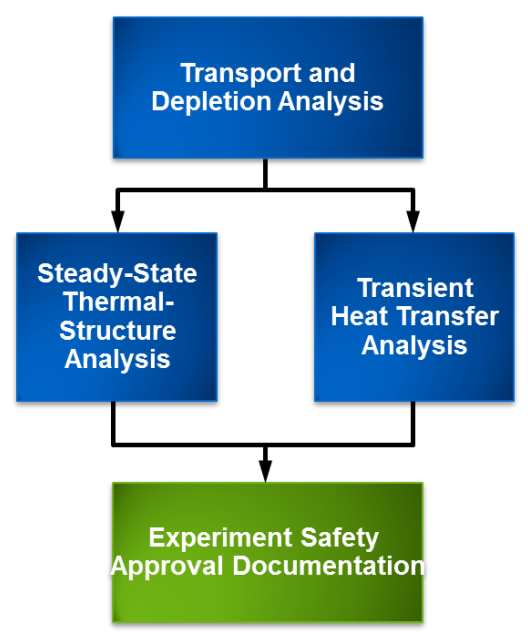

Fig. 2.4: Simple diagram of the experiment safety review process at the HFIR.

The target cooling analyses are subdivided into bounding steady-state and transient conditions that are computed using nuclear safety software quality assurance (QA)-approved codes COMSOL Multiphysics and RELAP5 [13], respectively, as detailed below.

- Steady-State Analysis in COMSOL:

- $50 \%$ reduced coolant flow under normal reactor operating conditions,

- $130 \%$ overpower and raised inlet temperature.

- Transient Analysis in RELAP5:

- Small break loss of coolant accident (SBLOCA),

- Loss of offsite power (LOOP). 
The safety analysis review ensures reactor safety with respect to the experiments, specifically 1) The target internal temperatures remain below component melting temperatures, 2) The structural integrity of the target housing is such that it safely contains the irradiated pellet materials and prevents leakage of fission products, and 3) The target surface temperatures remain below coolant saturation temperatures. In the analyzed scope of the models, the 1 st mode of failure under steady-state $130 \%$ overpower, analyzed using coupled heat transfer and structural mechanics equations in COMSOL, has been the limiting condition from a safety review perspective [4].

The third set of supporting neutronics safety calculations are performed to establish the target heating and nuclide inventories which provide a basis for the above described calculations as well as a comparison to future PIE results. The steady-state analyses will be the focus of this document, as the third set of supporting calculations for neutron transport and material depletion (performed in the codes VESTA, MCNP5, and ORIGEN-S) [14], [15], [16] and transient thermal hydraulic analyses (in RELAP5) [13] are beyond the scope of this report and may be documented in a separate report.

However, an important neutronics characteristic of these targets that impacts the scope of steady-state heat transfer calculations is an observed build-in of fissile isotopes that is approximately linear with irradiation time (with some decay between cycles). Therefore, the highest heat generation rates will always be observed at the last irradiation time step (or the end-of-cycle at the latest cycle) in the target of highest burnup.

\subsubsection{Phase 1: Single Pellet Capsules}

Three phase 1 target designs were qualified and irradiated in non-prototypical encapsulations that were specifically designed to prevent target failure due to the unknown pellet irradiation behavior (pellet swelling, fission gas release fractions, pellet-clad interaction (PCI)). The first target design, a single or bare pellet capsule (see Fig. 2.5 below), contained a single pellet of $\sim 1 / 4$ " diameter and length. The second target was a tensile specimen that was designed to confirm that chemical/mechanical reaction between the pellets and housing would not significantly weaken the housing tube wall.

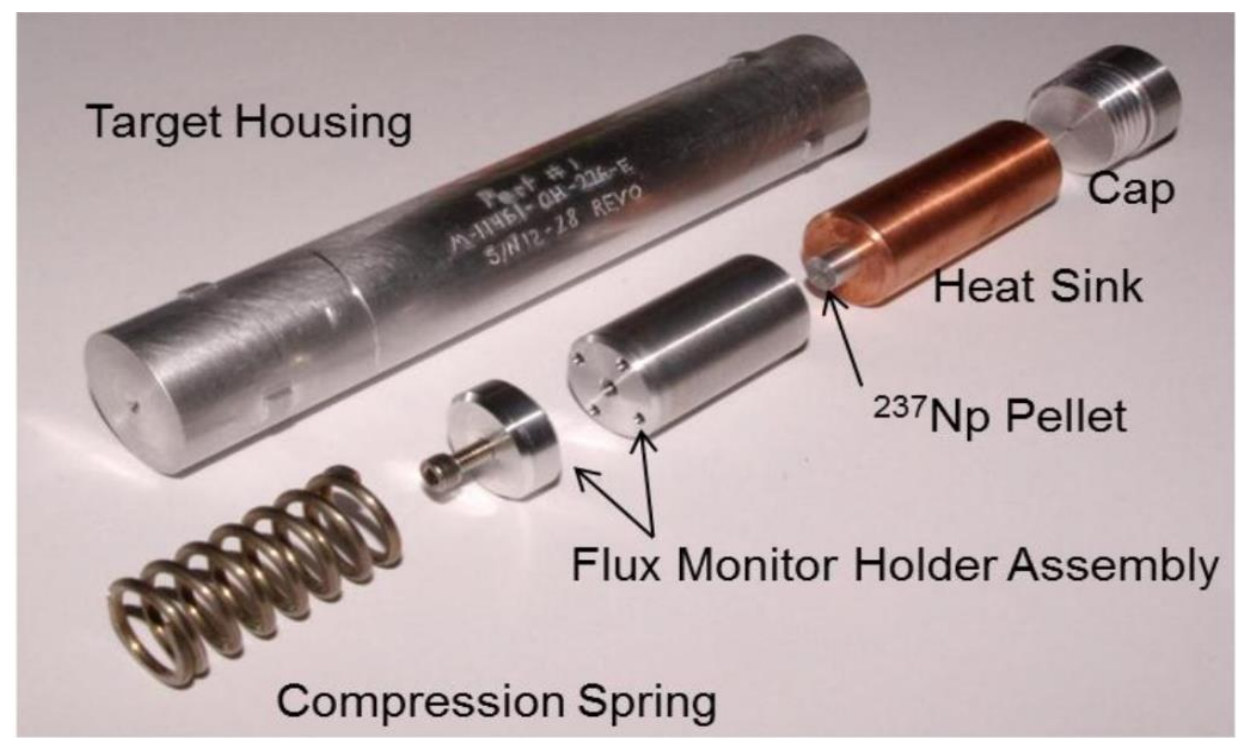

Fig. 2.5 : Single pellets target components.

The PIE results from the first cycle single pellet target irradiation revealed large densification or shrinkage of the pellet diameter that required a new reduced-length $\left(\sim 1 / 8^{\prime \prime}\right)$ pellet target design test, that was then irradiated for 1 and 2 cycles using $\mathrm{NpO}_{2}$ powder heat-treated to temperatures of $800{ }^{\circ} \mathrm{C}, 900{ }^{\circ} \mathrm{C}$, 
or $1200{ }^{\circ} \mathrm{C}$. Pellet heat-treatments above $800{ }^{\circ} \mathrm{C}$ were conducted with the anticipation that pre-irradiation sintering at higher temperatures would reduce initial void volume and thus pellet diametrical shrinkage, as well as improve thermophysical properties.

\subsubsection{Phase 2: Partially Loaded Targets}

The phase 2 partially loaded target designs contained $8 \mathrm{NpO}_{2} / \mathrm{Al}$ pellets heat-treated at either $900{ }^{\circ} \mathrm{C}$ or $1200^{\circ} \mathrm{C}$ in a prototypical target design. The targets were arranged in arrays of seven targets in specially designed holders. Fig. 2.6 shows the partially loaded target next to the holder used to hold seven targets during irradiation.

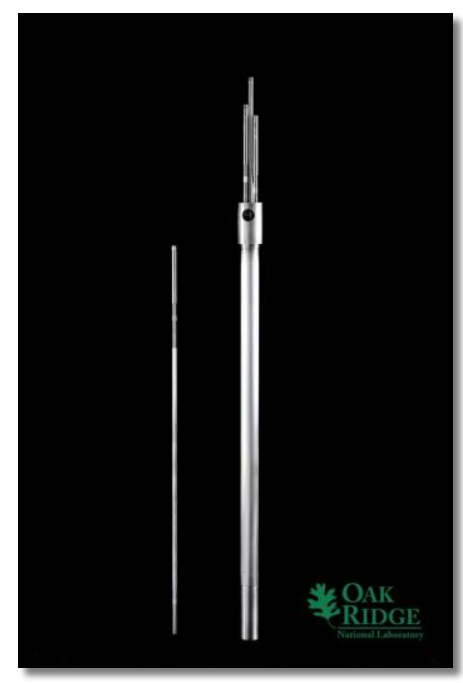

Fig. 2.6 : Partially loaded test targets with holder prior to irradiation.

The partially loaded targets were irradiated for both one cycle and two cycles. After each cycle, several targets were selected for PIE. During PIE, the targets were opened, pellets were retrieved, and postirradiation dimensions were measured and compared to their pre-irradiation values, of particular interest being the pellet diameter. In addition, fission gas release fractions as well as other PIE data were collected. As a result of the thermal safety analyses, the $1200{ }^{\circ} \mathrm{C}$ heat-treated pellets were chosen for two cycles of irradiation due to their reduced impact of pellet diametrical shrinkage.

\subsubsection{Phase 3: Fully loaded targets}

The phase 3 fully loaded target designs contain 50-52 $\mathrm{NpO}_{2} / \mathrm{Al}$ pellets all heat-treated at $1200{ }^{\circ} \mathrm{C}$ in a very similar encapsulation used in the partially loaded targets. The target irradiations have further confirmed irradiation behavior of the $\mathrm{NpO}_{2} / \mathrm{Al}$ pellets as well as provide meaningful information on anticipated production yields. These targets are considered the first generation of design production targets.

The fully loaded targets were irradiated for both one cycle and two cycles. After each cycle, several targets were selected for post irradiation examination (PIE). During PIE, the targets were opened, pellets were retrieved, and dimensions were measured. Due to the large number of pellets per target, a large number of data points were added per target compared to previous phases. Currently, the final demonstration step of chemical processing of the fully loaded targets is underway. 


\subsubsection{Phase 4: Production and optimization of targets}

Having completed the successful demonstration of irradiation for the first generation of design production targets in phase 3, optimization of the design and irradiation process is now an ongoing effort. As a part of that effort, an increased accuracy method for the neutronics calculation has demonstrated that the fully loaded production targets may be irradiated for three cycles within isotopic quality requirements [16]. A resulting part of the optimization is an increased accuracy thermo-mechanical model for the $3^{\text {rd }}$ cycle safety review. Furthermore, optimization efforts in the design and fabrication of the target are currently being undertaken including the exploration of stainless steel housing tubing at the target ends and springs in place of expansion spacers. The target holder itself is also being redesigned to eliminate the individual coolant channels in order to simplify operations removal of the targets from the target holder after irradiation [17]. Flow analyses of this new holder design as well as core flow diversion and beam tube flux impact analyses due to near-full loading of the HFIR PB are forthcoming.

\subsection{PRODUCTION PROGRESS OVERVIEW}

A summary of the current qualification efforts through cycle 456 (October 2014) is shown in Fig. 2.7 as a function of HFIR operating cycle. Included are the number of target designs that have been irradiated and the increased throughput of estimated ${ }^{238} \mathrm{Pu}$ production as the project approaches the final prototype phase and beginning of the production phase. The estimated ${ }^{238} \mathrm{Pu}$ production is approximate, as some build-in is expected to occur during the first several days of decay time and it is important to note that chemical recovery will not be perfectly efficient. The fabrication effort of a variety of designs between cycles was considerable, with qualification of increased neptunium loaded targets leading to increased ${ }^{238} \mathrm{Pu}$ production. An updated plot through cycle 465 (February 2016) shows the throughput has levelled off as fabrication and chemical processing portions of the ${ }^{238} \mathrm{Pu}$ supply project enter development before their ramp-up to production.

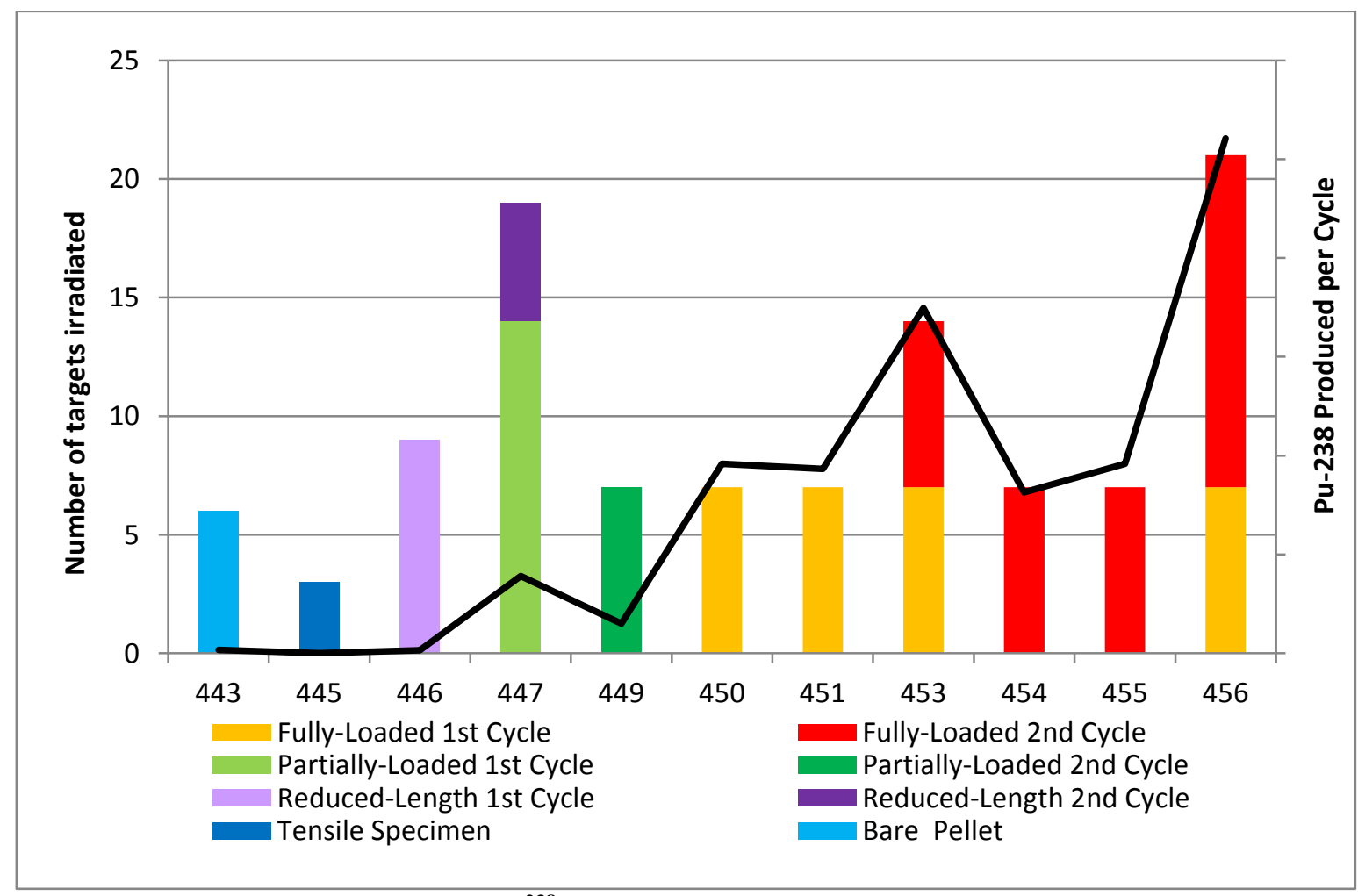

Fig. 2.7: Irradiated target designs and ${ }^{238} \mathrm{Pu}$ production by HFIR operating cycle through cycle 456 . 


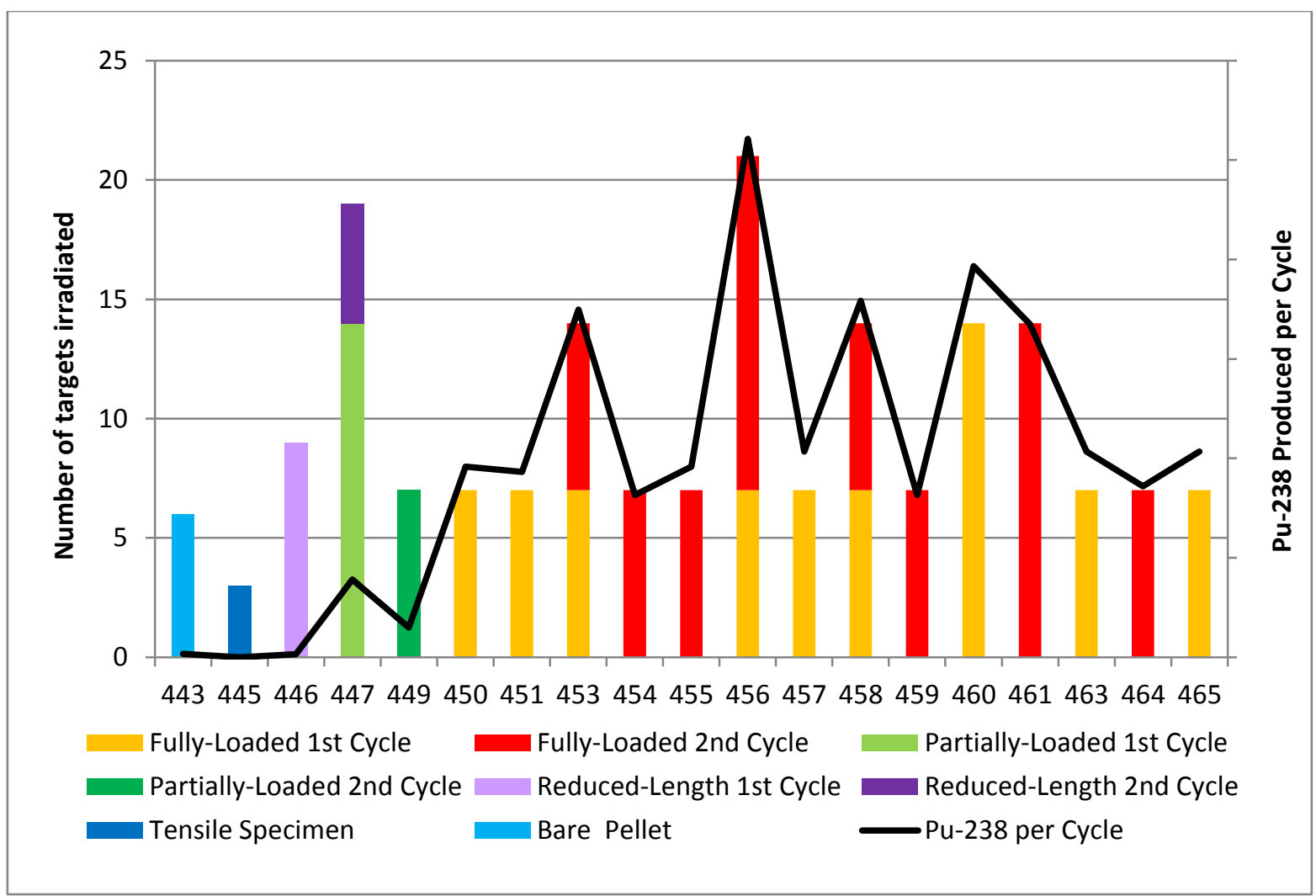

Fig. 2.8: Irradiated target designs and ${ }^{238} \mathrm{Pu}$ production by HFIR operating cycle through cycle 465.

\subsection{HFIR EXPERIMENT POSITIONS}

The HFIR provides a variety of in-core irradiation facilities as shown in Fig. 2.9. Moving from the inner to outer regions of the core these regions include the target flux trap, removable beryllium facilities, control rod access plug facilities, the PB vertical experiment facilities (VXFs) and slant engineering facilities. The VXFs in the PB are where the ${ }^{238} \mathrm{Pu}$ target irradiations have taken and are intended to take place, chosen as they have a smaller impact on the power reactivity due to their distance from the core centerline. There are twenty-two VXF positions in the PB, sixteen small VXFs and six large VXFs. For now, target holders in the small VXF positions are considered and, more narrowly, those eleven inner small VXF positions closest to the core axial centerline. Specifically for this report, the analyses focus on the VXF-15 and VXF-3 positions, VXF-15 as the bounding highest flux inner small VXF position and VXF-3 as a lower flux option when PIE data is insufficient for qualification of irradiations at VXF-15. Moving towards production, a significant modeling effort is to ensure safe irradiation of targets in as many positions as possible in the $\mathrm{PB}$, limitations including flux impact on the adjacent neutron scattering beam tubes and flow diversion from the core. 


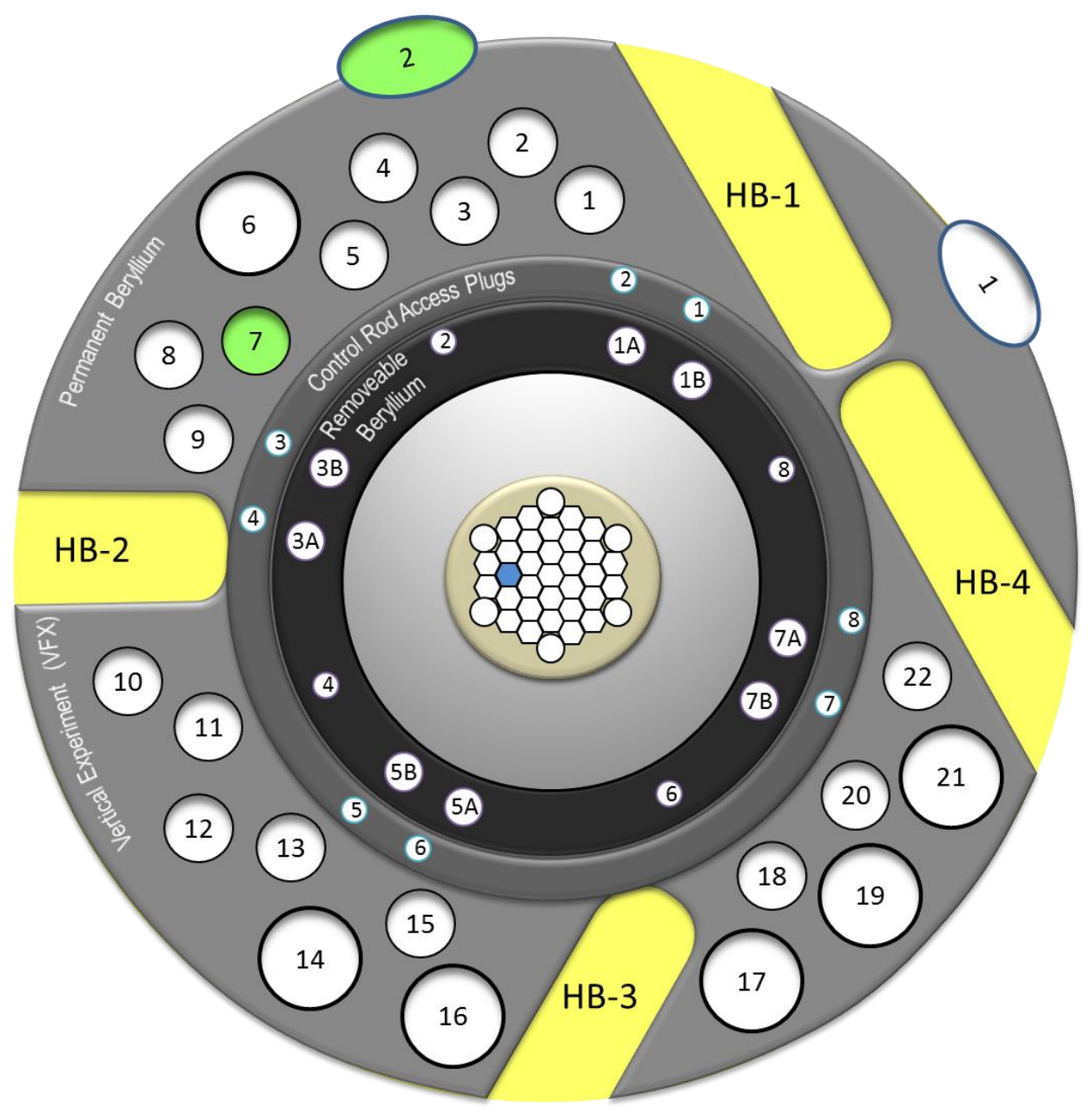

Fig. 2.9: HFIR in-vessel target regions and beam tubes.

\subsection{POTENTIAL DOCUMENTATION FOR PU-238 DEMONSTRATION}

Documentation of methods and results serve as an important feature for any project providing an opportunity for dissemination, review and reflection. To date, reports documenting the ${ }^{238} \mathrm{Pu}$ supply project's demonstration efforts at ORNL, including at the HFIR, REDC and other ORNL facilities have included internal calculations and reports as well as conference papers and presentations. While the former provide extensive, if restricted, knowledge on these efforts and the latter provide less-detailed and over-arching views of these efforts available to the public, neither serve as a comprehensive summary combining those virtues as this report does.

Fig. 2.10 provides an overview of the areas identified as amenable and valuable to documentation within the demonstration efforts of the ${ }^{238} \mathrm{Pu}$ supply project. As can be seen, of the four primary areas identified (fabrication, safety analyses, measurements, and chemical processing) the steady-state thermal-structure analyses documented in this report only cover a subset of one of these areas. 


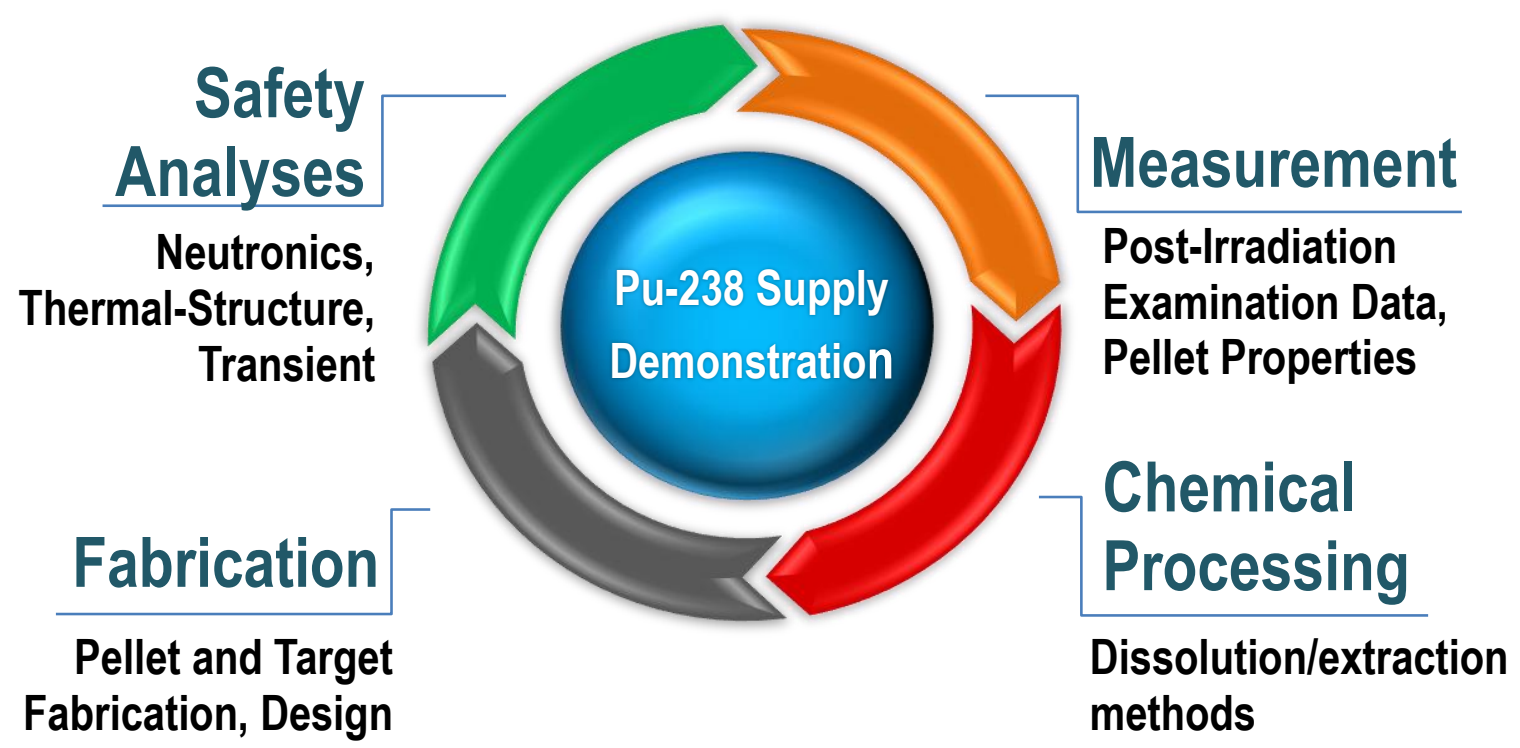

Fig. 2.10: Areas of the ${ }^{238} \mathrm{Pu}$ supply project demonstration efforts identified as amenable to documentation. 



\section{MODEL METHODOLOGIES}

The modeling methodologies in terms of model inputs, equations, and software utilization are explained here. Significant variation occurs between the methodologies for each model and where possible these variations are noted here, however the evolution of each model was a continuous process with some overlap in methods from each model that would require a needlessly complex explanation to fully detail. As models progressed, more accurate inputs and methods might allow a relaxation in conservatism or new unknowns might require an increase, however throughout the process it is always a priority to place the safe irradiation of the experiments before project schedule or cost.

\subsection{COMPUTATIONAL SOFTWARE}

All documented calculations were performed on the betty.ornl.gov computation cluster using research reactors division (RRD) QA controlled software, with preliminary calculations run on other machines. The COMSOL Multiphysics software [18], versions 4.3, 5.0, 5.1 and 5.2 were utilized to model the thermo-mechanical behavior in the target and calculate parameters like maximum pellet temperature and target cladding stress. The COMSOL Java API was used to run sets of simulations that were not amenable to parametric sweeps within the native COMSOL graphical user interface (GUI). In addition, supplementary calculation tools like the MATLAB R2015B Curve Fitting Toolbox and Microsoft Excel were used to process inputs and outputs to the COMSOL model.

COMSOL Multiphysics is a general-purpose software platform, based on advanced numerical methods, for modeling and simulating physics-based problems. COMSOL Multiphysics is a flexible tool that typically uses finite element analysis in a variety of physics and engineering applications, especially coupled phenomena, or multiphysics. The solid mechanics and heat transfer in solids built-in physics interfaces are utilized, as well as the material library module.

\subsection{MATERIAL PROPERTIES}

The measurements and collection of material properties for target materials has been an ongoing effort that will continue past the publication of this report. A full description of property measurements and their results is not within the scope of this report and would be better suited to its own separate publication, therefore only brief summaries of this effort and its relevance to the thermal safety analyses as inputs will be described here.

Primarily the material properties of the $\mathrm{NpO}_{2} / \mathrm{Al}$ cermet pellet, a custom fabricated material for this project, have been important items of interest for this project. The important material properties (including thermal conductivity, thermal expansion, Young's modulus, etc.) and their variation with temperature and fabrication technique are discussed here. The COMSOL material library is used for nonpellet materials and either verified or modified using alternate established sources.

\subsubsection{Irradiation Behavior}

The possibility of significant densification and swelling in the neptunium oxide pellets was discussed prior to the Phase 1 irradiations, however the expectation was that for the production burn-up levels the observed densification of the pellets would be minor and swelling would be the more measurable factor. While swelling presents a safety consideration in possible breach or failure of the target housing, densification or negative swelling presents a safety consideration as it increases the gap between the pellets and target housing, hence, reducing radial heat transfer, and elevating pellet temperatures near melting. 
The behavior of irradiated fuel oxides suspended in an aluminum mixture has been measured in previous experiments [19],[20],[21]. The experiment results exhibit the general characteristics of densification and swelling as described in the equations and Fig. 3.1 below. Fabrication void volumes experience a radiation-enhanced sintering which reduces the overall volume of the pellets for the early irradiation periods. Subsequently, the swelling due to fission gas and fission product release dominates the irradiation behavior as the reduction in void volume falls off.

$$
\begin{aligned}
& {\frac{\Delta V}{V_{\text {swell. }}}}=\alpha * B U \\
& \frac{\Delta V}{\text { dens. }}=P_{0}\left(e^{-\beta * B U}-1\right)
\end{aligned}
$$

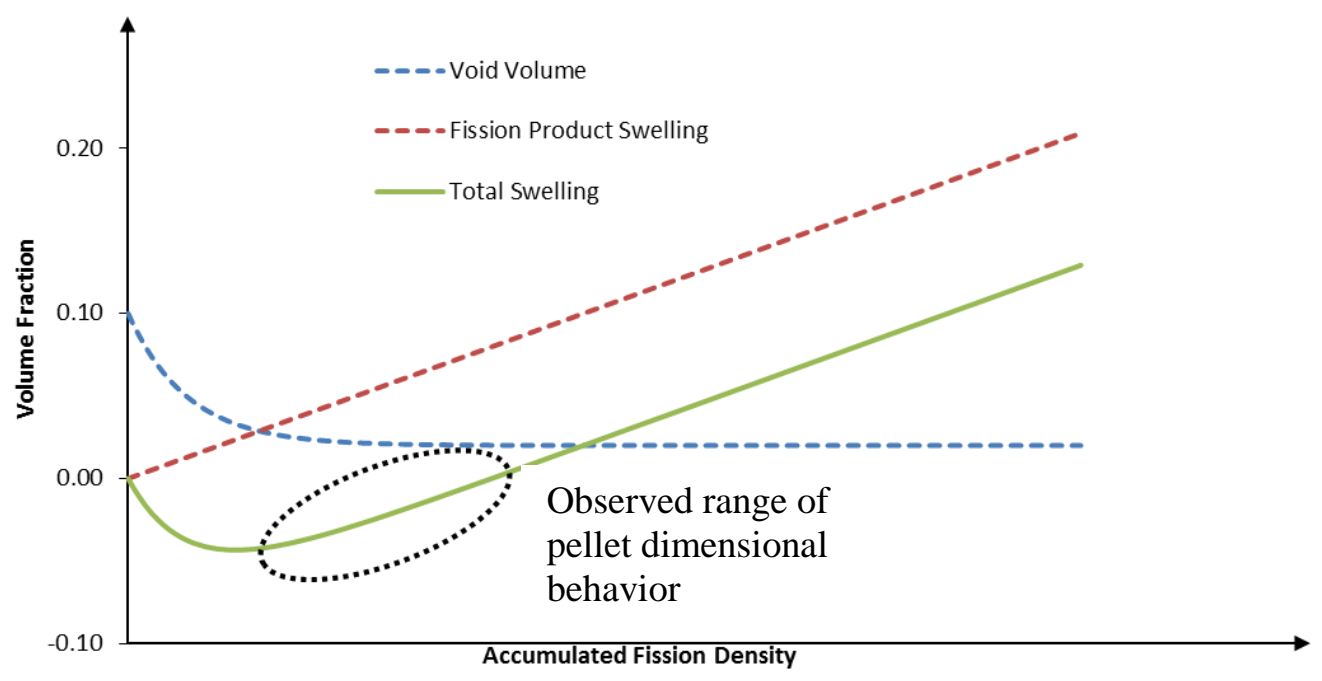

Fig. 3.1: General trend and contributions to pellet dimensional irradiation behavior.

The phase 2 and 3 partially and fully loaded target PIE measurements provide consistent data points, enabling the creation of a trend, as shown later for the $1200{ }^{\circ} \mathrm{C}$ heat-treated pellets. As shown in Fig. 3.1, the irradiation behavior, as measured by the pellet dimensional changes in the PIE results, has mostly been observed in the time period after maximum densification and swelling due to fission products is recovering the negative volume change, however a trend consistent with theory in Fig. 3.1 can be seen. The maxima densifications are observed early in the irradiation periods, which is consistent with previous oxide fuel studies at around less than 4,000 MW-d/t-fuel [22], [20], [21].

The other crucial irradiation behavior with respect to thermal safety analyses in the targets has been the fission gas release fraction, which is typically assumed as a constant over one or more irradiation cycles that bounds previous results in the range of burnups expected [23]. Altogether these irradiation behaviors have a significant effect on the heat transfer in the gap between the pellets and housing tube, via either varying gap size or the gas thermal conductivity. As shown in the radial temperature profile in Fig. 3.2, the temperature gradient in the gap can be very significant and is the primary driver behind maximum temperatures in the pellets. 


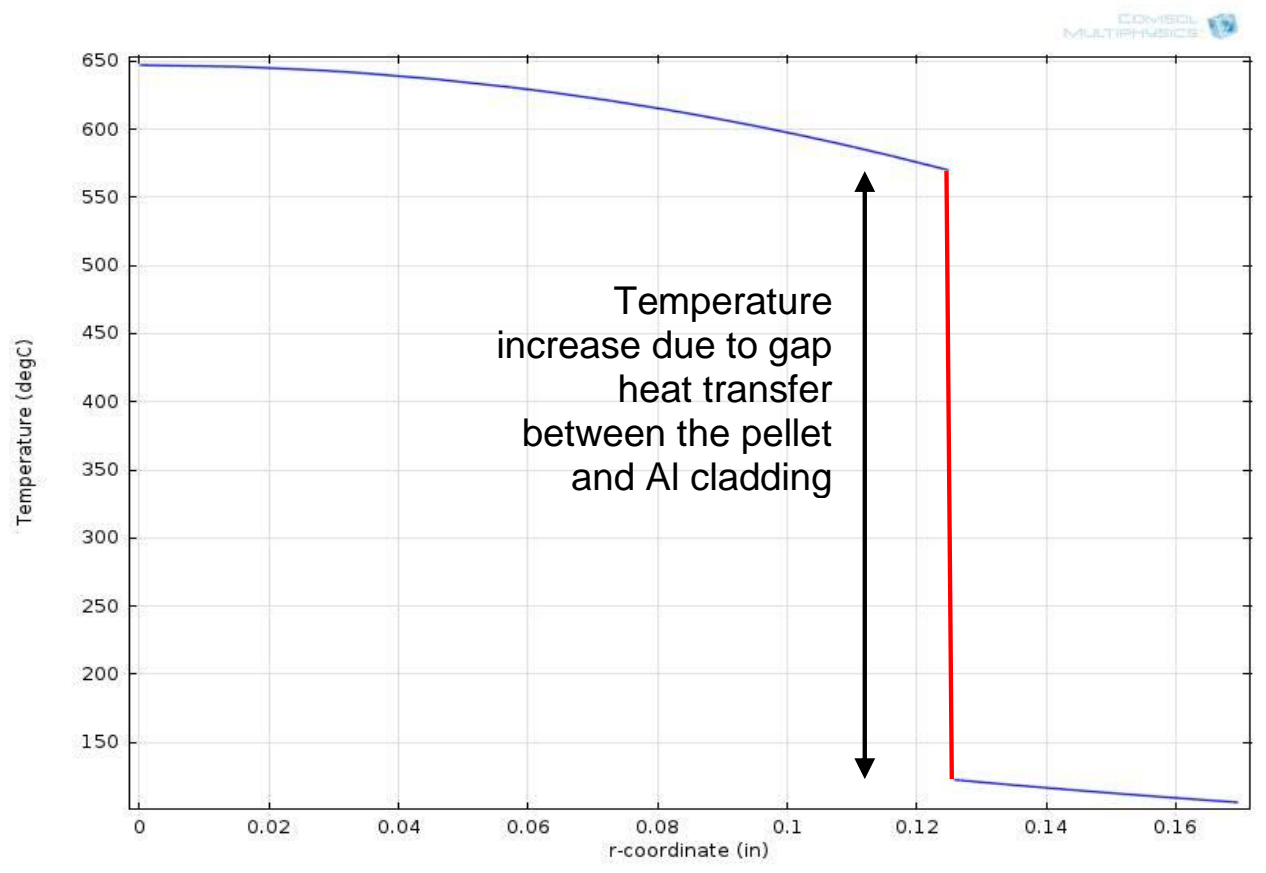

Fig. 3.2: Example radial temperature profile taken from the fully loaded target model.

\subsubsection{Pellet Properties}

\subsubsection{Thermal Conductivity}

The thermal conductivity of the pellet required initial measurements for the single pellet capsule irradiations, which showed for pellets heat-treated at around $590{ }^{\circ} \mathrm{C}$ that the thermal conductivity changed little with temperature and was around $50 \mathrm{~W} / \mathrm{m}-\mathrm{K}$ for the oxide+void packing in the measured pellets. A constant bounding value was used for the single pellet models. The first prototypical encapsulation experiment for the partially loaded target used updated measurements for heat treatments at $800{ }^{\circ} \mathrm{C}, 900$ ${ }^{\circ} \mathrm{C}$, and $1200{ }^{\circ} \mathrm{C}$ where increasing thermal conductivity was seen for increasing heat-treatment temperature [24], adjusting for conservative bounds in the fabricated oxide+void volume percentage and a slight decrease with temperature [13]. For the fully loaded targets, an updated conservative estimate for the $1200{ }^{\circ} \mathrm{C}$ heat-fired pellets was used, allowing for a narrower range of the oxide+void volume percentage given more extensive pellet fabrication experience.

\subsubsection{Thermal Expansion}

The initial thermal expansion measurements were measured at the same stage as the initial thermal conductivity measurements, showing a thermal expansion in proportion to that of pure aluminum according to its volume content in the pellets. A curve fit of this measurement was used as input for the thermal expansion coefficient. As with the thermal conductivity measurements, the partially loaded target model used updated measurements for heat treatments at $800{ }^{\circ} \mathrm{C}, 900{ }^{\circ} \mathrm{C}$, and $1200{ }^{\circ} \mathrm{C}$ (see Fig. 3.3) [25], where increasing thermal expansion was seen for increasing heat-treatment temperature. 


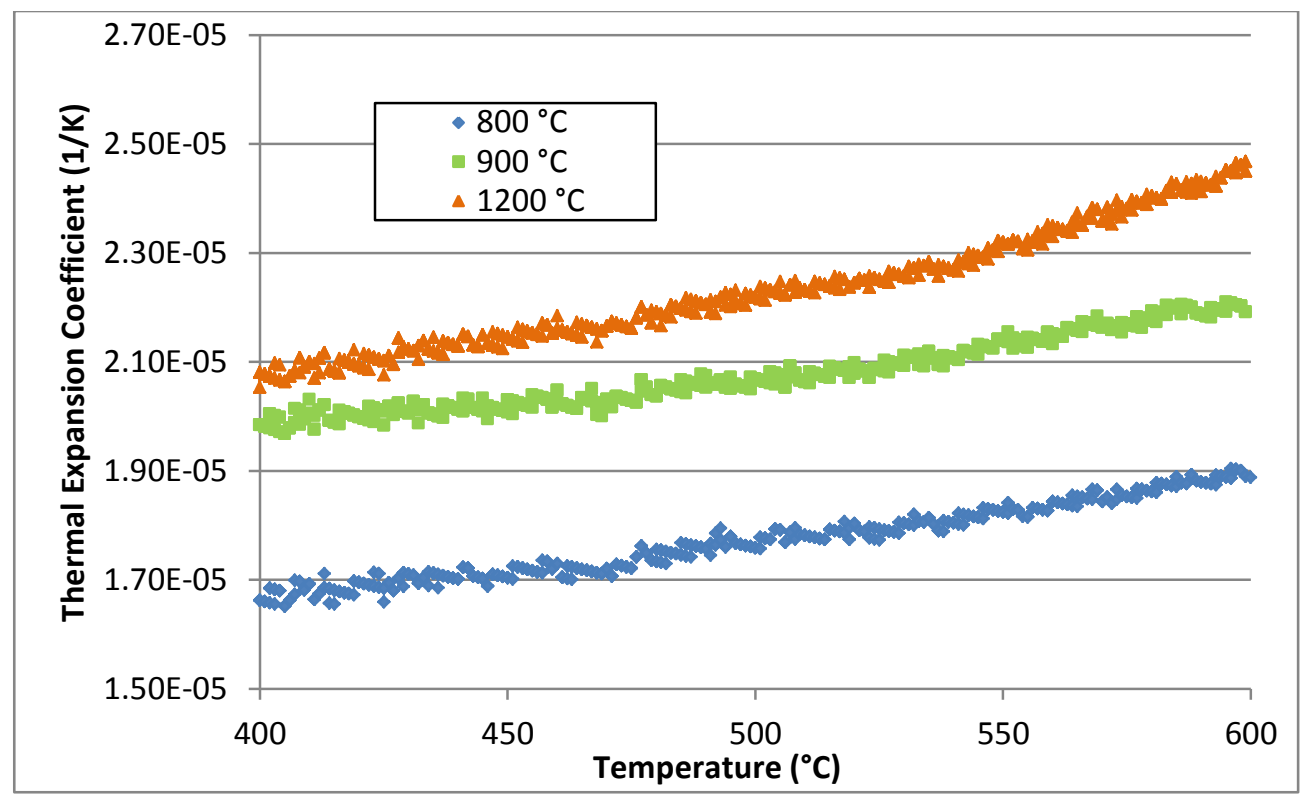

Fig. 3.3: Pellet thermal expansion for varying heat-treatment temperatures as a function of temperature.

\subsubsection{Young's Modulus and Poisson's Ratio}

The initial Young's modulus and Poisson's Ratio estimates were based on consensus expert opinion in determining a conservative estimate of these values (in addition using measurements of a surrogate oxide material) at $70 \mathrm{GPa}$ and 0.1 . These values were used for the single pellet capsules and prototypical encapsulation targets, however as axial stresses due to aggregate pellet stack swelling became a concern during the transition to the "best-estimate" production model, updated measurements for the elastic modulus were taken at different pellet temperatures as shown in Fig. 3.4 [26]. What was observed was a strong dependence on temperature, where the modulus and ultimate strength of the pellet decreased with increasing temperature. Temperature-dependence of Young's modulus is thus derived as an interpolated table of the values derived from the measurements at 20, 200, 300, 400, and $500{ }^{\circ} \mathrm{C}$. No Poisson's ratio measurements on the pellet material have been conducted, however a value between 0.1 and 0.35 is assumed, depending on which value is conservative for the assessment. 


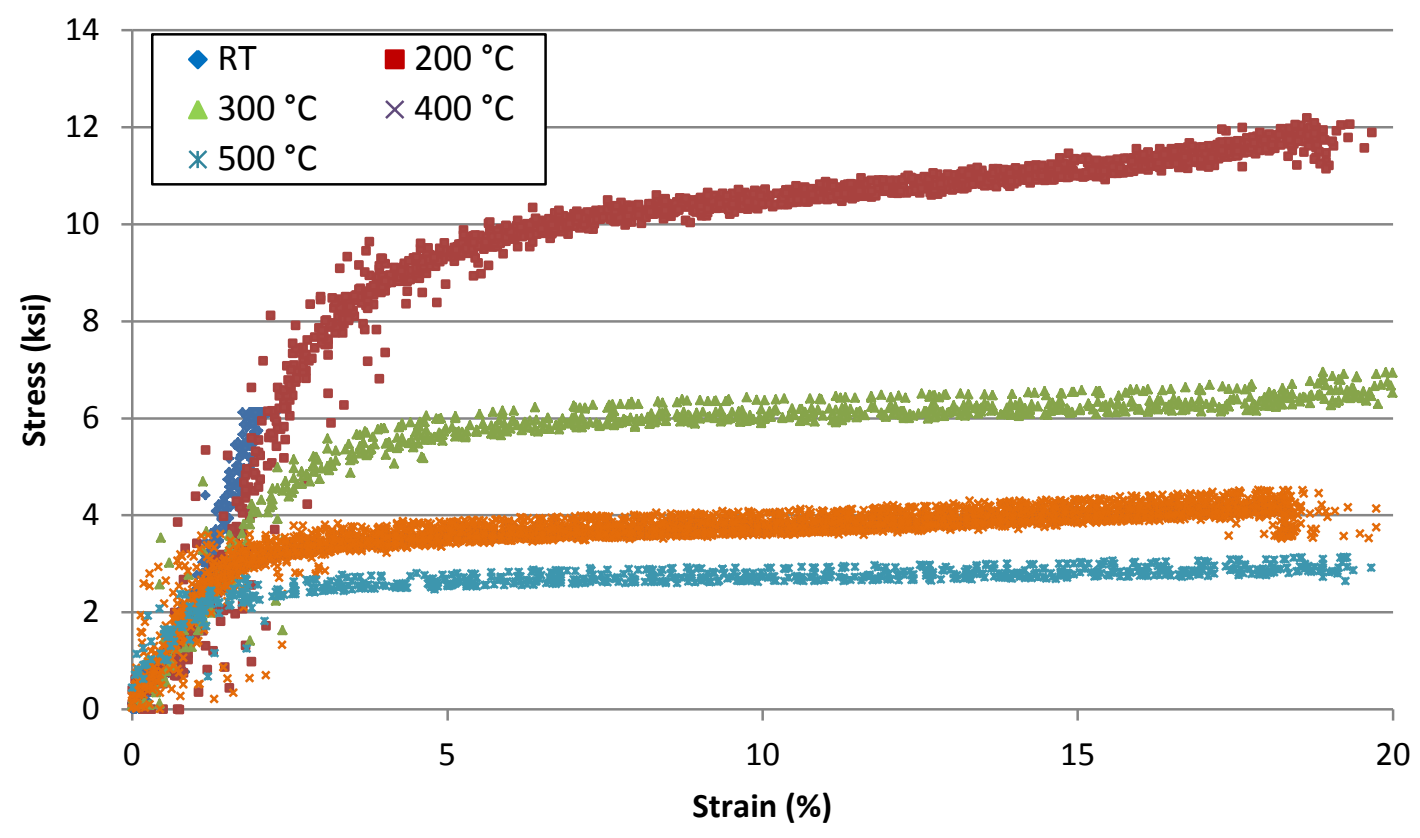

Fig. 3.4 : Measured pellet stress-strain curves at varying temperatures.

\subsubsection{Pellet-clad Interaction}

A tensile specimen irradiation experiment was conducted in order to examine the interaction between the $\mathrm{NpO}_{2} / \mathrm{Al}$ material and the 6061 aluminum cladding material, a commonly measured effect in commercial reactors known as pellet clad interaction (PCI). The results, from 3 test capsules of 4 specimens each, concluded that a negligible effect on the cladding strength occurred compared to irradiated cladding material not in contact with the pellet powder [11]. A greater loss in ductility occurred for cladding specimens in contact with $\mathrm{NpO}_{2}$, yet this greater loss in ductility (approximately 10\%) remained above a $5 \%$ elongation at failure.

\subsubsection{Density, Heat Capacity, Melting Temperature}

The pellet material density is typically taken directly or derived from pellet fabrication reports, in conjunction with conservative estimates of volume percentages of components. The current production model uses the same estimated density used in the input heat generation calculations as an initial density and adjusts with respect to thermal and irradiation dimensional changes.

Since the analyses in this report are steady-state and the heat capacity only affects the time derivative of the heat equation, an accurate estimate of the heat capacity is not needed. However, it is input as the heat capacity of aluminum in COMSOL.

The melting temperature of the pellet components $\mathrm{NpO}_{2}$ and $\mathrm{Al}$ are $\sim 2,800{ }^{\circ} \mathrm{C}$ [27] and $660{ }^{\circ} \mathrm{C}$ [28] making the utilized melting temperature of $650{ }^{\circ} \mathrm{C}$ a conservative estimate.

\subsection{GOVERNING PHYSICS}

The models' governing equations are briefly described below and in the following subsections the inputs, pellet dimensional behavior and gas gap/contact conductance is discussed in greater detail. The 
prototypical models takes advantage of the symmetry about the axial centerline of the targets to utilize two-dimensional (2-D) R-Z or axisymmetric geometry, thus heat transfer and mechanical loads are invariant of the rotation angle.

\subsubsection{Heat Transfer}

The built-in Heat Transfer physics interface is used, which is governed by the domain equation given in the below equation, where $\rho, \mathrm{C}_{\mathrm{p}}$, and $\mathrm{k}$ are the material density, heating capacity and thermal conductivity, respectively. $\mathrm{T}$ and $\mathrm{u}$ are the field variables temperature and velocity, while $\mathrm{t}$ is the time and $\mathrm{Q}$ is a volumetric heat source. For this problem, the transient heat and convection terms are eliminated as the analysis is for steady-state conditions in a solid medium (excluding fission gas regions).

$$
\rho C_{p} \frac{\partial T}{\partial t}+\rho C_{p} u \cdot \vec{\nabla} T+\vec{\nabla} \cdot(-k \vec{\nabla} T)=Q
$$

Heat source specifications take the following form:

$$
Q_{i}=f_{\text {power }} \rho_{i} \dot{q}_{m}
$$

where the subscript $\mathrm{i}$ denotes the target component domain, $\mathrm{f}_{\text {power }}$ denotes the power factor, $\rho_{\mathrm{i}}$ denotes the component density, and $\mathrm{q}_{\mathrm{m}}$ is the component mass-specific heating rate. The mass-specific heating rates are taken from input neutronics calculations, previously discussed. Heating data that is axial positiondependent is given for the pellets and housing, where the pellet mass-specific heating rate is defined as a 5-degree polynomial and as displayed for the $1^{\text {st }}$ cycle of irradiation for the fully loaded target in Fig. 3.5:

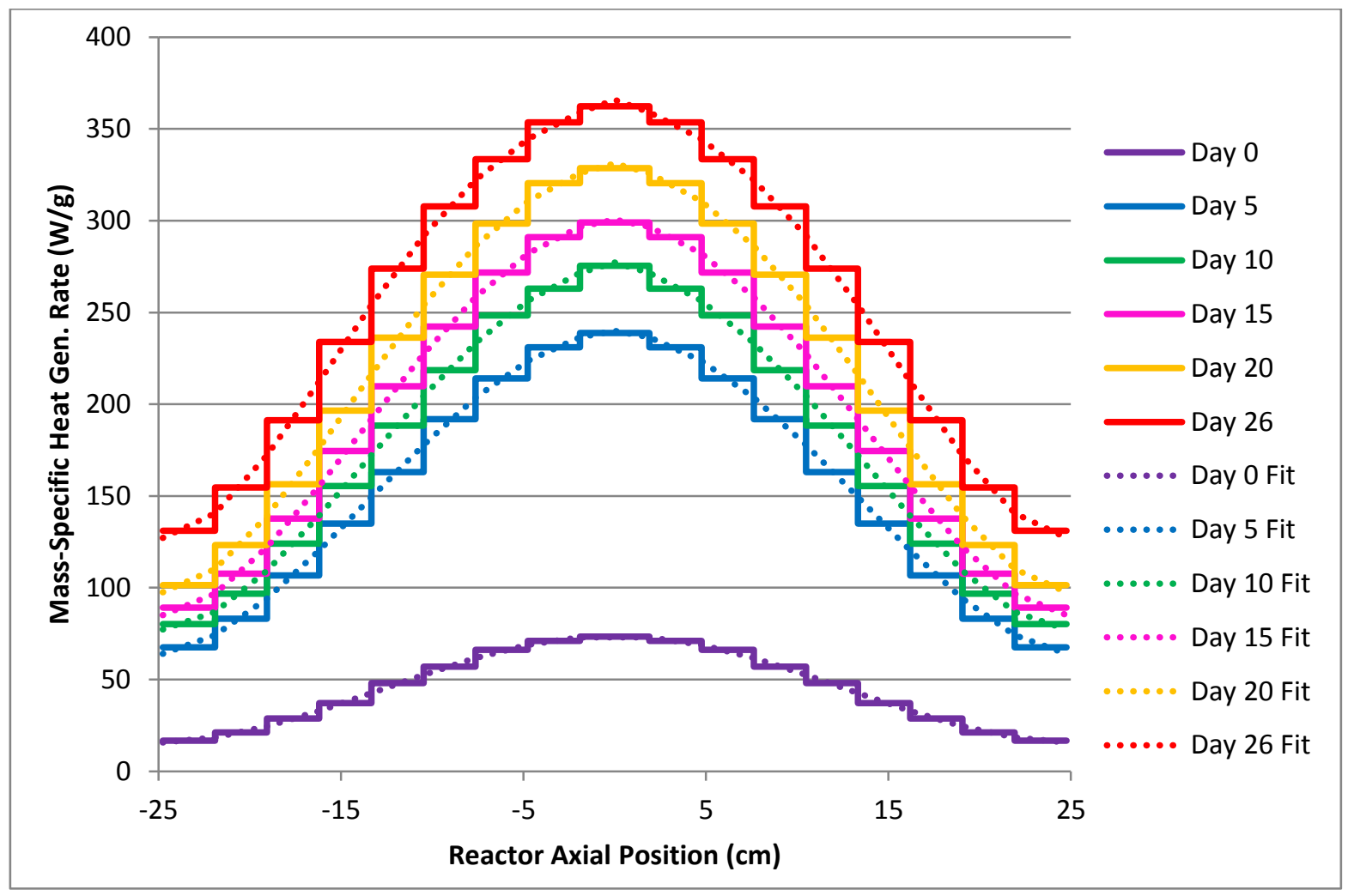

Fig. 3.5: Pellet heating rate vs. axial position for the polynomial fits and input data at $0,5,10,15,20$, and 26 days into the $1^{\text {st }}$ cycle. 


\subsubsection{Solid Mechanics}

The solid mechanics (variable identifier solid used in COMSOL) interface is designed for structural mechanics in R-Z geometries to solve the dependent variables $\mathrm{u}, \mathrm{v}$, and $\mathrm{w}$ for displacement. The contact pair conditions and gravity node are defined in under this interface. This physics interface is applied to all solid domains in the geometry (i.e. all but the He domains) in the production model and only the pellet(s) and surrounding cladding in the preceding models. In addition, the temperature field from the heat transfer interface is used to determine all temperature-dependent properties, serving as a coupling between the two physics.

The interface is governed by the domain equation given below, where the linear momentum is conserved in the equilibrium equation for forces, $\mathrm{F}$, and stresses in the target:

$$
\vec{\nabla} \sigma=F v
$$

The strain tensor, $\varepsilon$, is given in terms of the gradient of displacement field variable, $\mathrm{u}$, and the stress tensor, $\sigma$, is related to the strain tensor via Hooke's law, where $\mathrm{C}$ is an elasticity tensor, 0 denotes initial stresses and strains, and $\varepsilon_{\mathrm{th}}$ is the thermal expansion.

$$
\begin{gathered}
\varepsilon=\frac{1}{2}\left((\vec{\nabla} u)^{T}+\vec{\nabla} u+(\vec{\nabla} u)^{T} \vec{\nabla} u\right) \\
\sigma=\sigma_{0}+C\left(\varepsilon-\varepsilon_{0}-\varepsilon_{t h}\right)
\end{gathered}
$$

The bottom of the target is fixed in the z-direction to denote the fixed position of the target while sitting in the VXF position. The axial symmetry node applies only to the boundaries at $r=0$ and represents symmetry in the loads and geometry. These are the only external constraints on the geometry.

All models previous to the production model used the penalty factor method for contact pairs, while the newest production model makes use of a new feature called augmented Lagrangian, considered to be more robust and accurate.

\subsubsection{Thermal Expansion}

The thermal expansion strain is defined as $\epsilon_{t h}=\alpha\left(T-T_{\text {ref }}\right)$, where the reference temperature is $\mathrm{T}_{\text {ref }}$ and the coefficient of thermal expansion is $\alpha$. For all solid domains which are not the $\mathrm{NpO}_{2} / \mathrm{Al}$ pellets the coefficient of thermal expansion is retrieved from the built-in material properties in COMSOL, while the pellet thermal expansion property is user-input in the previous section. For the newest production model, the coefficient of thermal expansion is modified to include the irradiation swelling as follows:

$$
\alpha_{\text {modifiedL }}=\alpha_{L}(T)+\frac{1}{3} \frac{d V}{V}(F D(z)) \frac{1}{\left(T-T_{\text {ref }}\right)}
$$

The first term is simply the material property of the $\mathrm{NpO}_{2} / \mathrm{Al}$ pellets, and the second term includes the pellet swelling behavior under irradiation. This is included as the pellet volumetric swelling strain (defined as a function of fission density which itself is dependent on axial position) divided by the temperature difference term and a factor of three to convert to linear strain for isotropic materials. 


\subsubsection{Contact Conductance}

This section describes the local definitions that are used to calculate the "solid spot" or contact conductance between the pellet sides and housing tube, which is a function of the contact pressure and material properties. In addition, some other material properties are defined under this variable grouping.

For the purpose of this calculation, the following defined properties of the contacting surfaces are solved: the harmonic mean of the thermal conductivity, $\mathrm{k}$, the effective or reduced elastic modulus, E', and the effective combined surface roughness, $\sigma$. In equation form, these definitions are obtained from Equation 3.3 on page 23 and the example on page 40 from Madhusudana [29] as:

$$
\begin{gathered}
k_{m}=\frac{2 k_{1} k_{2}}{k_{1}+k_{2}} \\
E^{\prime}=2\left[\left\{\left(1-v_{1}^{2}\right) / E_{1}\right\}+\left\{\left(1-v_{2}^{2}\right) / E_{2}\right\}\right]^{-1}, \\
\sigma=\left(\sigma_{1}^{2}+\sigma_{2}^{2}\right)^{0.5}
\end{gathered}
$$

where the indices 1 and 2 in the equation above denote the two adjacent materials meeting at the gap and $\mathrm{k}, \mathrm{E}, v$, and $\sigma$ denote the thermal conductivity, Young's elastic modulus, Poisson's ratio, and surface roughness, respectively. For the side gaps, the materials are Al-6061 T4 temper (-t4) and the $\mathrm{NpO}_{2} / \mathrm{Al}$ pellet.

The mean absolute slope of the asperities, $\mathrm{m}$, representing the unevenness or ruggedness of a surface of the side pellet gap, is defined here. This quantity is purely a function of the surface roughness, and is also often written as "tan $\Theta$ ", and is found in [30] in equation form as

$$
m=5253 \sigma^{0.743} \text {. }
$$

A sensitivity study is conducted on this parameter to ensure use of the above correlation is accurate, where other correlations by Lambert [31] and Antonetti [32] are used to form a bounding estimate given the significant range shown in measurements [33], [34].

The Garimella reference [30] is that originally used in the calculation. However, it is bound by the Antonetti correlation over all surface roughness values and the Lambert correlation provides a bounding value for these two correlations for larger surface roughness values. The conservative estimation of the mean absolute slope of asperities is thus the minimum of all three correlations:

$$
m=\min \left\{\begin{array}{cc}
\text { Garimella } & 5253 \sigma[1 / m]^{0.743} \\
\text { Lambert } & 0.076 \sigma[1 / \mu m]^{0.52} \\
\text { Antonetti } & 0.124 \sigma[1 / \mu m]^{0.743}
\end{array}\right\}
$$

The solid spot conductance for elastic deformation, $h_{e}$, for the contacting surfaces is defined here. This portion of the total gap conductance represents that portion due to the pressure forces acting on the two touching solid surfaces. In equation form, this definition is obtained following Equation 3.34 of [29], and Page 20 of [30]. Note that the quantity $\tan \Theta$ also is written here as the variable $m$ which denotes the mean absolute slope of the asperities. In equation form the elastic solid spot conductance is written as 


$$
h_{e}=1.55\left(k_{m} m / \sigma\right)\left(P \sqrt{2} / E^{\prime} m\right)^{0.94}
$$

where the variable $P$ denotes the surface pressure acting on the surface. The pellet side surface receives pressure that results from the forces computed by the side gas-gap closure due to the thermal expansion and irradiation swelling of the pellet into the target housing. A separate variable is defined for this side contact pressure which requires utilization of a COMSOL feature which maps the surface pressure from the housing to the adjacent surface on the pellets. This variable must be maximized against a minimum pressure, chosen as 1 Pascal, in order to prevent zero divides.

The solid spot conductance for plastic deformation of the contacting surfaces, $\mathrm{h}_{\mathrm{p}}$, is defined in Equation 3.33 of [29] as

$$
h_{p}=1.13\left(k_{m} m / \sigma\right)(P / H)^{0.94}
$$

where $\mathrm{H}$ is the hardness of the softer surface material or minimum hardness of the two mating surfaces. It has been observed that the solid spot conductance under elastic deformation gives a conservatively lower value than the plastic deformation definition, and commonly this is used for all model versions except the production model. However, a plasticity index as defined from Equation 3.23 of [29] may be used to determine the type of deformation:

$$
\psi=m \frac{E^{\prime}}{H}
$$

where a value above 1.0 has been observed to exhibit plastic deformation even at light loads and a value below 0.7 exhibits elastic deformation even under heavy loads. A linear interpolation of the two conductance values for a plasticity index range between 0.7 and 1.0 is then utilized (only in the production model) to complete the continuous function of conductance as a function of plasticity:

$$
h_{s}=\left\{\begin{array}{cc}
\psi<0.7 & h_{e} \\
1.0>\psi>0.7 & \frac{1.0-\psi}{0.3}\left(h_{p}-h_{e}\right) \\
\psi>1.0 & h_{p}
\end{array}\right.
$$

The "mean separation between the surfaces" of two surfaces under conforming contact as provided by Equation 4.18 of [29] represents a mean minimum gap, $\delta_{\text {mean }}$, as input to the gap conductance defined in a later section, or alternatively the combined surface roughness may be used for significant pressures:

$$
\delta_{\text {mean }}=1.53 \sigma(P / H)^{-0.097}
$$

where $\mathrm{P} / \mathrm{H}$ is the ratio of applied surface pressure and the surface hardness. The hardness is set to be the minimum of the hardness of the two mating surfaces. The applied surface pressure is assumed constant at the pressure created by the spring force at both the top and bottom surfaces. This feature is generally only used for axial conduction between pellets, however since this is insignificant for the prototypical designs it is neglected by the conservative assumption that no axial conduction occurs between pellets. 


\subsubsection{Fission Gas}

The definitions in this section are used to ultimately calculate the effect of fission gas release on the heat transfer in the gas gap, via a reduction factor to the gas thermal conductivity, weighting factors used to calculate each gas's contribution to the "thermal jump" effect explained later, as well as mass fractions used to calculate gas mixture material properties.

The initial number of moles of helium is estimated by the following equation based on the ideal gas law, where $\mathrm{n}$ is the number of moles, $\mathrm{P}$ is pressure, $\mathrm{V}$ is volume, $\mathrm{R}$ is the ideal gas constant 0.0821 atm$\mathrm{L} /(\mathrm{mol}-\mathrm{K})$, and $\mathrm{T}_{\text {ref }}$ is the reference temperature at fabrication:

$$
n_{H e 0}=\frac{P_{H e} * V_{H e}}{R * T_{r e f}}
$$

The number of moles, n, of helium, xenon, and krypton gas can be calculated by the following equations:

$$
\begin{gathered}
n_{\mathrm{He}}=f_{\mathrm{He}} * n_{\text {HeFiss }}+n_{\mathrm{He} 0} \\
n_{i}=f_{i} * n_{\text {iFiss }}
\end{gathered}
$$

where the subscript $\mathrm{i}$ denotes the fission gas element xenon or krypton, $\mathrm{f}$ is the fission release fraction, and $\mathrm{n}_{\text {ifiss }}$ is the fission gas inventory of element $\mathrm{i}$ in moles.

The mole fractions, $\mathrm{x}$, of helium, xenon, and krypton can be calculated by the following equation, where the subscript $\mathrm{i}$ denotes the fission gas element:

$$
x_{i}=\frac{n_{i}}{n_{H e}+n_{X e}+n_{K r}}
$$

The mass of helium, xenon, and krypton gas can be calculated by the following equations, where $\mathrm{m}$ is mass, $\mathrm{M}$ is molar mass or atomic weight, and the subscript $\mathrm{i}$ denotes the fission gas element:

$$
m_{i}=n_{i} * M_{i}
$$

The mass fractions, $\mathrm{mf}_{\mathrm{i}}$, are then simply the ratio of the mass of the gas of interest to the total of the three fission gas masses, using the definitions above:

$$
m f_{i}=\frac{m_{i}}{m_{H e}+m_{X e}+m_{K r}}
$$

An intermediate variable, $\mathrm{C}_{\mathrm{i}}$, used to calculate a gas weighting factor for helium, xenon, and krypton gas, can be calculated by the following equation:

$$
C_{i}=\frac{m f_{i}}{\left(M_{i}\right)^{\frac{1}{2}}}
$$

A gas weighting factor, $\mathrm{w}_{\mathrm{i}}$, for helium, xenon, and krypton, which is used in Equation 4.3 of [29], can be calculated by the following equation: 


$$
w_{i}=\frac{\frac{m f_{i}}{\left(M_{i}\right)^{\frac{1}{2}}}}{\sum_{j=1}^{3} \frac{m f_{j}}{\left(M_{j}\right)^{\frac{1}{2}}}}=\frac{C_{i}}{\sum_{j=1}^{3} C_{j}}
$$

The thermal conductivity of the resulting gas mixture within the capsule is approximated by a reduction in thermal conductivity of the pure helium gas. This can be estimated by a curve fit of the xenon-gas mole fraction and is obtained from a NASA reference set of measurements [35]. This curve fit is included directly in the COMSOL model by the following equation, which conservatively includes the sum of the krypton and xenon mole fractions in place of the xenon mole fraction:

$$
\begin{gathered}
f_{k N A S A}=-1.7299 *\left(x_{X e}+x_{K r}\right)^{5}+5.6988 *\left(x_{X e}+x_{K r}\right)^{4}-7.7342 *\left(x_{X e}+x_{K r}\right)^{3}+5.9074 \\
*\left(x_{X e}+x_{K r}\right)^{2}-3.1041 *\left(x_{X e}+x_{K r}\right)+1
\end{gathered}
$$

In addition, two conservative curve fits to data that is found in the TPMD [36] are used as well (for a thinhot wire and thick-hot wire method of measuring the thermal conductivity):

$$
\begin{aligned}
& f_{\text {kthinwire }}=-0.5372 *\left(x_{X e}+x_{K r}\right)^{5}+2.6203 *\left(x_{X e}+x_{K r}\right)^{4}-4.9526 *\left(x_{X e}+x_{K r}\right)^{3}+4.9348 \\
& *\left(x_{X e}+x_{K r}\right)^{2}-3.0198 *\left(x_{X e}+x_{K r}\right)+1 \\
& f_{\text {kthickwire }}=2.9406 *\left(x_{X e}+x_{K r}\right)^{6}-10.5127 *\left(x_{X e}+x_{K r}\right)^{5}+15.6983 *\left(x_{X e}+x_{K r}\right)^{4}-13.4061 \\
& *\left(x_{X e}+x_{K r}\right)^{3}+7.7818 *\left(x_{X e}+x_{K r}\right)^{2}-3.4658 *\left(x_{X e}+x_{K r}\right)+0.9999
\end{aligned}
$$

The reduction in helium thermal conductivity is therefore the average of these three fits:

$$
f_{k H e}=\frac{\left(f_{k N A S A}+f_{\text {kthinwire }}+f_{\text {kthickwire }}\right)}{3}
$$

Generally, the thin-hot wire method results and NASA results agree fairly well, while the thick-hot wire is usually more conservative (has a greater reduction in helium thermal conductivity) than the other two.

The initial single pellet models used the NASA fit with only the xenon mole fraction as a fit parameter, later the other fits and krypton mole fraction were added in the prototypical models for greater conservatism.

\subsubsection{Thermal Gap Jump}

The definitions in this grouping are used to calculate the thermal or gap "jump" effect described in [29]: an artificial addition to the gap separation distance between two metal surfaces used to account for the ineffectiveness of gas-to-solid heat transfer. The gap jump distance is calculated at three locations across the gap: at the pellet outer surface, the housing inner surface, and the center or average gap. As an improvement to previous models, the gap distance contributions to both sides are added to arrive at a more accurate total gap jump distance ([29], Equation 4.6), rather than using an average value. This is found to be conservative with respect to the average gas gap approximation.

In order to calculate these gap jump distances separately, all of the parameters contained herein are calculated using the gas/surface temperatures at the appropriate locations. The pellet surface temperature, $\mathrm{T}_{\mathrm{p}}$, and inside housing temperature, $\mathrm{T}_{\mathrm{h}}$, are calculated using surface coupling operators, while the average gap temperature, $T_{\mathrm{g}}$, is the average of the two. All subsequent definitions related to the gap jump calculation (as shown below) are then recreated with subscript $\mathbf{p}, \mathbf{h}$, or $\mathbf{g}$ to denote their values at the 
pellet side, housing side, and average gap locations, respectively. These definitions without subscripts are evaluated at their local values in the model.

The data available for the accommodation coefficient of gases is specific to metal types and its surface cleanness. Therefore, the specific gas-metal accommodation coefficient is difficult to find for this application and relations for $\mathrm{UO}_{2}$ were generally preferred.

The accommodation coefficient for helium gas was taken from page 51 of Reference [29], based on experimental results of $\mathrm{UO}_{2}$ and stainless steel surfaces, and is represented as a variable to be as follows, where the temperature $\mathrm{T}$ is in units of Kelvin:

$$
\alpha_{H e}=0.425-2.3 \times 10^{-4} T .
$$

The accommodation coefficient for xenon gas was taken from measurements by Ullman et al. [37] for $\mathrm{UO}_{2}$ and stainless steel surfaces correlated by Thomas and Loyalka [38]:

$$
\alpha_{X e}=0.749-2.5 \times 10^{-4} T
$$

An interpolation based on atomic or molecular weight between the two correlations for xenon and helium gas was used for krypton's accommodation coefficient:

$$
\alpha_{K r}=\alpha_{H e}+\left(M_{K r}-M_{H e}\right) * \frac{\alpha_{X e}-\alpha_{H e}}{M_{X e}-M_{H e}}
$$

This was found to be bounded, on the high side, by the suggested value of $0.8+/-0.1$ from Hall and Martin for $\mathrm{UO}_{2}$ surfaces [39], which is conservative in the context of the final thermal jump definition, later defined.

These variables represent the mean free path of the respective gases. An equation for the mean free path of a gas is readily available (for example, from [40], page 9-2, equation 2) as

$$
\lambda_{\text {gas }}=\left[1 / \sqrt{2} \pi n d^{2}\right]=\left[k_{B} T / \sqrt{2} \pi d^{2} p_{\text {gas }}\right] \text {, where }
$$

$$
\begin{aligned}
& n=\text { the number of gas molecules per unit volume }\left(\text { molecules } / \mathrm{m}^{3}\right), \\
& k_{B}=\text { Boltzmann's constant }=1.38060504 \times 10^{-23} \mathrm{~J} / \mathrm{K}, \\
& T=\text { the temperature of the gas which is a solved field in the COMSOL model }(\mathrm{K}), \\
& d=\text { the collision diameter of the gas molecule }(\mathrm{m}), \text { and } \\
& p_{\text {gas }}=\text { the pressure of the gas which is an input to the COMSOL model }(\mathrm{Pa}) .
\end{aligned}
$$

The mean free path for the fission-product gases $\mathrm{Xe}$ and $\mathrm{Kr}$ were previously calculated using ratios to helium at constant temperature [41], however their mean free path is now calculated using the equation above and their molecular or collisional diameters. While the solution is not very sensitive to this parameter, the gas collision or molecule diameter is derived as the average from three different methods of characterization: Van der Waals radii [42], [43], viscosity [43], and second viral coefficients [44]. The helium pressure is assumed to be constant at the pressure during the capsule assembly at $1 \mathrm{~atm}$. 
These variables represent the "temperature jump distance" and are specific to individual gases as provided by Equation 4.2 on page 46 of [29] and repeated here

$$
g=\frac{(2-\alpha)}{\alpha} \frac{2}{(\gamma+1)} \frac{k_{g}}{\left(\mu C_{v}\right)} \lambda=\frac{(2-\alpha)}{\alpha} \frac{2 \gamma}{(\gamma+1)} \frac{k_{g}}{\left(\mu C_{p}\right)} \lambda
$$

where

$$
\begin{aligned}
& \alpha=\text { accommodation coefficient, } \\
& \gamma=\text { ratio of specific heats }=C_{p} / C_{v}, \\
& \mathrm{k}_{\mathrm{g}}=\text { thermal conductivity of the gas, } \\
& \mu=\text { viscosity, } \\
& \mathrm{C}_{\mathrm{v}}=\text { specific heat at constant volume, } \\
& \mathrm{C}_{\mathrm{p}}=\text { specific heat at constant pressure, and } \\
& \lambda=\text { mean free path of gas molecules. }
\end{aligned}
$$

Another variable represents the gas jump for a mixture of gases provided by Equation 4.3 on page 47 of [29]:

$$
g_{m}=\sum\left(x_{i} g_{i} / M_{i}^{0.5}\right) / \sum\left(x_{i} / M_{i}^{0.5}\right)
$$

where

$$
\begin{array}{ll}
\mathrm{x}_{\mathrm{i}} & =\text { mass fraction of constituent gas } \mathrm{i}(\mathrm{He}, \mathrm{Xe}, \mathrm{Kr}), \\
\mathrm{M}_{\mathrm{i}}= & \text { molecular mass of constituent gas } \mathrm{i} \text {, and } \\
\mathrm{g}_{\mathrm{i}}= & \text { temperature jump distance of constituent gas } \mathrm{i} .
\end{array}
$$

The definitions from this section lead to the definition of the gas gap conductance, following Equation 4.4 on page 47 of [29] as

$$
h_{g}=\frac{k_{g}}{\delta+g_{1}+g_{2}}
$$

where $\delta$ is the physical gas-gap size between the two surfaces.

The total thermal conductance between two surfaces (the pellet and cladding/housing here) is then the sum of the gap conductance and contact conductance (defined previously), where radiation conductance, $\mathrm{h}_{\mathrm{r}}$, is conservatively considered negligible due to the low absolute temperatures in the target:

$$
h=h_{c}+h_{g}+h_{r}=h_{c}+h_{g}=h_{c}+\frac{k_{g}}{\delta+g_{1}+g_{2}}
$$

In COMSOL, the total gap resistance heat transfer, $\mathrm{h}_{\mathrm{s}}$, is input, according to the above and previous sections' definitions:

$$
h_{s}=k_{s} / d_{s}=h_{c}+\frac{f_{k H e} k_{H e}(T)}{\max (\sigma, \delta)+g_{1}+g_{2}}
$$




\subsubsection{Target Surface: Heat Transfer Coefficient, Bulk Temperature, and Oxide Layer}

The target surface cooling for the single pellet models was calculated using a different heat transfer coefficient and no inclusion of bulk temperature or oxide layer effects, therefore the methodology discussed here is for the prototypical and later target models.

The average heat transfer coefficient, $\mathrm{h}$, is used for external forced convection as a convection-cooling boundary in COMSOL and is obtained from many sources including Incrupera [45]. Although an internal forced convection correlation (such as Dittus-Boelter or those supplied in COMSOL) would be appropriate for the target annular flow geometry, an external flow correlation was selected because it predicts a conservatively smaller heat transfer coefficient. The functional form used is as follows:

$$
\begin{aligned}
& \text { for } R e_{L} \leq 5 * 10^{5}, h=2 \frac{k}{L} \frac{0.3387 \operatorname{Pr}^{1 / 3} \operatorname{Re}_{L}^{1 / 2}}{\left(1+(0.0468 / P r)^{2 / 3}\right)^{1 / 4}}, \text { and for } \\
& R e_{L}>5 * 10^{5}, h=2 \frac{k}{L} \operatorname{Pr}^{1 / 3}\left(0.037 R e_{L}^{4 / 5}-871\right)
\end{aligned}
$$

where:

$$
\begin{aligned}
\operatorname{Pr} & =\text { the Prandtl number, }{ }^{\mu C_{p}} / k \\
\operatorname{Re} & =\text { the Reynolds number, } \rho U L / \mu, \\
\mathrm{L} & =\text { plate length, defined as target length, } \\
\mu & =\text { the dynamic viscosity of water, } \\
\mathrm{C}_{\mathrm{p}} & =\text { the heat capacity of water, } \\
\rho & =\text { the density of water, and } \\
\mathrm{U} & =\text { the coolant velocity, given by a calculated } 5.0 \text { gallons per minute (gpm) volumetric flow and }
\end{aligned}
$$

In COMSOL, several variables define the total heating for discrete target components as a function of axial position along the coolant flow direction, where they have a minimal value of zero at the top of the target and maximum at the bottom of the target. These variables are most simply described as the local mass-specific heating multiplied by the local density, cross-sectional area and axial position of the component(s).

The bulk temperature is a function of axial centerline position and it makes use of the above variables. The equation to determine it is a simple heat balance, where all heat generated in the target is removed to the coolant flow, assuming no other heat sinks:

$$
T_{b u l k}(z)=p f \frac{z \sum H_{i} \rho_{i} A_{i}}{\dot{V}_{w} \rho_{w} C_{p w}}+T_{\text {inlet }}
$$

where:

$\mathrm{T}_{\text {bulk }}=$ bulk coolant temperature,

pf $=$ the power factor fraction (1.0 or 1.3$)$, 
$\mathrm{z}=$ the axial position along the coolant flow,

$\mathrm{H}_{\mathrm{i}}=$ the mass-specific heating rate of component $\mathrm{i}$,

$\rho_{\mathrm{i}}=$ the density of component $\mathrm{i}$,

$\mathrm{A}_{\mathrm{i}}=$ the cross-sectional area of component $\mathrm{i}$,

$\mathrm{V}_{\mathrm{w}}=$ the coolant volumetric flow rate, $5 \mathrm{gpm}$, and

$\mathrm{T}_{\text {inlet }}=$ the inlet temperature (at the top of the target).

The following definitions are used to calculate the thickness of an oxide layer on the aluminum target surface. Per the HFIR SAR, Chapter 4, corrosion is expected on the fuel plates and oxide buildup correlations are used based on measurements with aluminum. These correlations are conservatively applied here although there is reason to expect that at the much lower heat fluxes this buildup would be considerably less or negligible (target fluxes are $\sim 3 * 10^{3} \mathrm{Btu} /\left(\mathrm{h}-\mathrm{ft}^{2}\right)$ compared to the experimental range of 1.0 to $\left.2.0^{*} 10^{6} \mathrm{Btu} / \mathrm{h} / \mathrm{ft}^{2}\right)$. The oxide buildup correlation from the HFIR Safety Analysis Report [12] (developed for the HFIR aluminum fuel plates as detailed in [46]) is conservative for estimating the thickness of oxide buildup on the target housing.

The oxide thickness is given by the correlations referenced previously:

$$
X_{k}=443\left(\psi_{k-1}+t\right)^{0.778} e^{\frac{-8290}{T_{S k}}}
$$

where:

$\mathrm{X}_{\mathrm{k}}=$ the oxide layer thickness for cycle $\mathrm{k}$ (mils),

$\mathrm{t}=$ the time in the $\mathrm{k}^{\text {th }}$ operating cycle (hours), and

$\mathrm{T}_{\mathrm{Sk}}=$ the surface temperature of the target for cycle $\mathrm{k}\left({ }^{\circ} \mathrm{R}\right)$.

And the buildup terms, $\psi_{\mathrm{k}-1}$, are used to include the effect of buildup from previous cycles:

$$
\psi_{k-1}=\left(\psi_{k-2}+\Delta t\right) e^{10,656 * \frac{T_{S k-1}-T_{S k}}{T_{S k-1} T_{S k}}}
$$

where:

$\psi_{\mathrm{k}}=$ the buildup term for cycle $\mathrm{k}$ (hours), and

$\Delta \mathrm{t}=$ the 26-day operating cycle time (hours).

The oxide layer is modeled by using the computed oxide layer thickness to provide additional heat transfer resistance between the plate surface and the coolant bulk temperature. This is equivalent to utilizing a COMSOL "thin film resistance" and is implemented by coupling this boundary condition to the convective cooling boundary condition by the following adjustment to the heat transfer coefficient:

$$
h_{\text {modified }}=h \frac{1}{1+\delta_{\text {oxide }}\left(X_{\text {oxide }} * \frac{h}{k_{\text {oxide }}}\right)}
$$

where:

$\delta_{\text {oxide }}=\quad$ an "on/off switch" for the oxide buildup that has a value of 0 or 1 , 
$\mathrm{h}=$ the convective cooling heat transfer coefficient, and

$\mathrm{k}_{\text {oxide }}=$ the thermal conductivity of the oxide, boehmite, $1.3 \mathrm{Btu} /(\mathrm{h}-\mathrm{ft}-\mathrm{degF})$.

\subsection{SOLVER METHODOLOGIES}

Two solution methods were used: 1) direct fully-coupled solver was the preferred setting for the solver for all models, solving all equations in one step, and 2) a segregated solver using a lumped fully coupled step of the temperature and displacement field variables, followed by a second solution step of the contact pair variable(s). The former method was primarily used and preferred, although it uses greater computational resources and poses greater convergence issues, due to its more robust and accurate solutions.

A steady-state solution is sought and obtained for all solutions shown in this report to the default residual value of 1e-3. A smaller residual, .e.g., 1.0e-6, will typically add several iterations, but no significant change in the temperature field, the maximum of which, is usually what is being examined for this type of simulation.

The initial guess for the solution is important to convergence, sometimes requiring manual scaling of the field variables in order to improve stability or speed. The difficulty in model convergence, particularly for those cases with strong contact between the pellet side and inside containment housing tube surface, has commonly required approaching solutions with an increased load, either increasing the power factor, irradiation day, or other parameter in increasing steps, while using the previous solution as an initial guess.

The finite-element basis function that is used for the variable interpolation between node points of the model observed some variation for each model, where its increase, along with the solution mesh, considerably increases both the computation resources and accuracy of the solution. Linear, quadratic, and cubic linear basis function were used, with commonly either quadratic or cubic basis solutions used for the final solution. In addition, mesh refinements were commonly performed to ensure adequate solution convergence, with variations in memory usage between a few GB to around 25 GB. 


\section{SINGLE PELLET MODELS}

The single pellet models are of experiment capsules containing a single $\mathrm{NpO}_{2} / \mathrm{Al}$ cermet pellet in a nonprototypical design encapsulation. These capsules are designed specifically to prevent the capability for failures due to the unknown pellet irradiation behaviors at the time, including pellet dimensional changes, fission gas release fractions, and PCI. This section of irradiation tests is commonly referred to as the phase 1 testing, with irradiations and PIE of the test capsules now completed.

Each of the two single pellet models use three-dimensional (3-D) geometries in $1 / 4$ symmetric radial or pie slices, as they both include a non-axisymmetric spring and in order to confirm the negligibility of certain 3-D effects. Since the capsule design between the "bare pellet" and reduced-length pellet are the same except for the pellet length, the models themselves experience no major changes between these two versions. The simulations by these models are performed at end-of-cycle (EOC) only since heat generation rates and fission gas inventories are greatest at these times, and the radial gap and fission release fractions are assumed as a bounding constant value.

\subsection{SINGLE PELLET MESH}

Four different mesh cases were analyzed and used for each single pellet model, designated either numerically or by name as (1) extra-coarse, (2) coarser, (3) coarse, and (4) normal, where the numerical convention is used primarily by the reduced-length pellet model. Although each of the solutions were checked against the finest mesh (case 4 or normal) with quadratic basis functions, the extra-coarse mesh and case 3 meshes were determined to be sufficiently accurate and used for the documented results for the bare pellet and reduced-length pellet models, respectively, both for linear basis functions.

The pellet mesh densities for the bare pellet model for case 1 and case 4 , the coarsest and finest meshes respectively, are shown in Fig. 4.1. The reduced-length model's pellet mesh density for case 3 is shown in Fig. 4.2, along with the surrounding lower heat sink (LHS) domain, revealing that pellet mesh densities were significantly increased for the reduced-length pellet model. The bare pellet model's mesh densities for certain internal components, including the pellet, upper heat sink, flux monitor cap, screw and spring, are shown in Fig. 4.3 as well as a view of mesh densities in the entire capsule, both for mesh case 3 . Mesh densities for components outside the pellet domain experienced little variation between the bare pellet and reduced-length pellet models. 

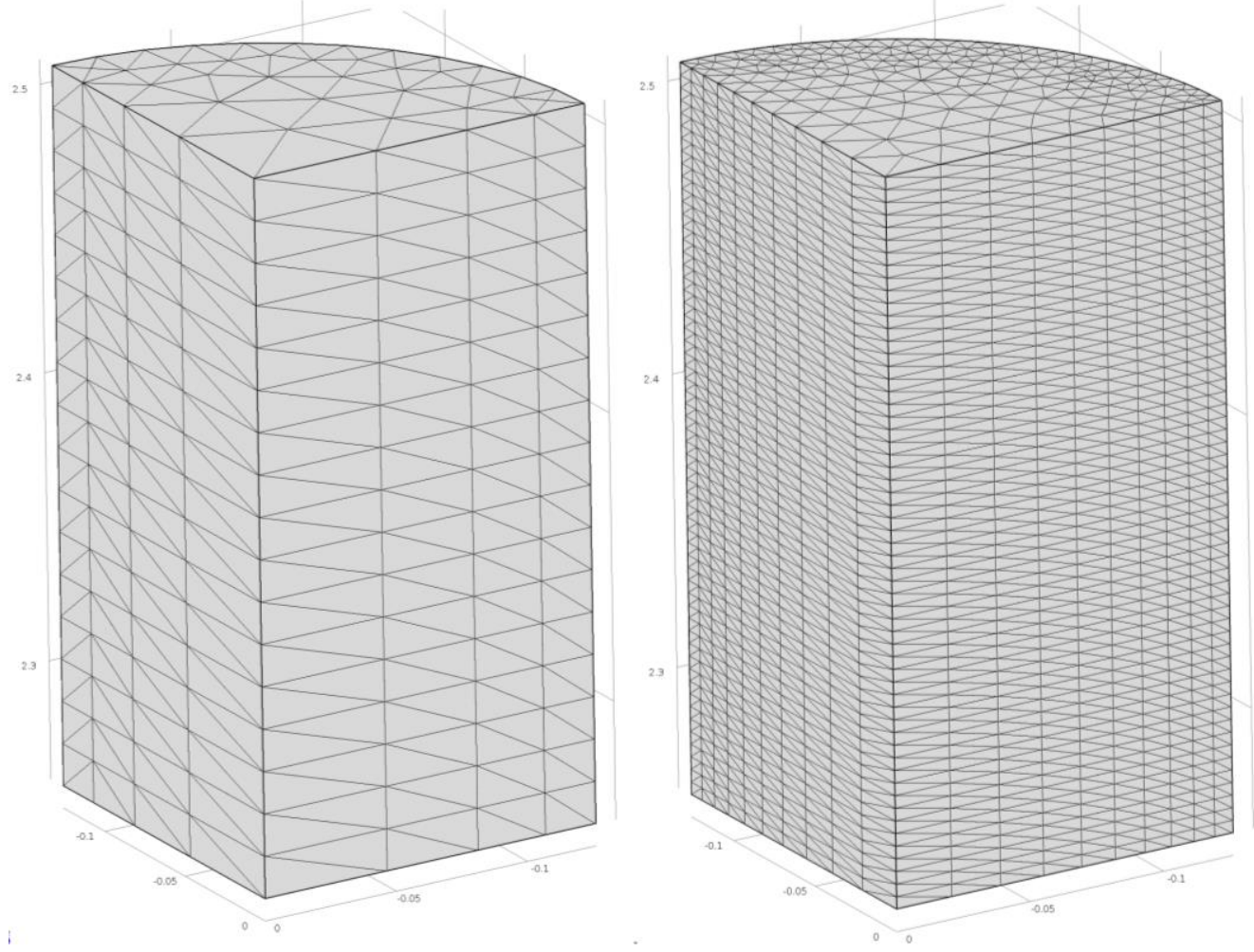

Fig. 4.1: Bare pellet mesh for the extra-coarse and normal mesh cases at the pellet domain.

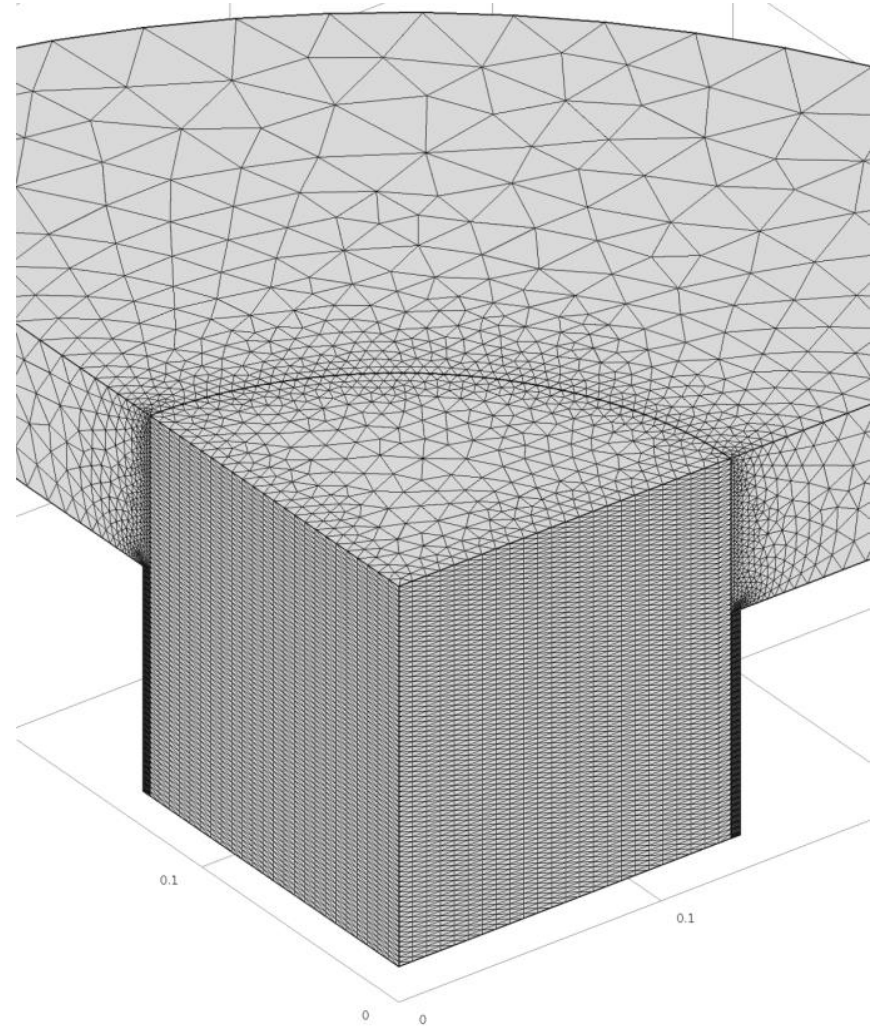

Fig. 4.2: Reduced-length pellet mesh for mesh 3 case at the pellet domain with surrounding LHS. 


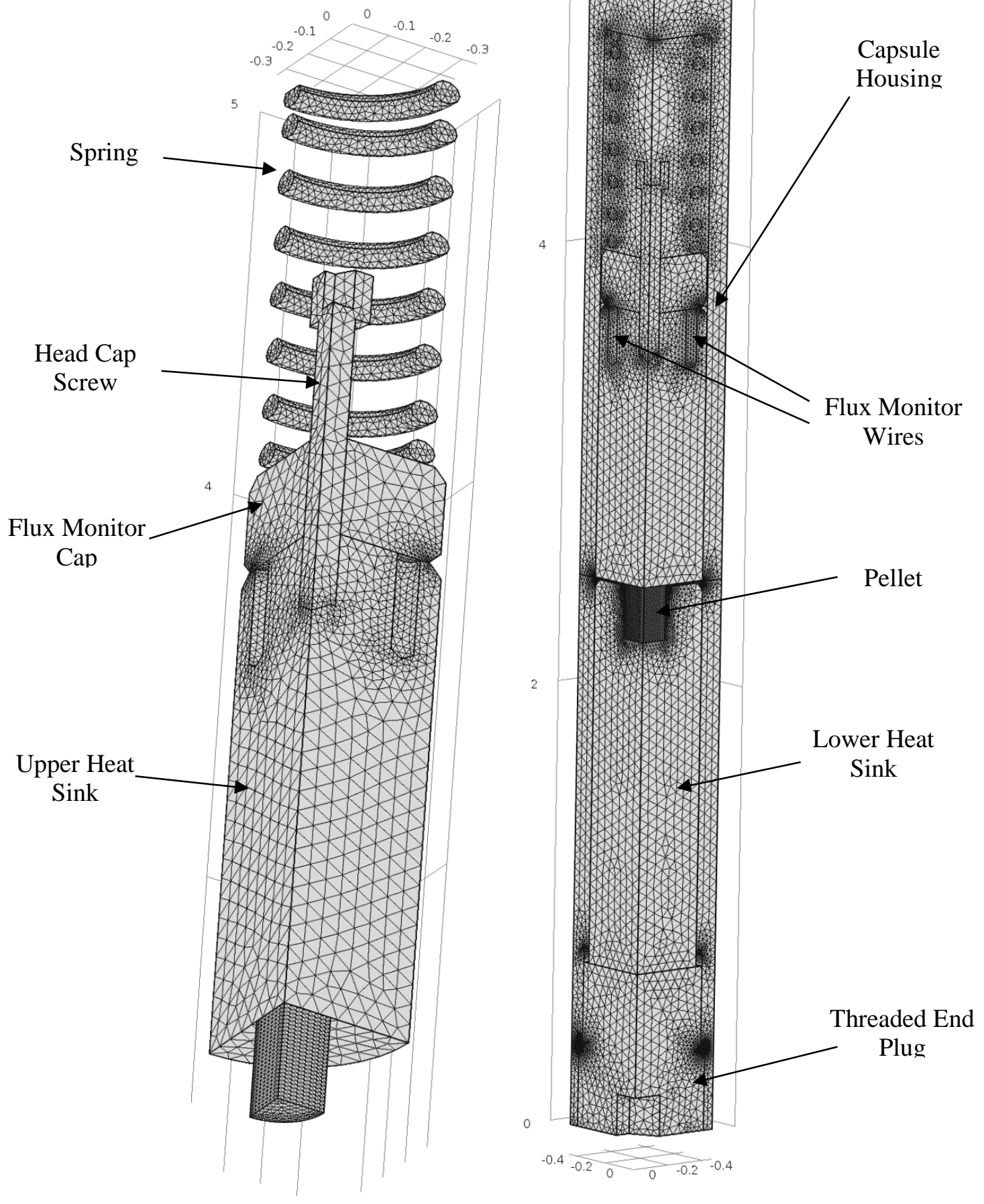

Fig. 4.3: Bare pellet meshes for capsule components and the entire capsule for the coarse mesh case. 


\subsection{BARE PELLET MODEL}

The bare pellet model results were first analyzed at their end-of-cycle 1 (EOC-1) values, for both a design-basis (DB) and safety-basis (SB) case as defined in the calculation. The differences between these cases included $130 \%$ overpower conditions for SB case, with $135^{\circ} \mathrm{F}$ coolant inlet temperature and bounding dimensions, within design tolerances, and coolant volumetric flow to include sufficient conservatism. The DB case is set at $100 \%$ power with nominal dimensions and coolant flow conditions. These dimensions included gas gaps between internal components, assumed as constant values in order to be conservative and save on computational resources. In addition, as required by procedure, a 50\% flow case is analyzed and showed little changes in the maximum target surface temperature.

At EOC-1, each of these two cases were analyzed at two different radial "cold gap" or fabrication gap sizes of 1.1 and 1.5 mils, and each of them were run at incremental power factors in a parametric sweep from 0.8 to 1.3 (or 130\%). As input, they used bounding heat generation rates and fission gas inventories from the highest flux capsule positions in the HFIR PB. As can be seen in Fig. 4.4, for the 1.1 mil SB case the pellet will melt (at $650{ }^{\circ} \mathrm{C}$ ) at around a 1.27 power factor. For the 1.5 mil SB case, the pellet was shown to melt at around a 1.16 power factor. For the gap sizes given, each of these cases would then be unsatisfactory from an experiment safety standpoint. Some side pressure on the containment was observed to occur at a power fraction of 1.3 for the SB case's simulation, at around $182 \mathrm{kPa}$ or $26 \mathrm{psi}$, as the pellet side gap is shown to close in Fig. 4.5.

These evaluations were updated for EOC-2 simulations that took credit for the actual positions of two asinstalled pellets, identified as 12-35 and 12-40, rather than assume a worst-case position centered at the HFIR core horizontal midplane. It should be noted that these evaluations at EOC-2 implicitly bounded the previous EOC-1 results for the same conditions and forms of input due to continual fissile isotope build-in. As a result, these positions experienced lower heat generation rates and, as the SB EOC-2 cases are plotted along with the EOC-1 cases on Fig. 4.4, they did not exceed the melting temperature for a 1.1 mil cold gap, seeing maximum temperatures of approximately 560 and $590{ }^{\circ} \mathrm{C}$ for pellets $12-35$ and 12 40, respectively.

A contour plot of the capsule temperatures is shown in Fig. 4.6 for SB EOC-1 conditions, where the hot spot in the pellets can be seen as well as increased temperatures in the screw and surrounding helium domains near the spring. The thermally expanded pellet (deformation multiplied by 100) is shown in Fig. 4.7 with its temperature contour and a temperature height expression of an $\mathrm{x}-\mathrm{y}$ cut plane at the maximum pellet temperature location is shown in Fig. 4.8. 


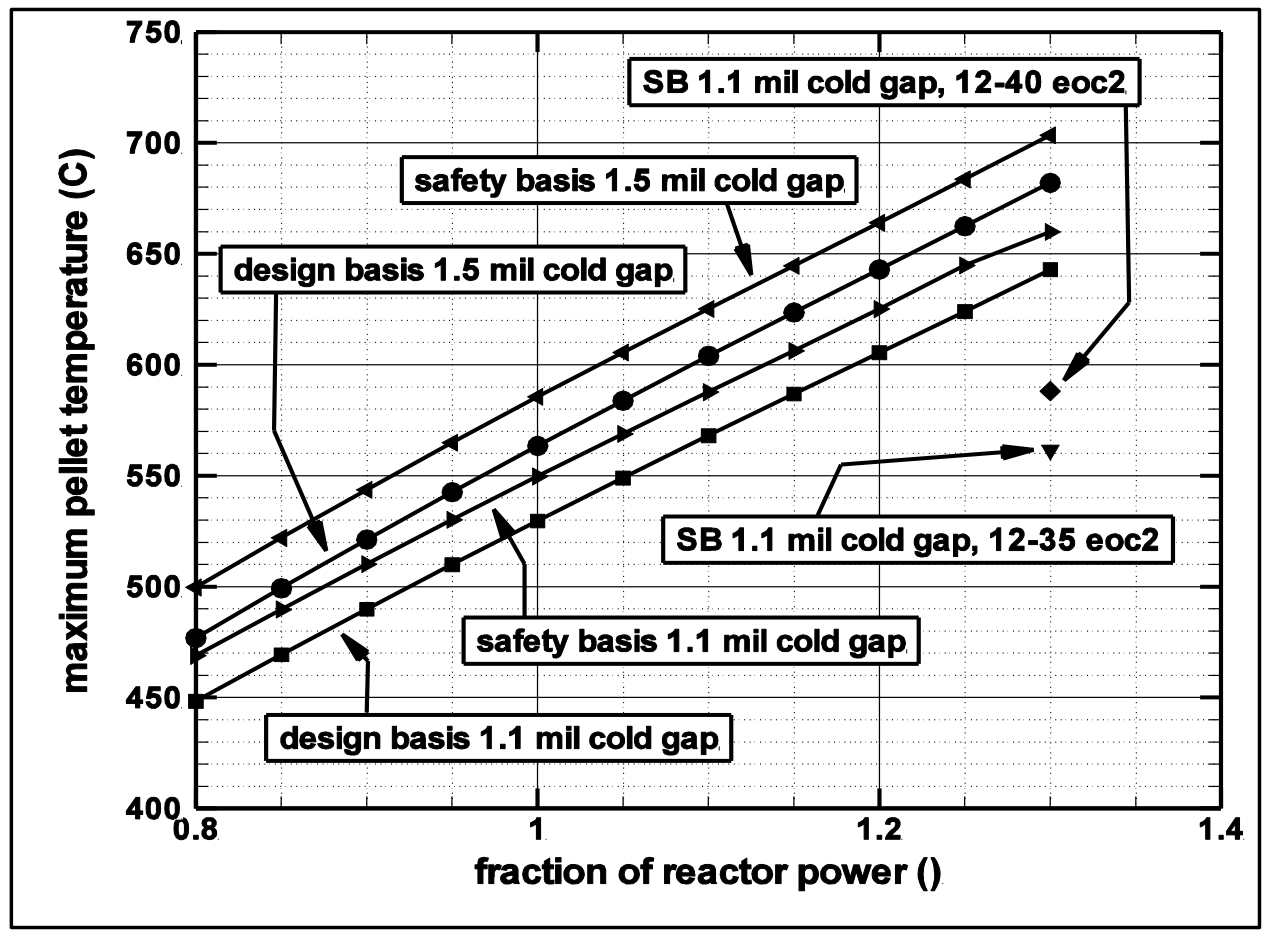

Fig. 4.4: Maximum pellet temperature as a function of fractional reactor power and initial cold radial gap size.

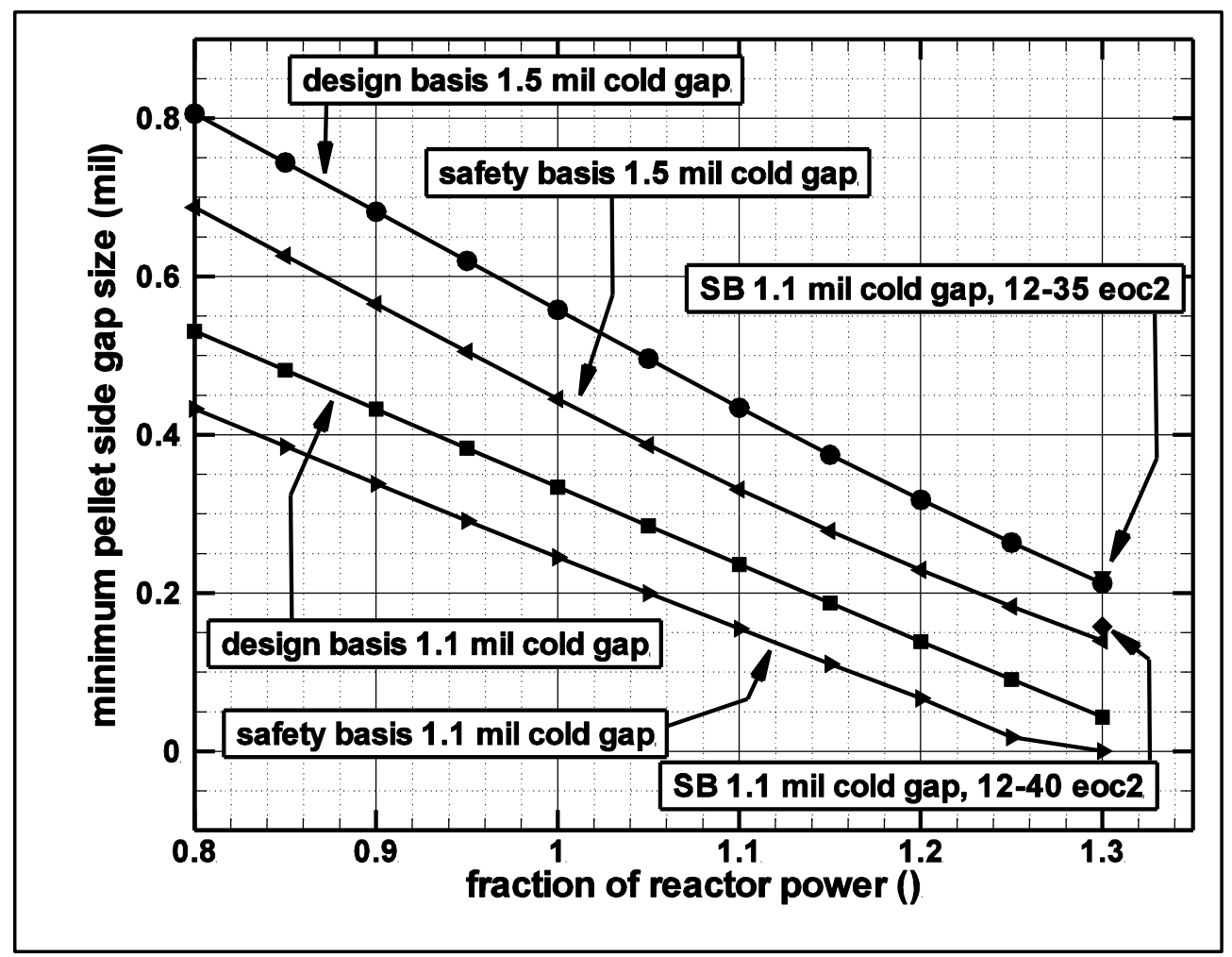

Fig. 4.5: Minimum pellet side gap size as a function of fractional reactor power and initial cold radial gap size. 


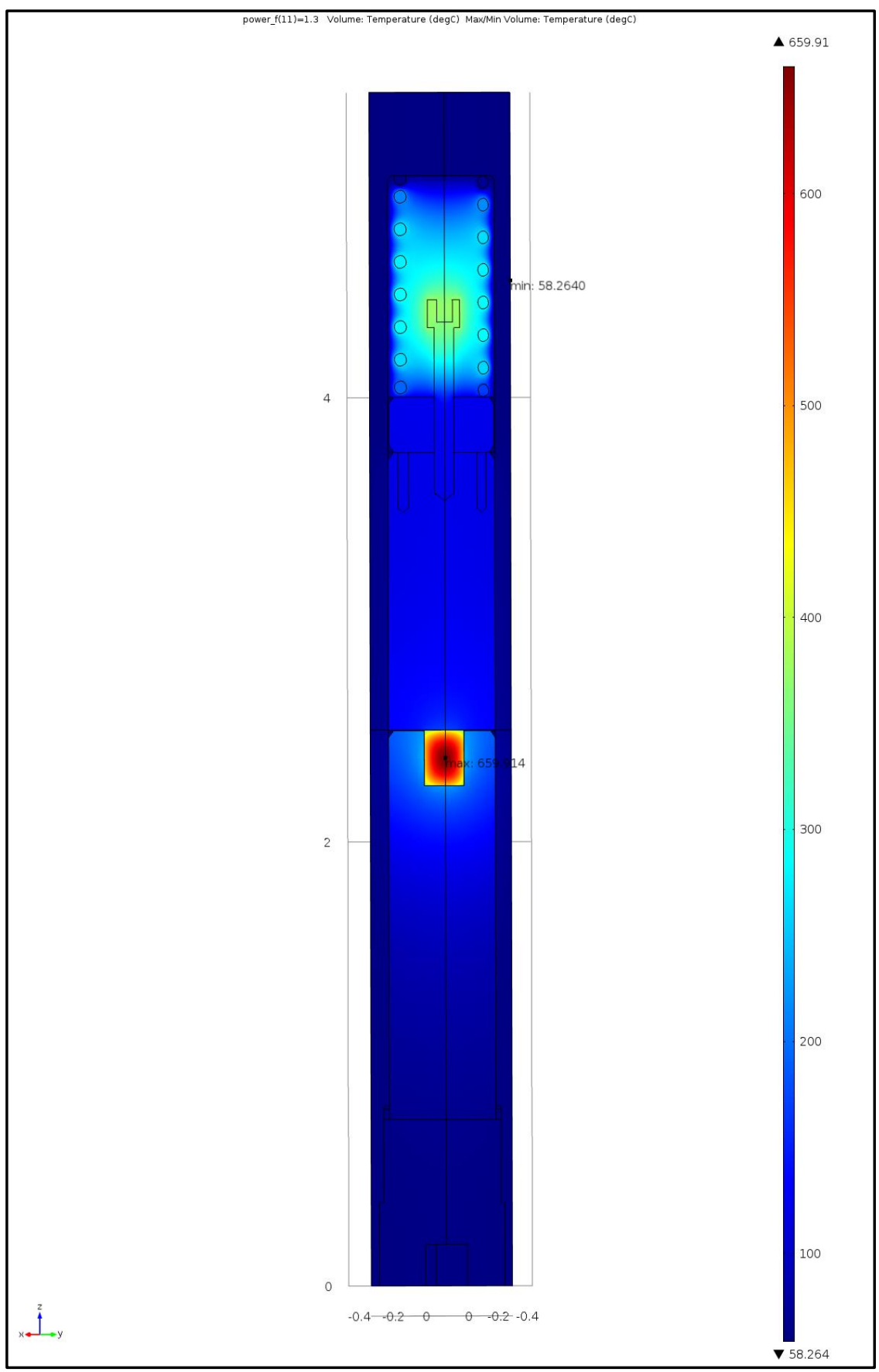

Fig. 4.6: Temperature contour of the $1 / 4$-pie slice modeled bare pellet capsule for the 1.1 mil cold-gap safetybasis conditions at $130 \%$ power. 


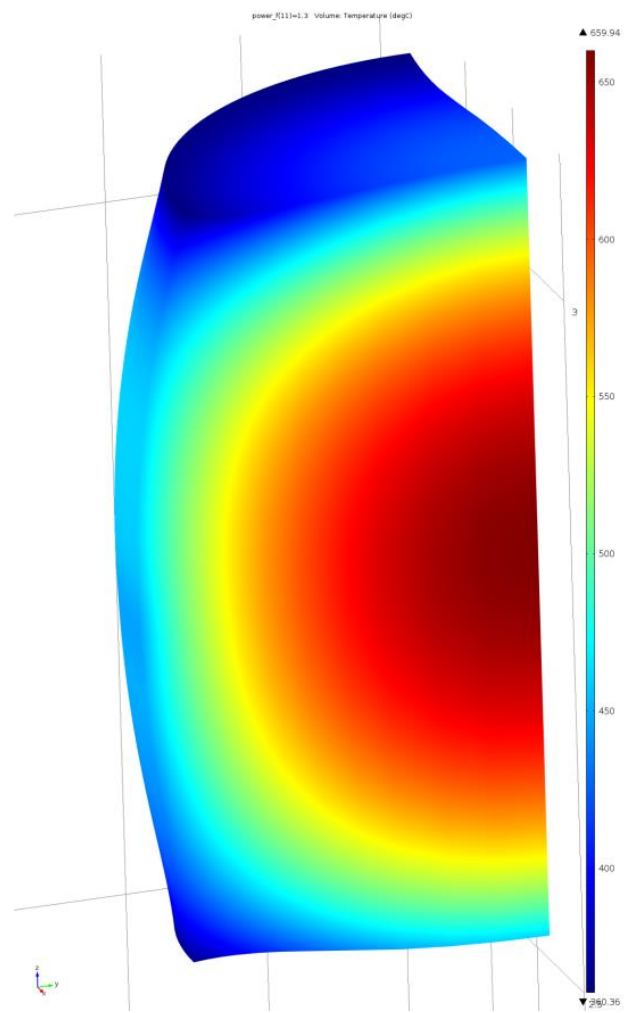

Fig. 4.7: Temperature contour of the pellet domain with thermal expansion deformation $x 100$ for the 1.1 mil cold-gap safety-basis conditions at $130 \%$ power.

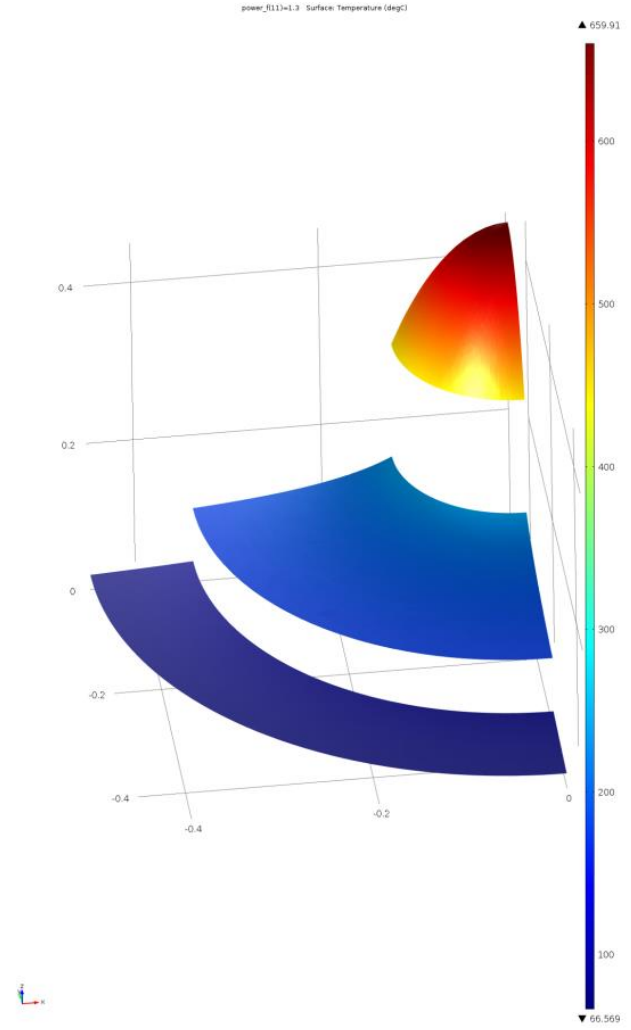

Fig. 4.8: Temperature height profile for an $X-Y$ cut plane at location of maximum pellet temperature for the 1.1 mil cold-gap safety-basis conditions at $130 \%$ power. 


\subsection{REDUCED-LENGTH PELLET MODEL}

The reduced-length pellet capsule design is identical to the bare pellet capsule, except for two significant changes: 1 ) the pellet length reduced from $\sim 1 / 4$ " to $\sim 1 / 8$ " in order to reduce the total heat generated where only heat transfer in the axial direction must be credited to ensure maximum pellet temperatures do not change due to irradiation pellet shrinkage/densification, and 2) the inclusion of pellet fabrications of different pellet heat-treatment temperatures at $800{ }^{\circ} \mathrm{C}, 900{ }^{\circ} \mathrm{C}$, and $1200{ }^{\circ} \mathrm{C}$, whereas the bare pellet capsules had included only pellets heat-treated at $800{ }^{\circ} \mathrm{C}$. However, since the higher heat-treatment temperature fabricated pellets exhibit thermophysical properties that are exclusively advantageous to heat transfer, it is both conservatively bounding and more efficient to consider only the $800{ }^{\circ} \mathrm{C}$ pellet loading case with their associated conservative pellet properties in the steady-state thermal analysis.

As in the previous bare pellet model analyses, a DB case and SB case are defined with identical variations except for a new pellet radial shrinkage term that is increased from 1.5 to 2 mils between the DB and SB case. A very large cold fabrication gap is assumed to be 7 mils radially. Due to these large gaps, the axial heat transfer is predominant, consisting of $\sim 90 \%$ of the pellet heat removal and thus the effect of irradiation shrinkage is not expected to impact the maximum temperatures in the pellet.

The maximum temperatures were calculated for power factors from 0.5 to 1.3 , where the $130 \%$ overpower case yielded a maximum temperature of $\sim 647^{\circ} \mathrm{C}$ depending on the mesh and basis function, which is below the melting temperature at $650{ }^{\circ} \mathrm{C}$. Fig. 4.9 gives the axial temperature profile for this case, where maximum temperatures are in the pellet, followed by temperature spikes at the bottom and top of the screw.

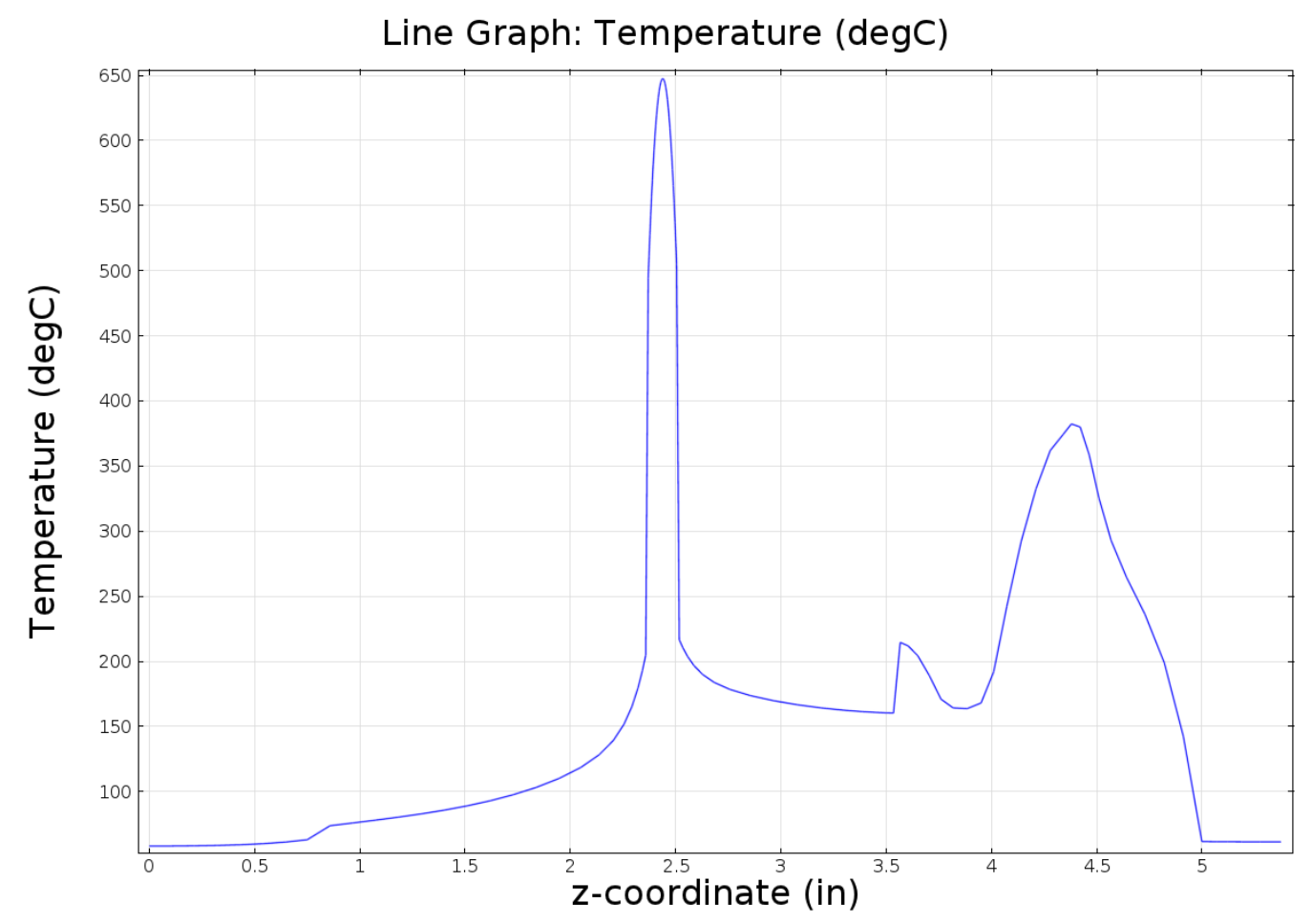

Fig. 4.9: Temperature profile along the axial centerline for $130 \%$ SB conditions with mesh-1 quadratic solution. 


\section{PROTOTYPICAL MODELS}

The prototypical targets included the partially loaded and fully loaded targets, both of which were qualified for two cycles. During model development, careful awareness of the qualifying PIE data (typically not yet available) was needed in order to ensure that the calculation scope would adequately ensure the safe irradiation of the targets. This often required parametric approaches, including solutions sweeping and solution searching methods, which would provide outputs within the anticipated range of qualifying PIE data.

The prototypical models shared common features including both being modeled in 2-D R-Z cylindrical, or axisymmetric geometries, which offered improvement on computation time that was less available for the single pellet models due to the non-symmetric spring component and necessary due to a closing side gap that would require overly constricting mesh limitations in 3-D. With increasing number of pellets and pellet side surfaces ( 8 or 52) however, the need to solve the structural mechanics equations over a larger domain and the highly non-linear contact heat transfer over a larger surface area created greater challenges in assuring model accuracy and convergence.

\subsection{PROTOTYPICAL TARGET GEOMETRIES}

One difference in the approach to target geometry from the single pellet capsule models to the prototypical target models is the former's geometries were built by importing the geometry from CAD, then adjusting the geometry as needed to reach the final geometry. As opposed to this top-down approach, a bottom-up approach was taken for the prototypical target geometries, building the geometries entirely from global parameters defined in COMSOL. This was done in order to gain easier control of the model geometry, for purposes of adjusting to conservative design tolerances and to be able to execute parametric sweeps to examine the effects of geometry changes, among other reasons.

The partially loaded target (see Fig. 5.1) was the first of the prototypical target designs, all around 33" in length, with many features that hold over for the fully loaded target and production target designs. The Al-4047 top end cap (TEC) and bottom end cap (BEC) both contained plenums for increased helium volume and the TEC had a threaded top for HFIR operations removal of the target. A TIG weld at the BEC and an E-beam weld at the TEC connect the end caps to the housing tube. Two stainless steel grade 316 (SST316) spacer tubes are at either end of the target, a lower spacer tube (LST) and an upper spacer tube (UST), with thin walls to accommodate a greater plenum volume. The pellet stack contains eight (8) $\mathrm{NpO}_{2} / \mathrm{Al}$ pellets, around $\sim 0.25$ " diameter and $\sim 0.375$ " in length, with a tantalum (Ta) dummy pellet at either end, which is placed to dampen end flux peaking with its high neutron absorption cross section. A $\sim 35$ mil thick Al-4047 housing tube encapsulates the internal components, containing six outer fins designed to stabilize the target in its holder (to prevent excess vibration) and to better mix flow.

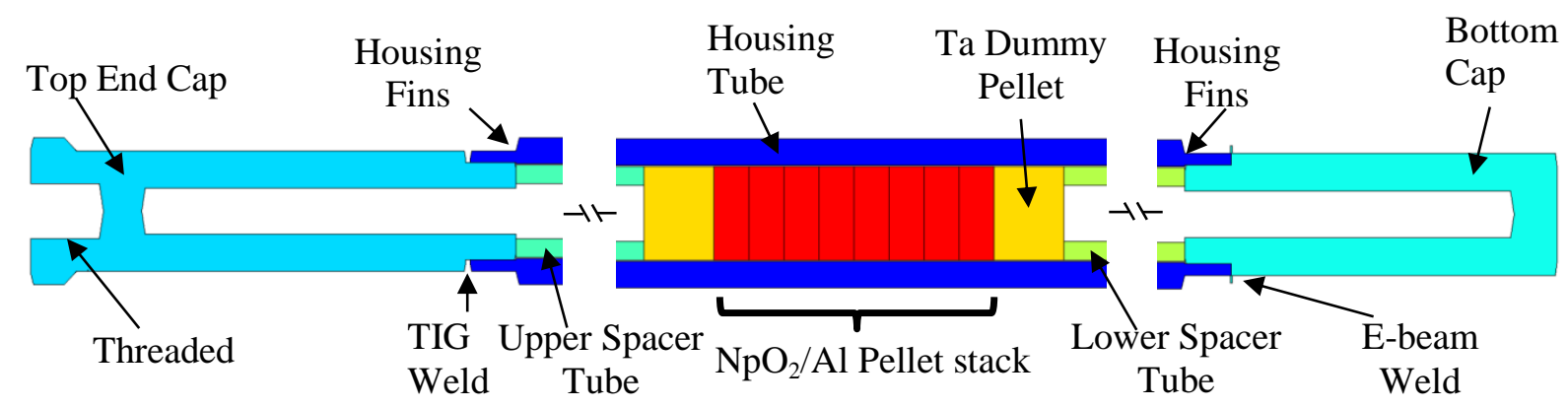

Fig. 5.1 : Representation of partially loaded model target pin components. 
The fully loaded target geometry (see Fig. 5.2) shares several common features with the partially loaded target, including a TEC with a threaded top and helium plenum. However, the end caps are Al-6061-t6 and the welds are switched to an E-beam weld at the TEC and TIG weld at the BEC, which has no plenum and uses an additional swage joint, to complete the target encapsulation. Due primarily to a large increase in the pellet stack, the lengths of the spacer tubes significantly decrease. A weld backing/support tube (WBT) is added below the UST to support the E-beam weld. The dummy pellet material is now Al6061-t6, as damping pellet end fluxes is no longer a major concern for the large pellet stack, with aluminum weld wires at their center. The major difference is a 50-52 NpO2/Al pellet stack that increases the stack length from $\sim 3$ " to $\sim 19.5$ ". The housing tube is of similar design except for its material is now Al-6061-t4.

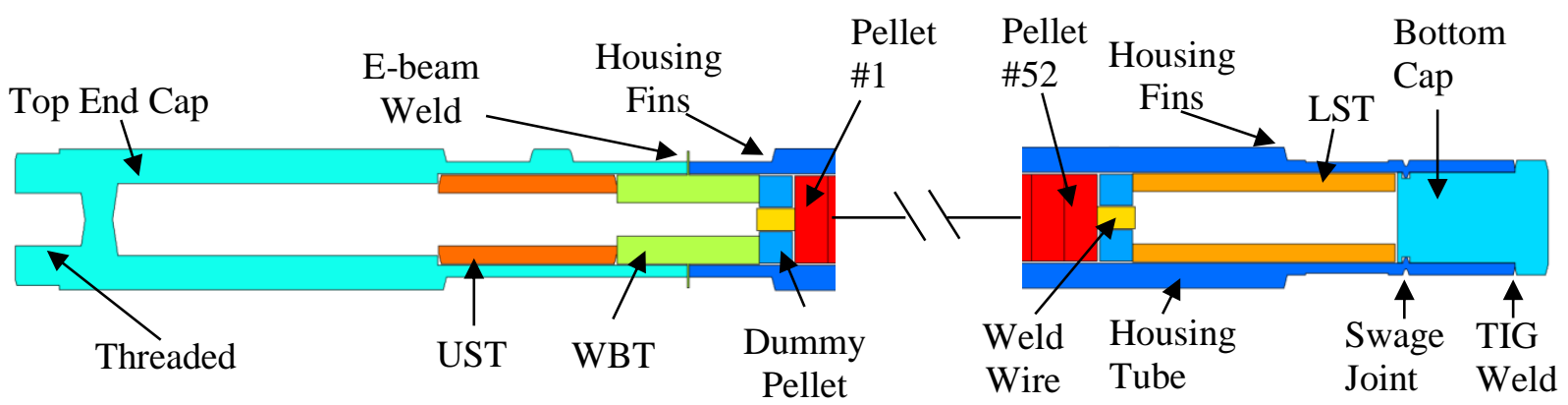

Fig. 5.2 : Representation of fully loaded model target pin components.

\subsubsection{Target Holder Geometry}

The target holder geometry for the prototypical models (as well as the production model in chapter 6) is the same, made of an aluminum alloy consistent with other HFIR holders. Seven prototypical target pins are held in seven bolt holes that act as coolant channels to each pin or target. One pin is located in the center of the holder, with six outer pins rotated $60^{\circ}$ around the holder. By convention, "Pin 1" is denoted as the pin facing the reactor core with the other pins named sequentially in the clockwise direction and pin 7 as the center pin. Pin 1, being closest to the reactor core, experiences the highest heat generation rates and therefore receives the greatest degree of examination by these safety calculations. 


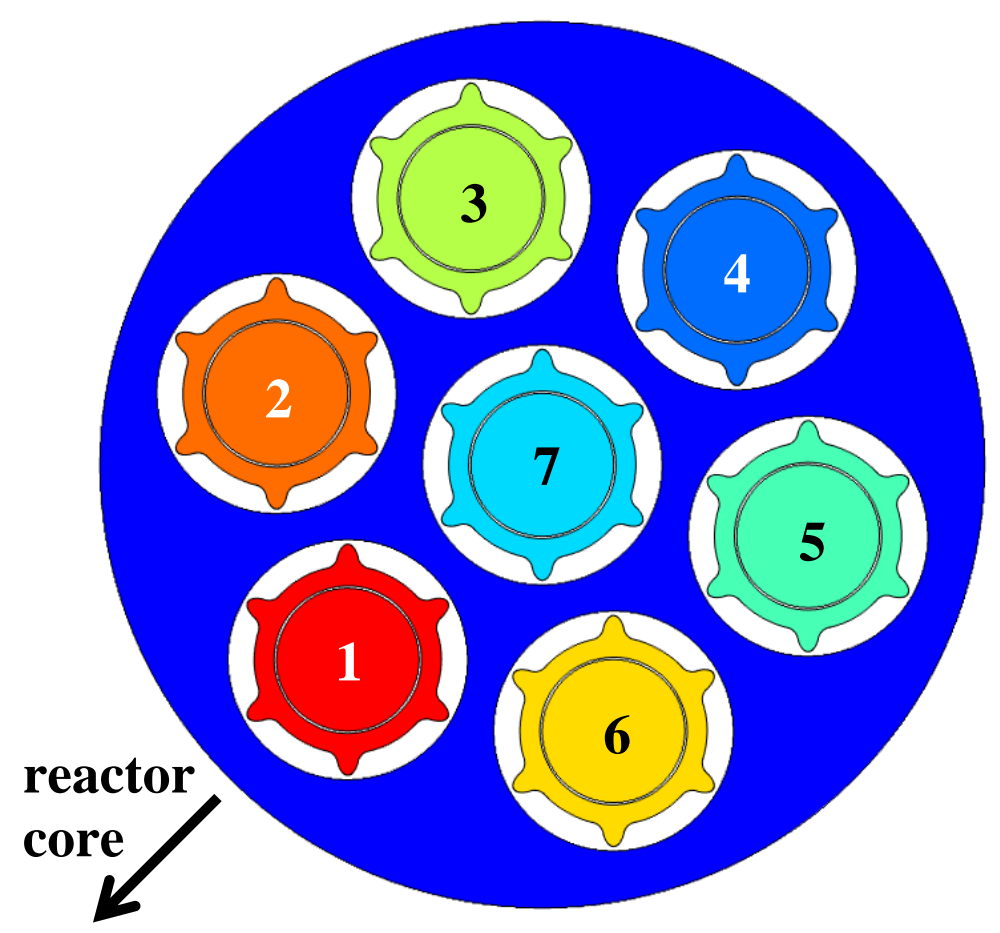

Fig. 5.3: Radial cut-view of prototypical target holder with seven prototypical target "pins".

\subsection{PROTOTYPICAL MESH}

A total of five mesh sizes were designed in analyzing these models. These 5 sizes in order of increasing detail are designated (1) extremely-coarse, (2) extra-coarse, (3) coarse, (4) normal, and (5) fine. Each mesh case is characterized by a free mesh size name that corresponds to the mesh case names (extremelycoarse, extra-coarse, coarse, normal, and fine). Four mesh cases were analyzed for the partially loaded target and fully loaded target models as listed in Table 5.1.

Table 5.1: Mesh cases for partially and fully loaded target analyses.

\begin{tabular}{|c|c|c|}
\hline \multirow{2}{*}{ Mesh Case } & \multicolumn{2}{|c|}{ Mesh Size } \\
\cline { 2 - 3 } & $\begin{array}{c}\text { Partially Loaded } \\
\text { Targets }\end{array}$ & $\begin{array}{c}\text { Fully Loaded } \\
\text { Targets }\end{array}$ \\
\hline 1 & extra-coarse & extremely-coarse \\
\hline 2 & coarse & extra-coarse \\
\hline 3 & normal & normal \\
\hline 4 & fine & fine \\
\hline
\end{tabular}

The mesh is designed so that the pellet mesh is the dominate control feature of the mesh design. This was done after preliminary analysis revealed that the predominate temperature change in the problem occurs in and around the pellet, with all other temperature features extending out beyond the pellet requiring less detail than within the pellet.

An extensive mesh-density evaluation of this problem was performed early in the study and revealed that the mesh case 1 (extremely coarse for the fully loaded target model and extra coarse for the partially loaded target model) was sufficient to analyze this problem provided that a quadratic finite-element basis function was also exercised with the fine-mesh to confirm that the quadratic-basis function at the first $\left(1^{\text {st }}\right)$ 
mesh level was sufficiently accurate. Therefore, the results corresponding to mesh cases 2,3 , and 4 are not the utilized results, only the $1^{\text {st }}$ mesh case results will be examined in this section excluding mesh refinement efforts.

The primarily used mesh cases for each target model (extremely-coarse for the fully loaded target and extra-coarse for the partially loaded target) are shown in the pellet domain in Fig. 5.4. The higher refinement meshes (coarse, normal, and fine) are shown in the pellet domain in Fig. 5.5. The extremelycoarse, extra-coarse and fine $\mathrm{m}$ in the pellet and housing-adjacent domains are shown in Fig. 5.6. The extra-coarse mesh in the domain of the TEC and BEC welds is shown in Fig. 5.7 and Fig. 5.8, respectively, for both the partially loaded and fully loaded target models.

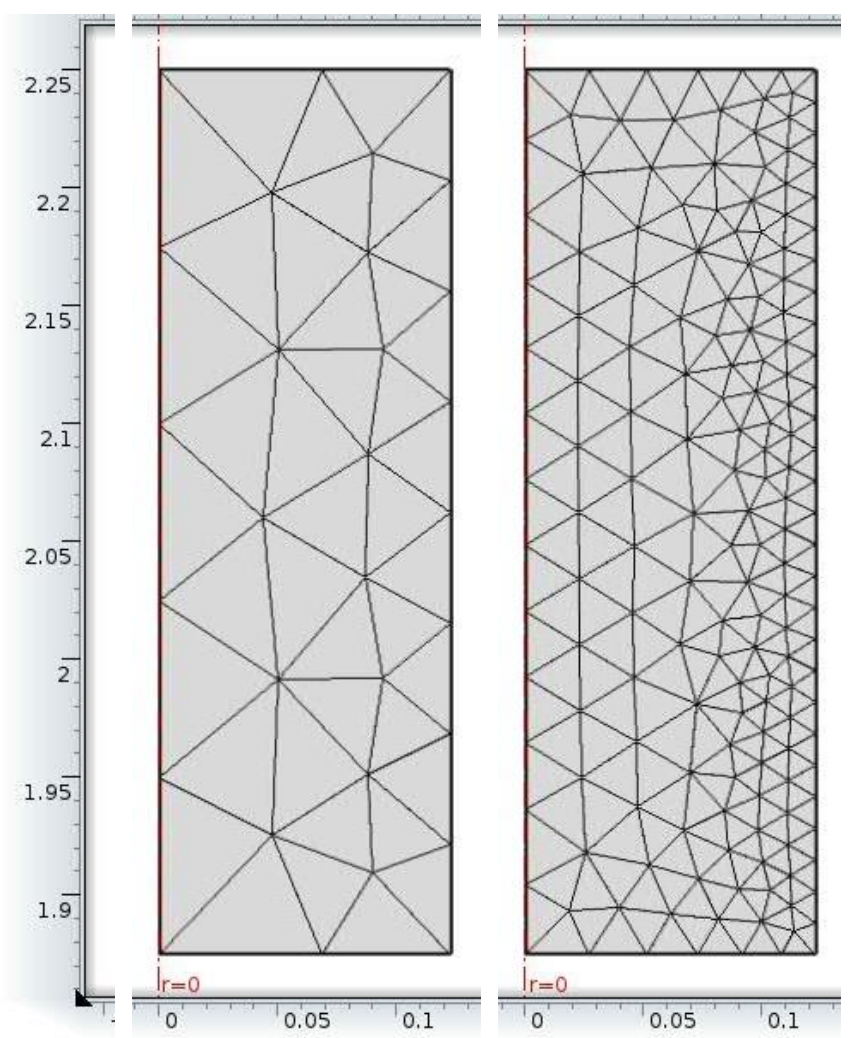

Fig. 5.4: Extremely-coarse and extra-coarse mesh at the pellet domain that serve as the primary mesh for the fully and partially loaded targets, respectively. 

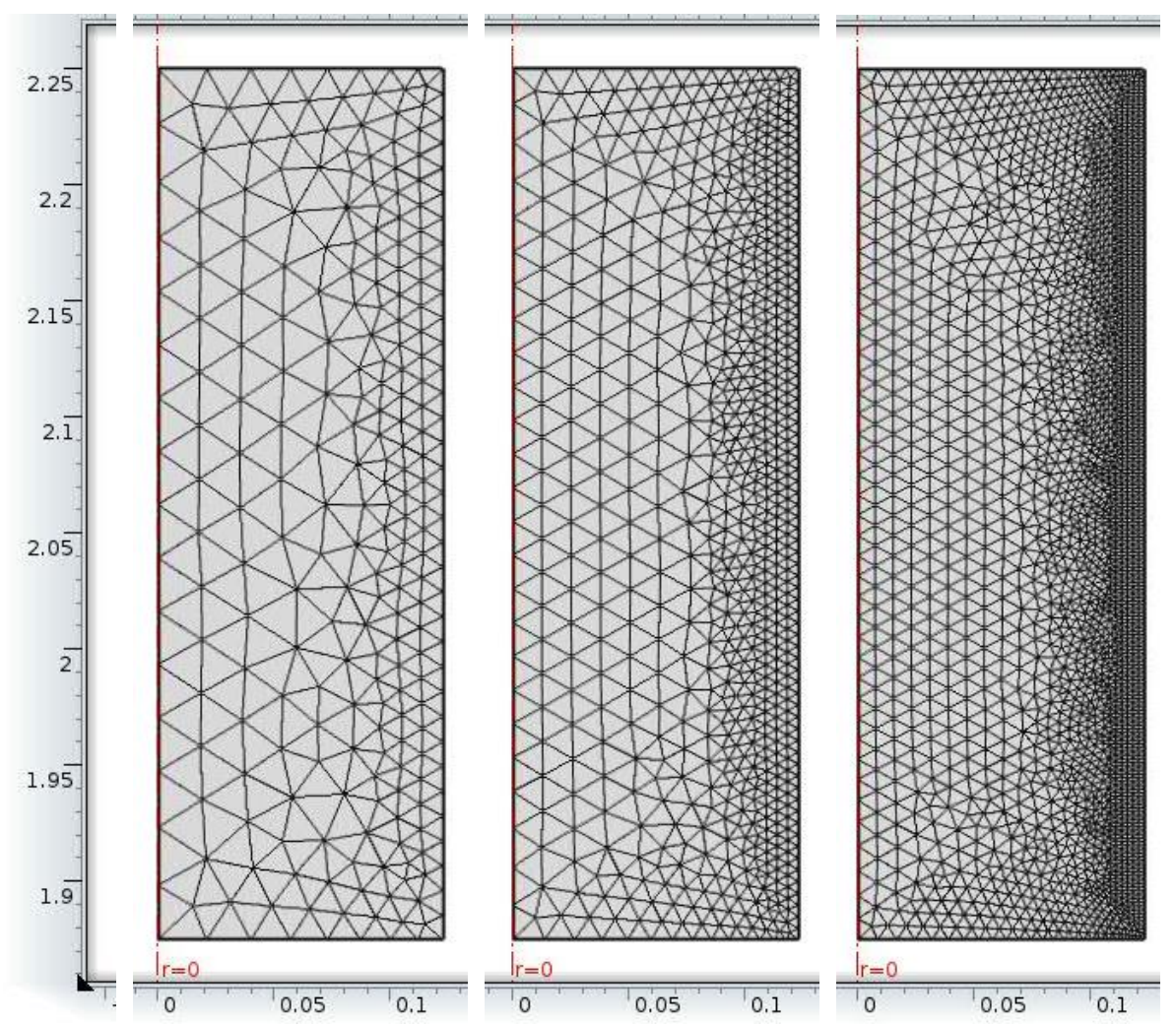

Fig. 5.5: Coarse, normal, and fine mesh at the pellet domain.
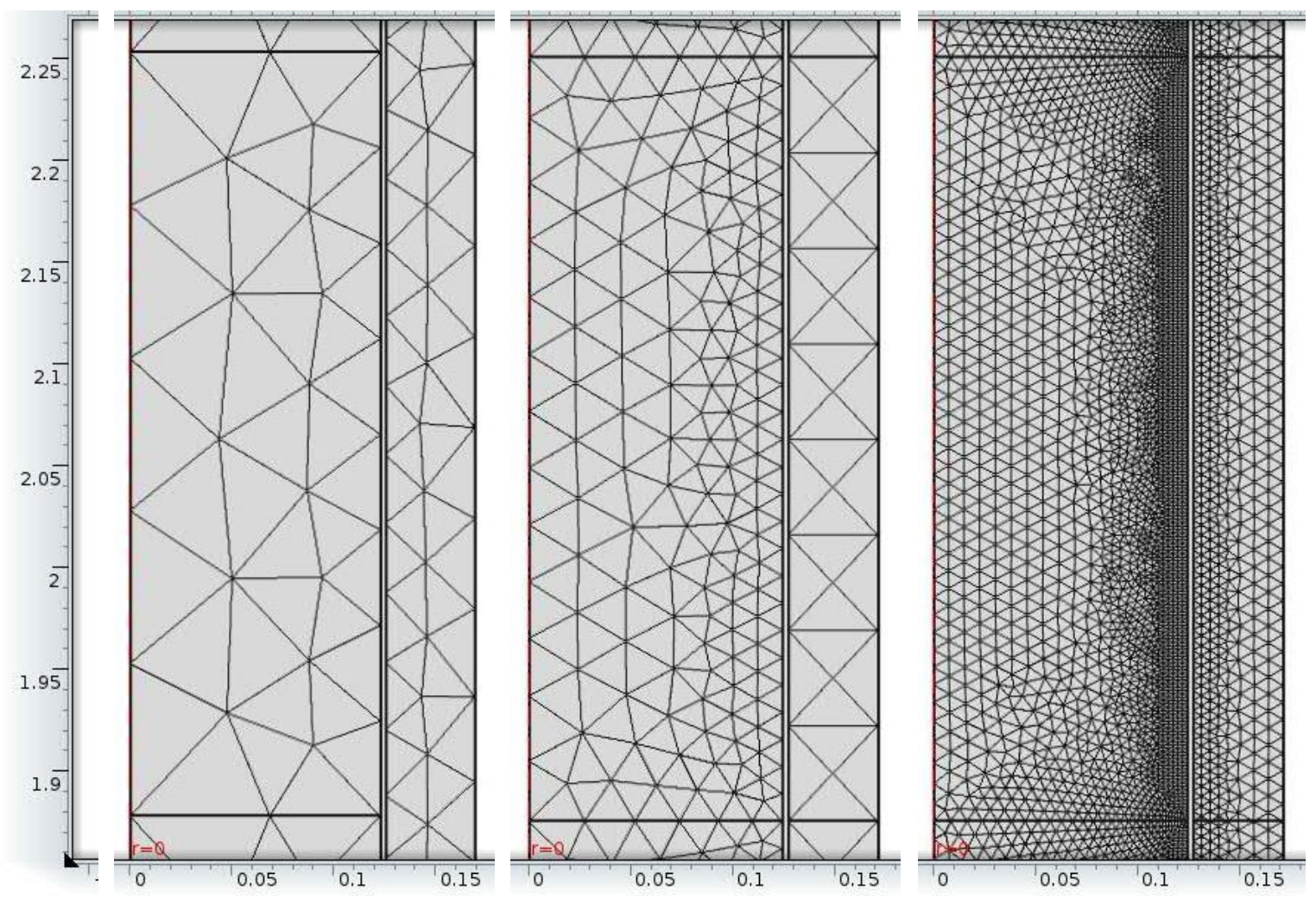

Fig. 5.6: Extremely-coarse, extra-coarse, and fine mesh at the pellet and housing adjacent domains. 

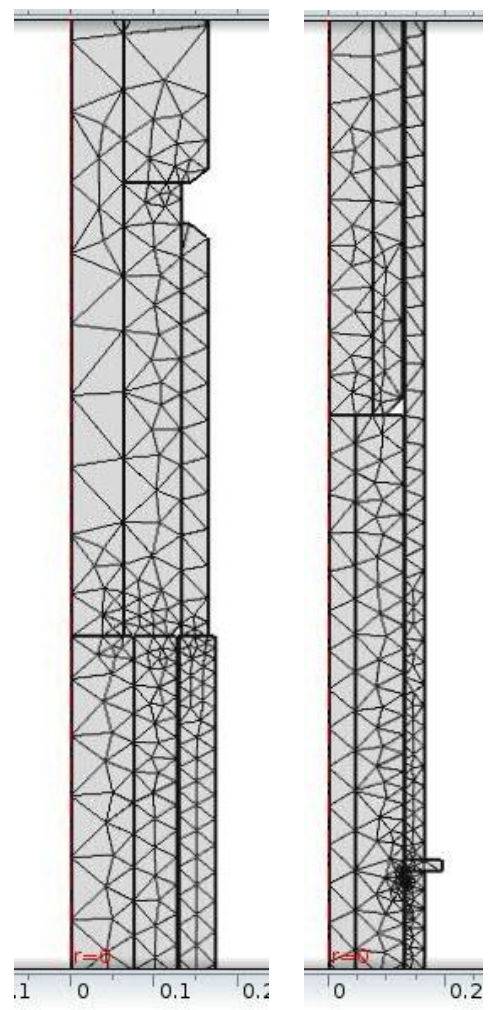

Fig. 5.7: Extra-coarse mesh at the TEC/UST/housing and TEC/UST/WBT/housing domains for the partially loaded and fully loaded target models, respectively.
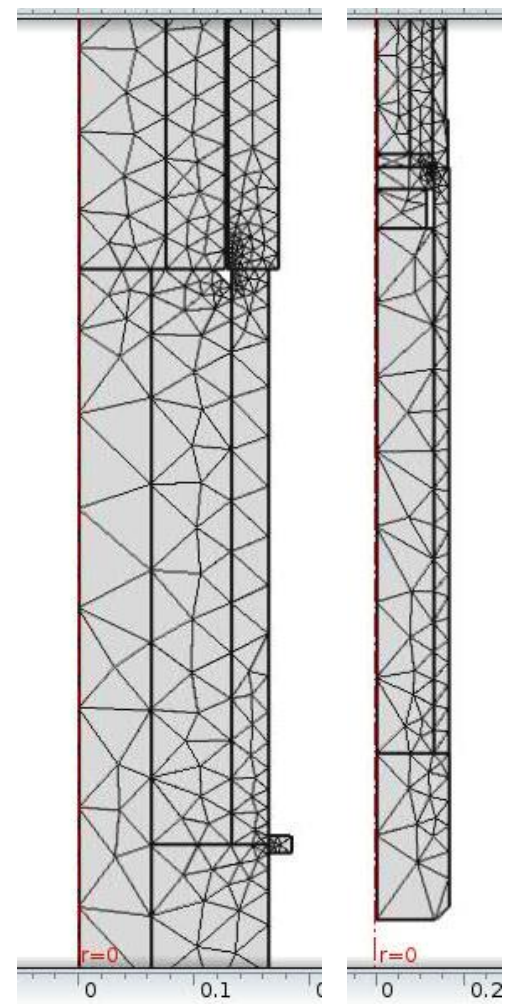

Fig. 5.8: Extra-coarse mesh at the BEC/LST/housing domains for the partially loaded and fully loaded target models. 


\subsection{PARTIALLY LOADED TARGET MODEL}

The partially loaded target model, containing eight (8) $\mathrm{NpO}_{2} / \mathrm{Al}$ pellets, marked a significant diversion from previous target designs as well as in the modeling methodology from the single pellet capsules. The target consists of a prototypical design including a pellet stack inside an aluminum tubing cladding, with end caps welded to the "housing tube" cladding. Internal components include spacer tubes and tantalum dummy pellets at the ends of each stack in order to decrease flux peaking at the pellet stack ends. After target fabrication, the housing tube is hydrostatically collapsed onto the internal components, in order to minimize the radial gas gap, and helium-leak checked to ensure integrity of the welds.

The target model uses a 2-D R-Z geometry, in order to take advantage of the axial symmetry of the target and decrease computational resource demands that would otherwise prove significant given the increase in pellet loading. In addition, many of the equations and inputs, particularly for the fission gas inventories, are updated and improved for improved accuracy and/or to identify areas requiring greater conservatism.

\subsubsection{Partially Loaded Model Analysis}

The partially loaded model was analyzed at both EOC-1 and EOC-2 in order to qualify irradiations of the partially loaded target for 2 cycles in position VXF-15. At this time, two heat treatments during pellet fabrication were under consideration, at higher temperatures of $900{ }^{\circ} \mathrm{C}$ and $1200{ }^{\circ} \mathrm{C}$ in order to reduce the void density and thus increase advantageous thermophysical pellet properties like its thermal conductivity and thermal expansion.

In addition to the added solution space of different pellet types, there was a considerable unknown in the size of the cold radial side gap, small variations of which significantly increase pellet temperatures. Due to schedule limitations, the dimensional PIE data from reduced-length pellet capsule irradiations and the target fabrication experience to estimate a maximum radial fabrication gap were not expected to be available in time to perform the safety analysis, so instead the thermal analysis was set up as a parametric study to allow for satisfactory qualification of the targets once data was available. The dimensional PIE data was expected to be available as discrete data points, not sufficient for fitting as a function of pellet burnup, and the radial fabrication gap would be available as a bounding value. The parametric analysis was then completed to find the allowable pellet diametrical shrinkage and its corresponding radial fabrication gap that yielding maximum temperatures just below the melting temperature for the SB condition. This parametric analysis was completed for both pellet heat-treatments for EOC-1 and EOC-2 as shown in Fig. 5.9 and Fig. 5.10, respectively. There is a significant difference between the allowable diametrical shrinkages for the two heat-treatments (around 0.5 mils) and significant decrease in these values from the first to second cycle $(\sim 1.5 \mathrm{mils})$. As can be seen, this also confirmed that the net allowable radial gap size (radial densification/shrinkage and fabrication gap) did not vary with changing diametrical shrinkage (i.e. the increased heating density due to densification is negligible).

The partially loaded target 3-D rotated temperature profile in the range of the pellet stack and its surrounding components can be seen in Fig. 5.11, where temperatures drop off precipitously outside the pellet stack. A zoomed-in view of the pellet side gap temperature profile in Fig. 5.12 with deformation due to thermal expansion enabled and a distorted view shows the characteristic hourglass shape also shown in $\mathrm{UO}_{2}$ pellets. The axial temperature profile along the axial centerline is shown in Fig. 5.13 where the maximum temperature in the pellet third from the bottom of the pellet stack can again be seen.

Fig. 5.14 shows the result of six PIE measurements of the diametrical pellet shrinkage from the reducedlength pellets, three for the $900{ }^{\circ} \mathrm{C}$ heat-treatment pellets and two for the $1200{ }^{\circ} \mathrm{C}$ pellets, with bounding lines determined using the corresponding fabrication gap from Fig. 5.10. The figure shows the $1200{ }^{\circ} \mathrm{C}$ 
pellets fall within their bounding tolerance of $\sim 3.6$ mils while the $900{ }^{\circ} \mathrm{C}$ pellets have a data point that is outside their tolerance. For this reason, only $1200{ }^{\circ} \mathrm{C}$ heat-fired pellets were irradiated for the partially loaded targets.

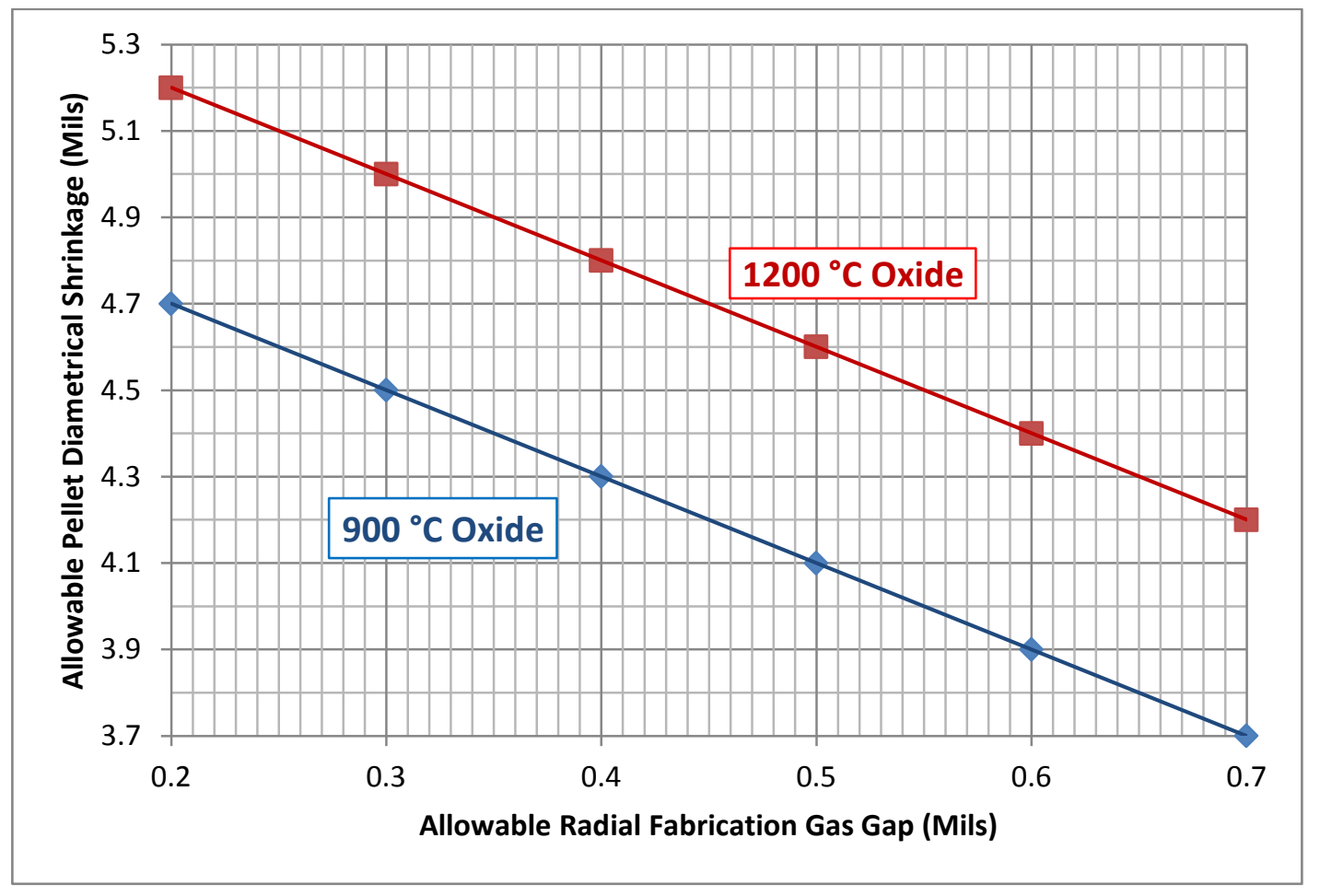

Fig. 5.9: Allowable pellet shrinkage vs. fabrication gas gap for safety-basis of a 1 Cycle Irradiation.

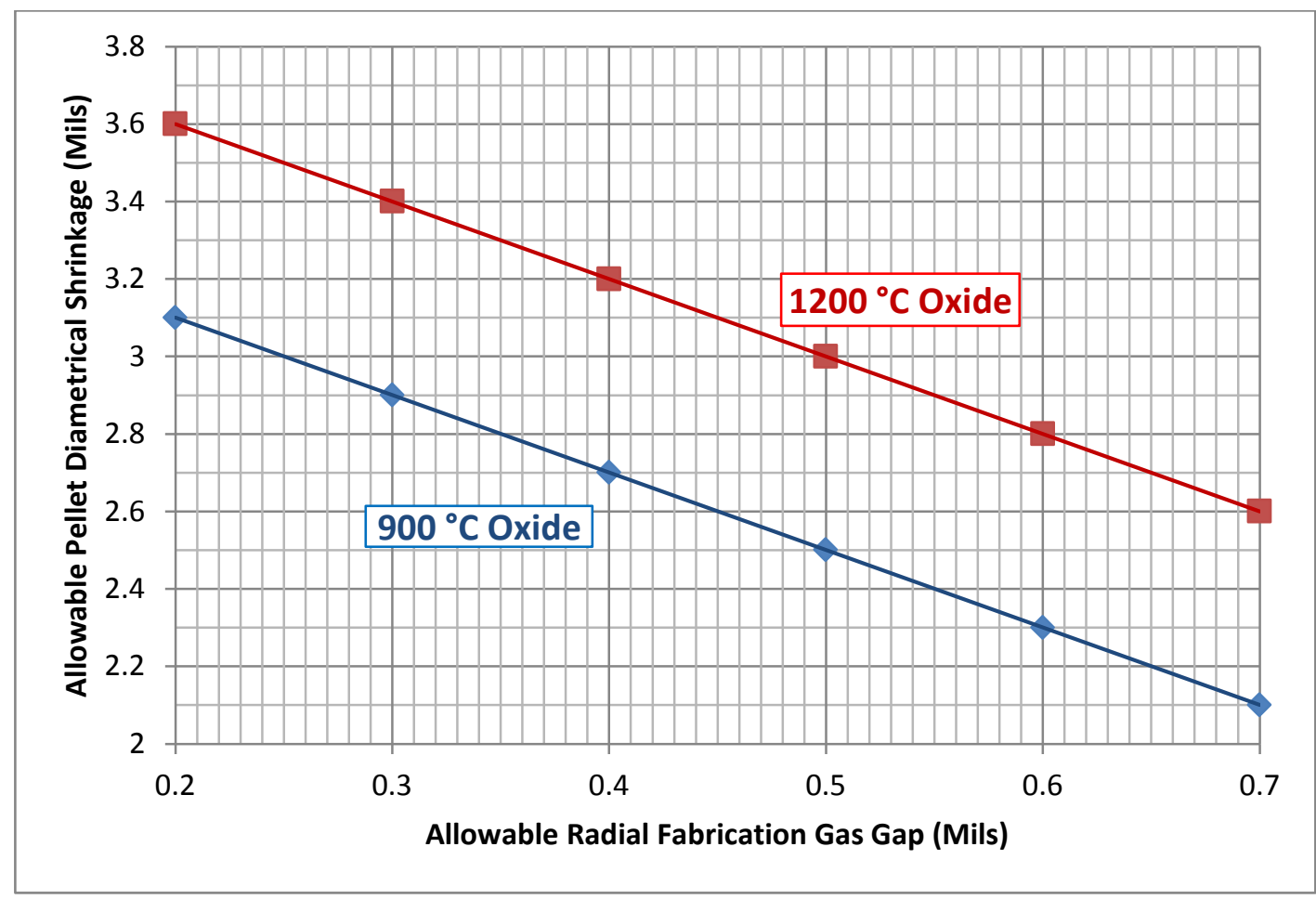

Fig. 5.10: Allowable pellet shrinkage vs. fabrication gas gap for safety-basis of a 2 Cycle Irradiation. 


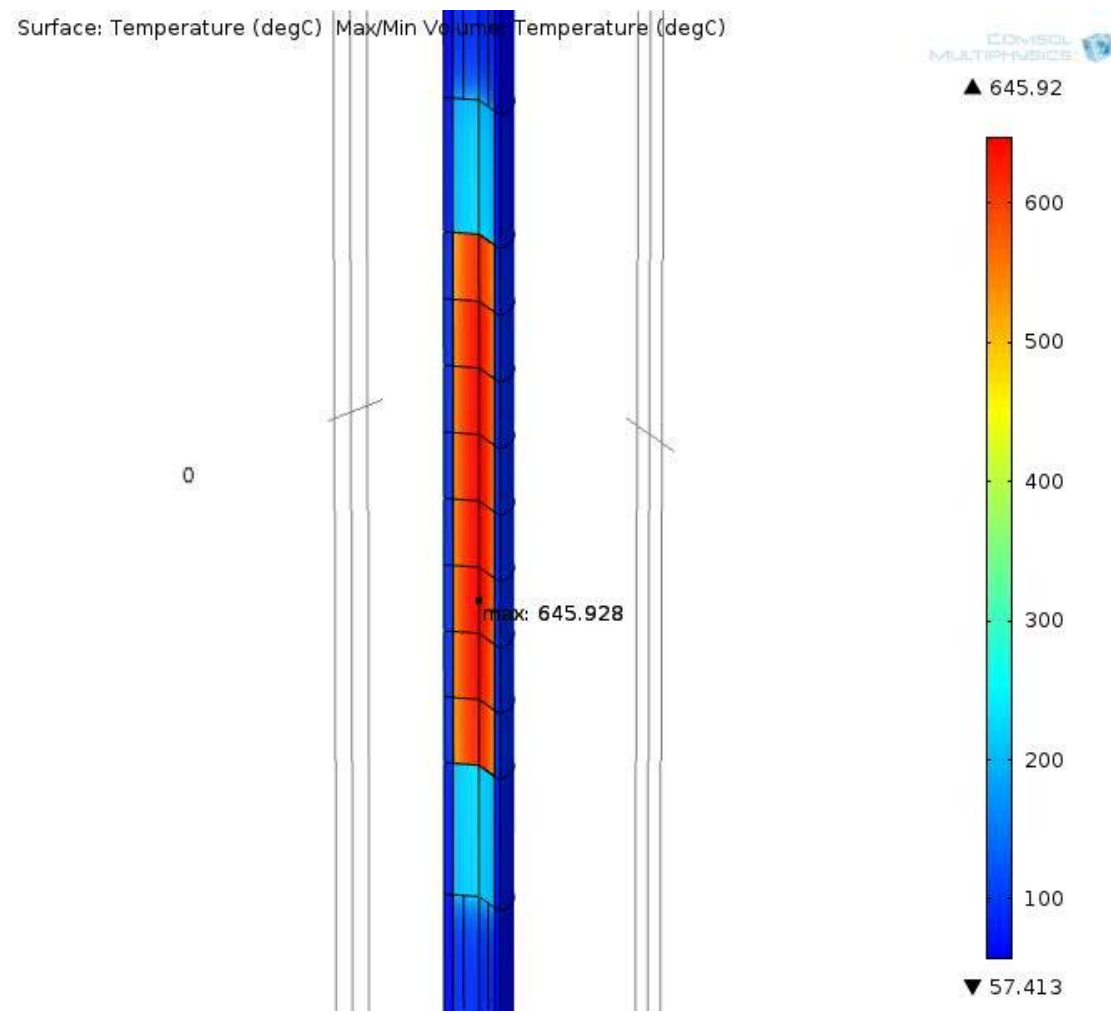

Fig. 5.11: 3-D rotated temperature contour of the 2-D axisymmetric modeled volume of the partially loaded target assembly for the $900^{\circ} \mathrm{C}$ Pellet EOC-1 DB conditions at 50\% flow and $100 \%$ power.

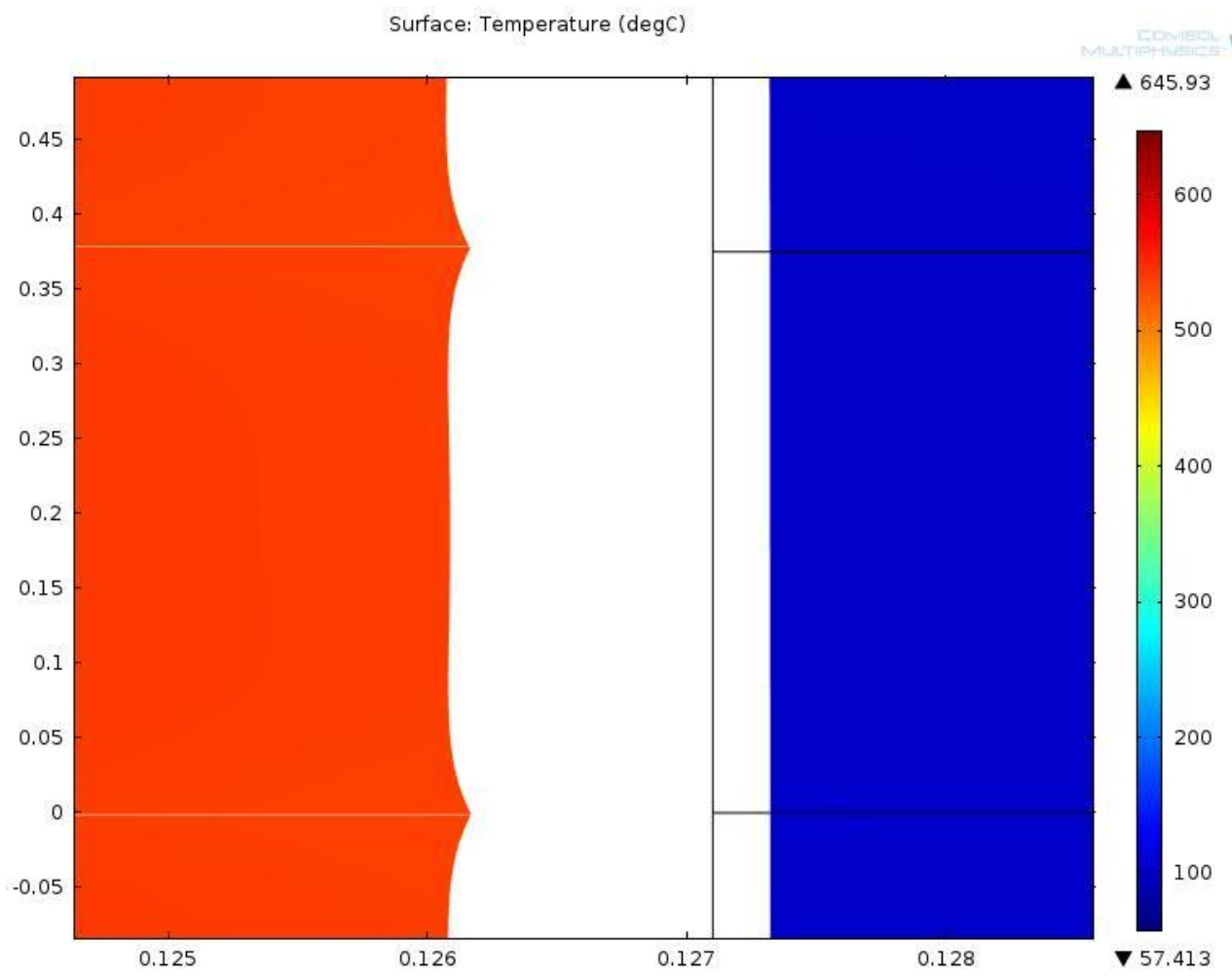

Fig. 5.12: Temperature contour with deformation of the 2-D axisymmetric modeled volume of the zoomed-in pellet stack/housing gas gap for the $900^{\circ} \mathrm{C}$ Pellet EOC-1 SB conditions at $130 \%$ power. 


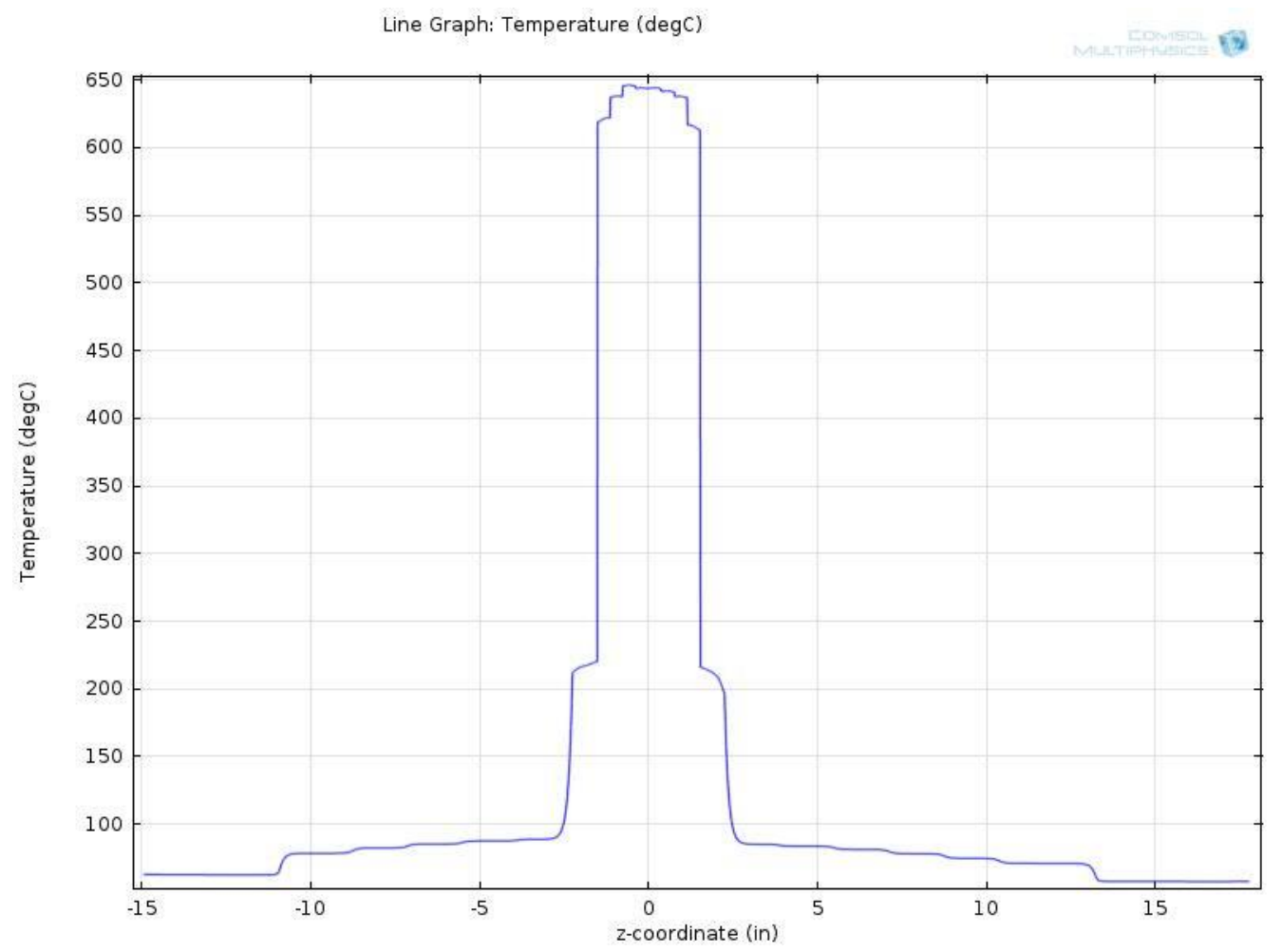

Fig. 5.13: Temperature vs. axial position along the axial centerline for the $900^{\circ} \mathrm{C}$ Pellet $\mathrm{EOC}-1 \mathrm{SB}$ conditions at $130 \%$ power.

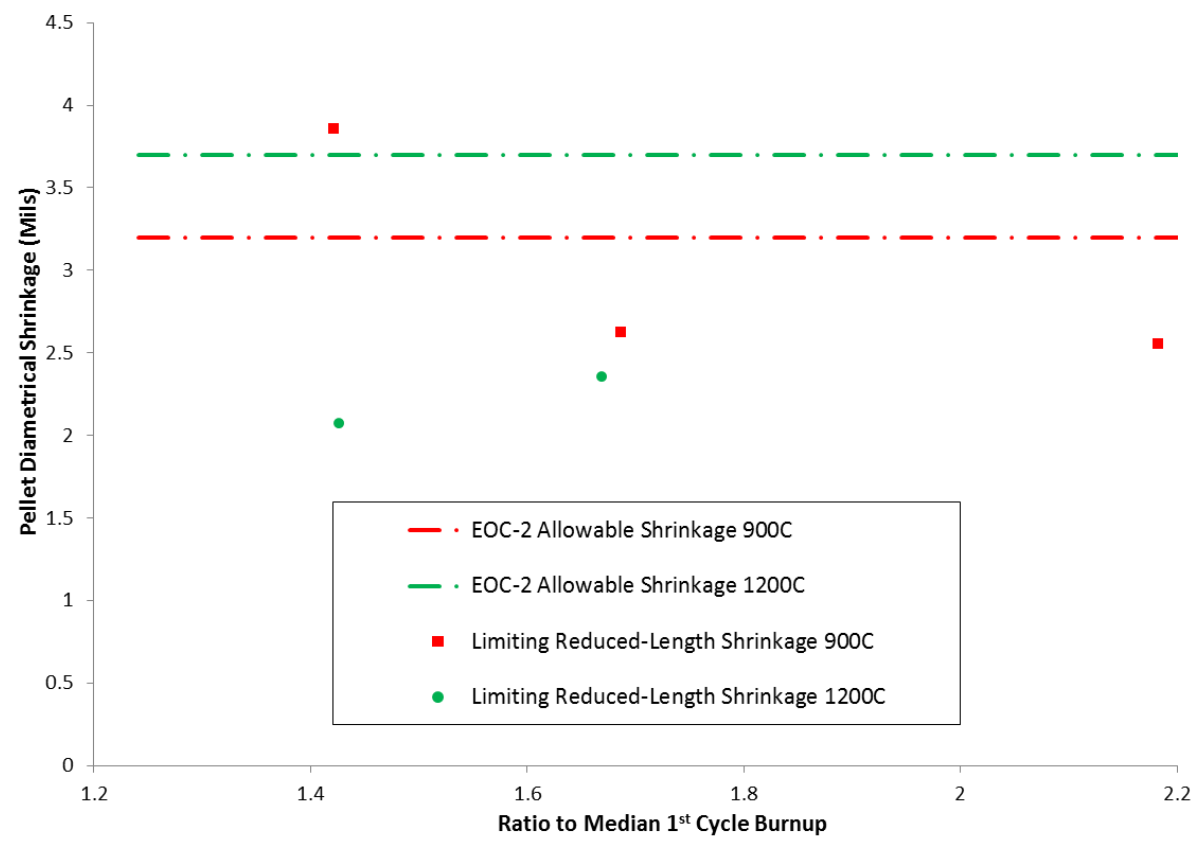

Fig. 5.14: The limiting pellet diametrical shrinkage for 0.1-0.3 mil fabrication gap against the measured PIE shrinkages for each pellet heat-treatment. 


\subsection{FULLY LOADED TARGET MODEL}

This target has a substantially increased loading from previous models, rising from 8 to $50-52 \mathrm{NpO}_{2} / \mathrm{Al}$ pellets, as a result several changes in the scope of the model were required in order to accommodate substantially augmented fission gas releases to the helium plenum, net irradiation-induced swelling/expansion of the pellet stack in the axial direction, and large axial variations in the pellet stack for heat generation rates, burnup, and the resulting effects of these changes. One simplification was that two pellet heat treatments no longer needed to be considered, as the $1200{ }^{\circ} \mathrm{C}$ pellets were the only qualified for irradiation for the fully loaded target. Several official revisions to the model occurred, for purposes of evolving target qualifications and inputs: R0) qualification of the targets for 1 cycle of irradiation, R1) qualification for 2 cycles, R2) repeat R1 to incorporate updated PIE fission gas release fractions, R3) incorporate updated PIE dimensional behavior for axial-dependent effects at a lower flux position VXF-3, and R4) update the R3 for position VXF-15.

\subsubsection{Revision 0 calculation}

At the time of the revision 0 analysis, the $1200^{\circ} \mathrm{C}$ heat-fired pellet had been decided as the only fabrication type used for the fully loaded target. Due primarily to a significant decrease in the helium plenum size and thus a much larger impact on the gas gap thermal conductivity, the allowable diametrical shrinkage decreased from the partially loaded target to fully loaded target. The model was simulated for two irradiation positions, the lower flux position VXF-3 and the highest flux position VXF-15, at EOC-1 in the same parametric solution search method previously described and the results of which are shown in Fig. 5.15.

The 3-D rotated temperature contour plots in Fig. 5.16, for a spatially undistorted and distorted view, show that the pellet just below the reactor horizontal midplane is the location of maximum temperature for cycle 1 and that the temperatures (as with the input heat generation rates) follows the HFIR core flux cosine curve with respect to axial position. Focusing on the aforementioned "hot pellet", its 3-D rotated stress profile with 10000x deformation, plotted in Fig. 5.17, shows even more clearly the characteristic hourglass shape expected. The axial centerline temperature profile in Fig. 5.18 again shows the cosine curve temperature distribution with only small peaking at the ends (compared to the partially loaded target) due to a greater number of targets and self-shielding.

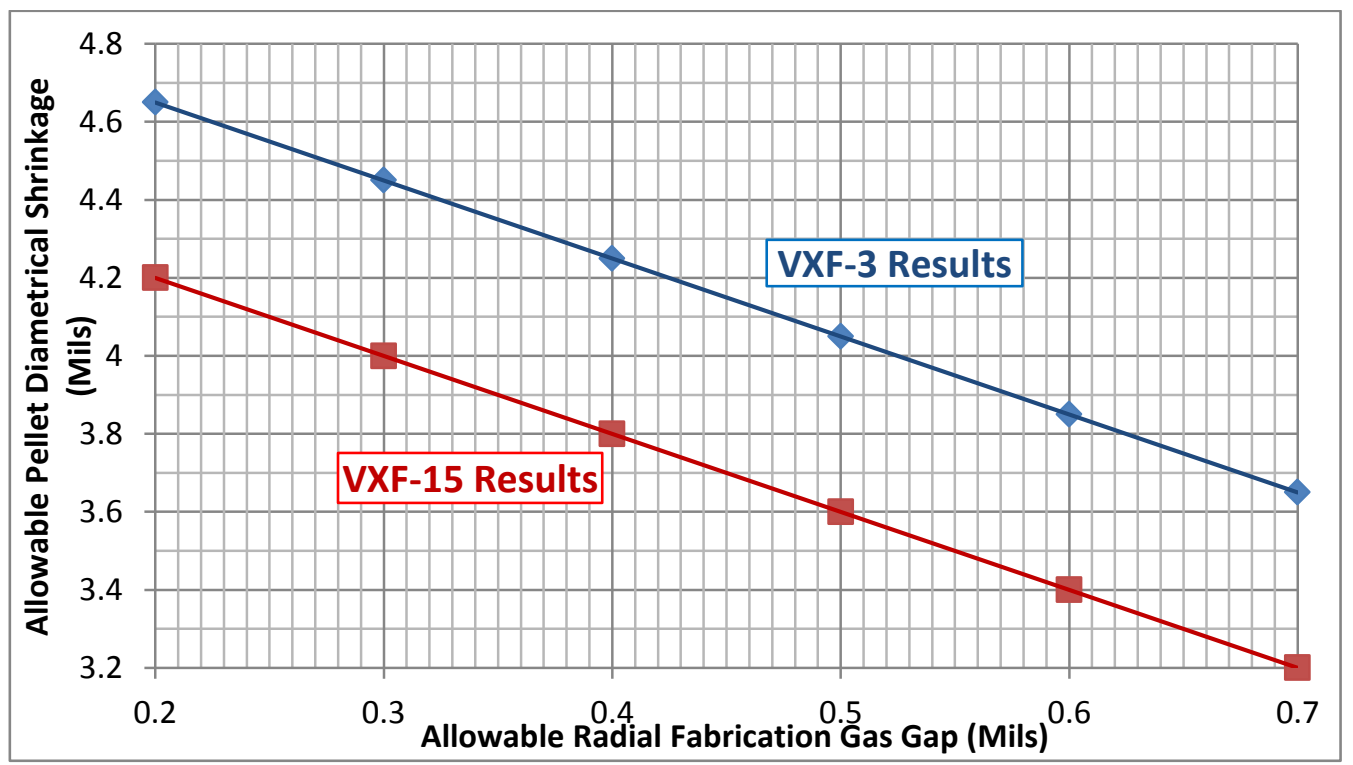

Fig. 5.15: Allowable pellet shrinkage vs. fabrication gas gap for safety-basis of a 1 cycle irradiation. 

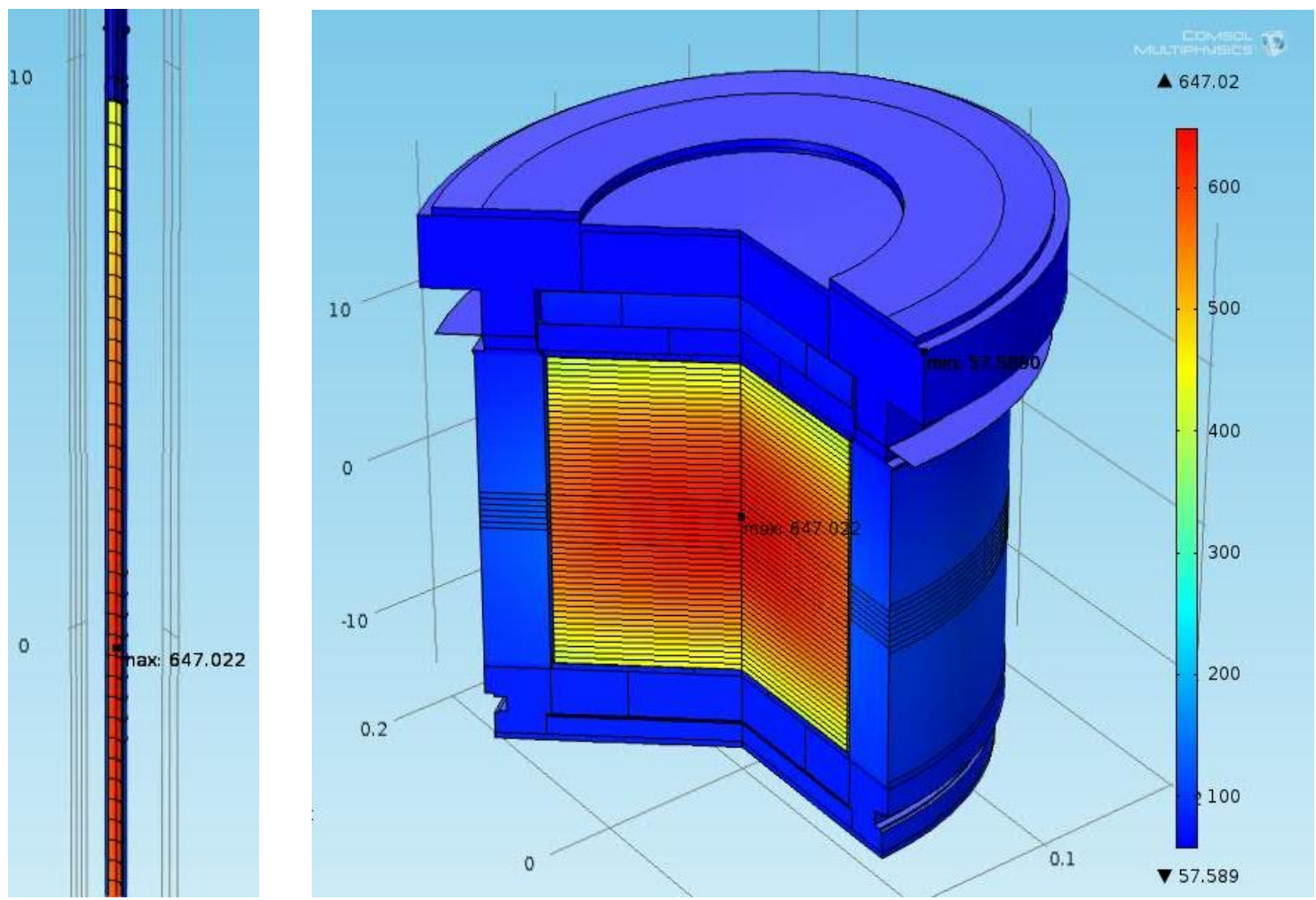

Fig. 5.16: 3-D rotated temperature contour for an undistorted and distorted view at VXF-15 EOC-1 SB conditions at $130 \%$ power.

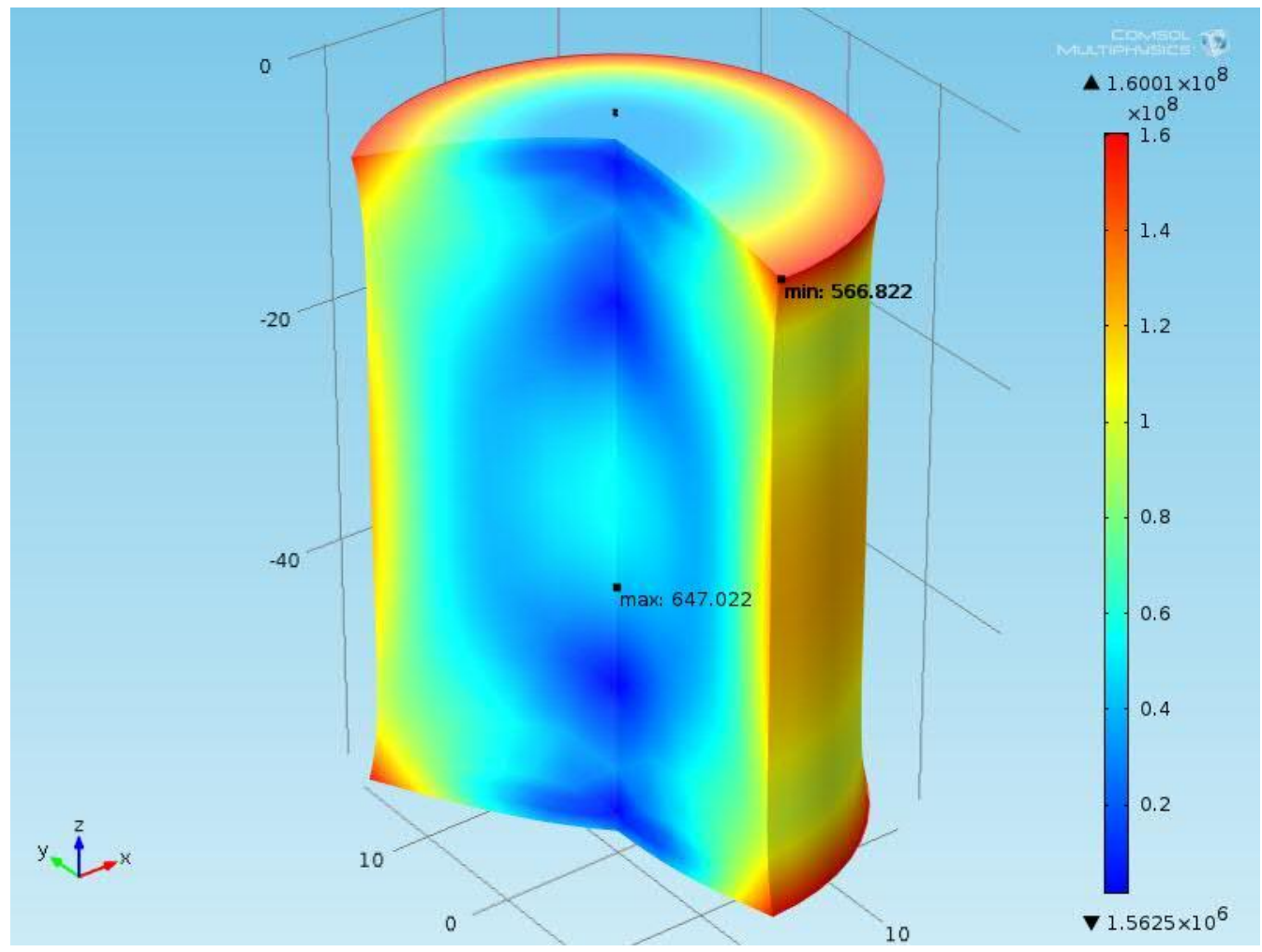

Fig. 5.17: 3-D rotated stress contour with 10000x deformation of the 2-D axisymmetric modeled volume of the hot pellet for the VXF-15 EOC-1 SB conditions at $130 \%$ power. 


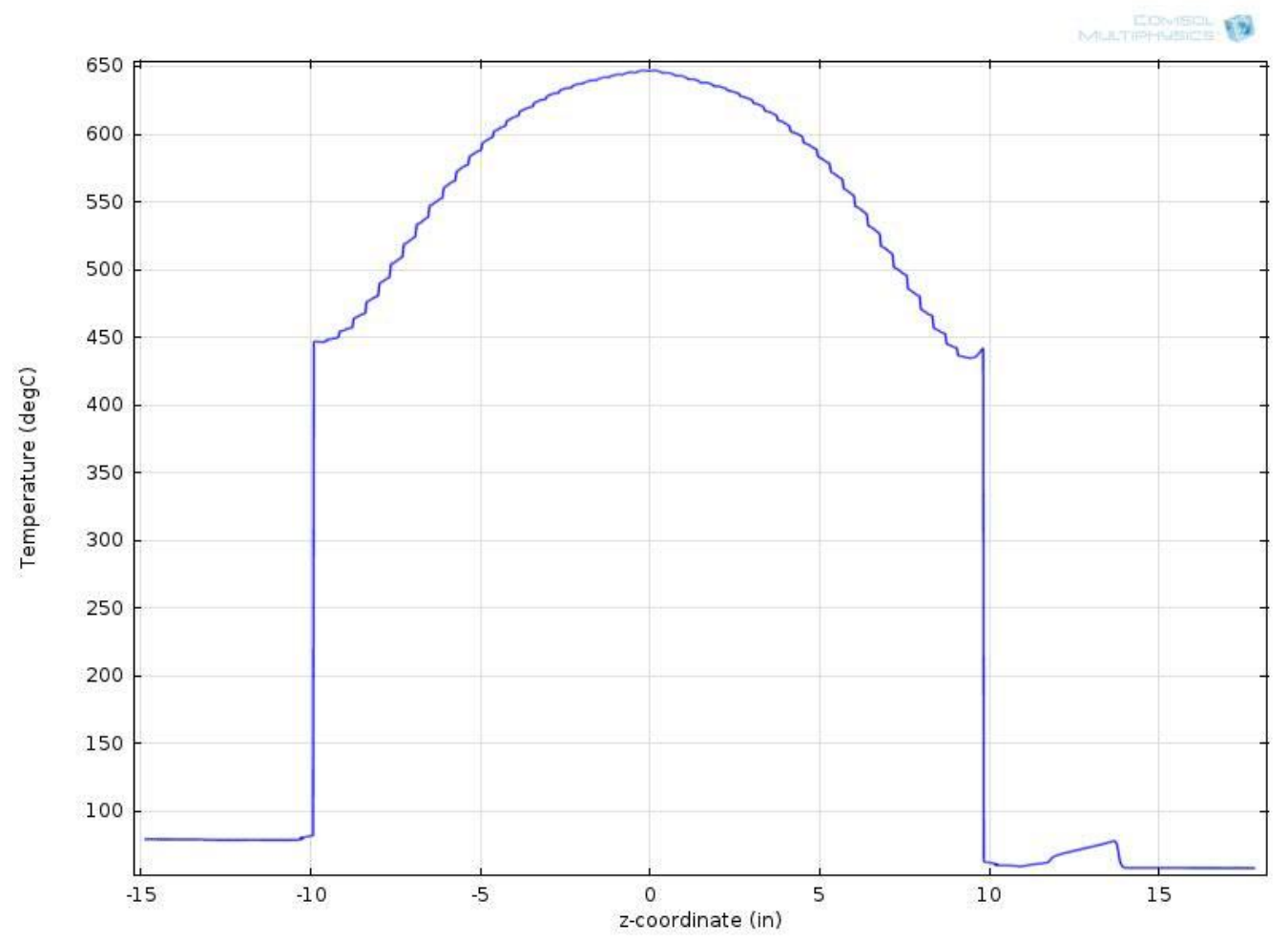

Fig. 5.18: Temperature vs. position along the axial centerline for the VXF-15 EOC-1 SB conditions at $130 \%$ power.

\subsubsection{Revision 1 and 2 calculations}

The revision 1 calculation was updated for the second irradiation cycle of the fully loaded target in positions VXF-3 and VXF-15. Unlike previous irradiations, there was a concern for the irradiation burnup-dependent dimensional changes within the cycle's irradiation time and their effect on the peak pellet temperatures. In addition, schedule limitations couldn't allow the calculation to await a wider burnup range of PIE data to define the calculation scope in terms of expected limiting densification values. For this reason, a parametric solution search method was needed in order to calculate the maximum allowable pellet diametrical shrinkage (assuming a $\sim 0.1-0.3$ mil fabrication gap) as a function of the heat generation rates in the pellets. This was accomplished via the Java API for COMSOL programming, where an initial guess shrinkage gap value was given at $100 \mathrm{~W} / \mathrm{g}$. From there, a default step was taken in the direction of $650{ }^{\circ} \mathrm{C}$ for the input shrinkage, and thereafter linear interpolation was used until the maximum temperature was within some tolerance of the melting temperature $(649+/-$ $\left.0.5^{\circ} \mathrm{C}\right)$. After that, the current shrinkage input was then used for the next pellet heating rate until $400 \mathrm{~W} / \mathrm{g}$ (the maximum calculated heating rate in the $2^{\text {nd }}$ cycle) was reached. Revision 2 analyses consisted of a simple update to this analysis via increased fission gas release fractions. The resulting maximum allowable pellet diametrical shrinkage values are shown in Fig. 5.19 below, for both positions VXF-3 and VXF-15. An example of this plot, along with PIE results from the partially loaded targets is shown in Fig. 5.20, which verifies that the fully loaded target is satisfactory with regard to pellet temperatures. 


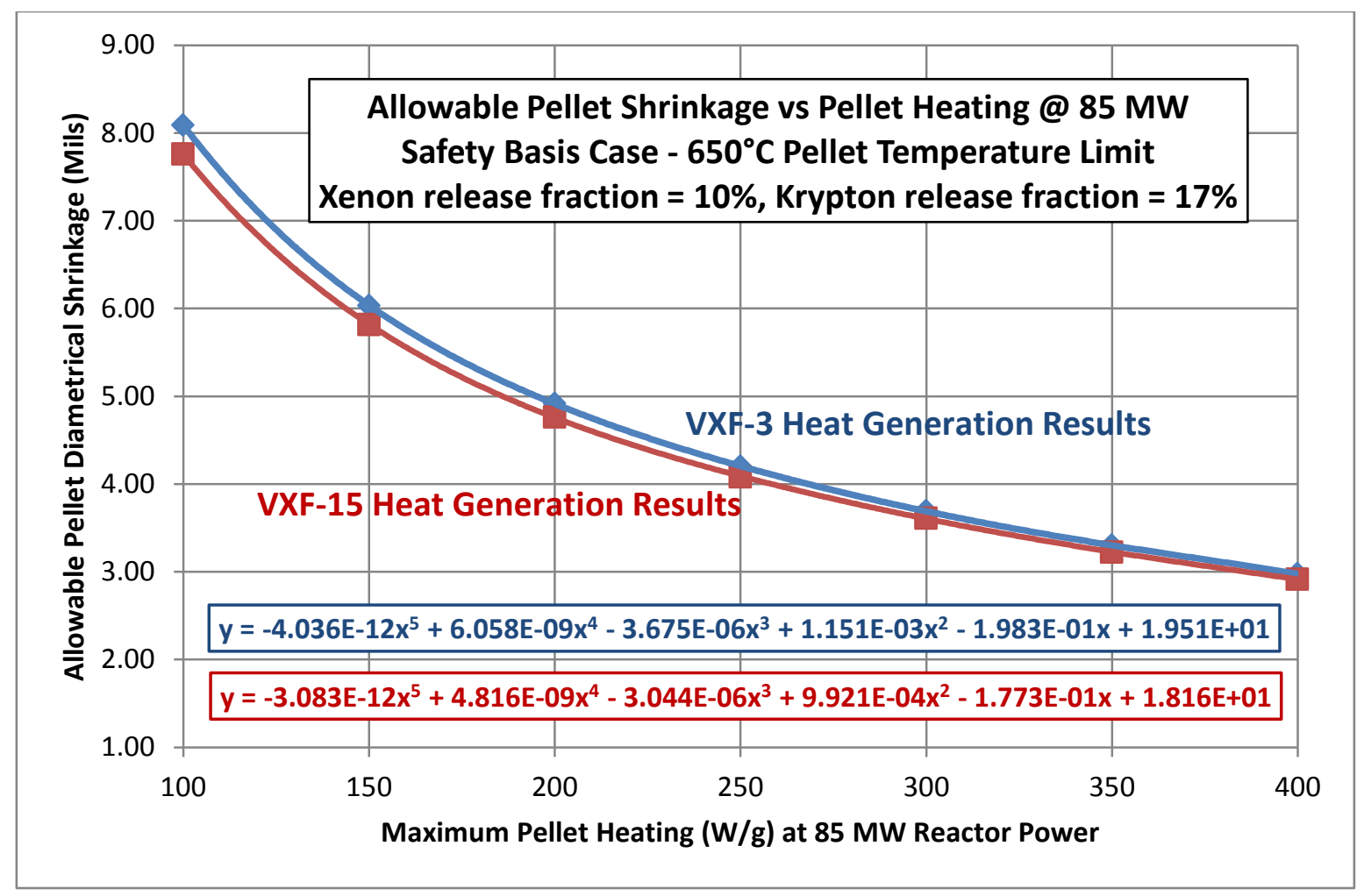

Fig. 5.19: Allowable pellet shrinkage vs. maximum pellet heating for safety-basis of a 2 cycle irradiation.

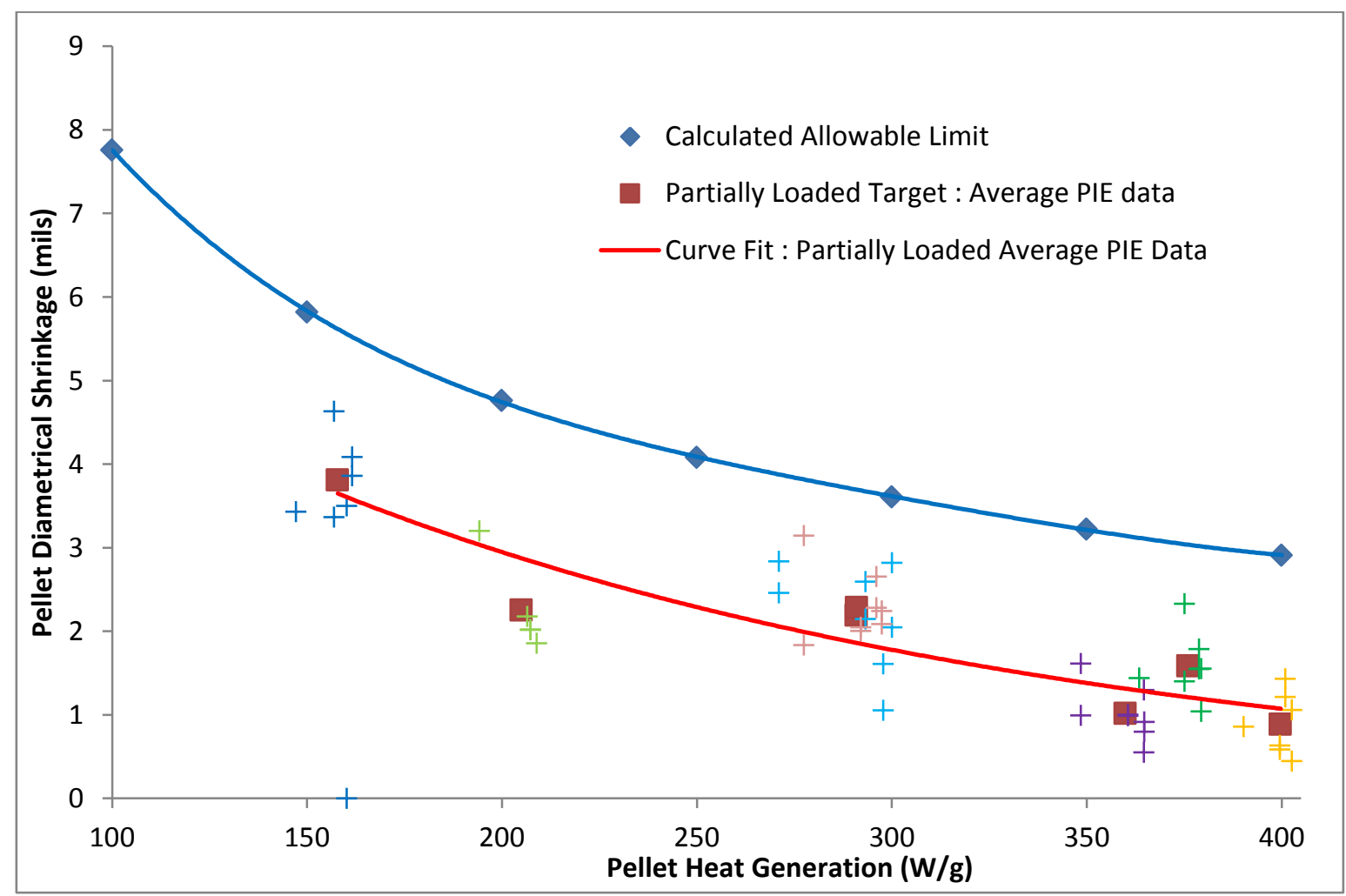

Fig. 5.20: Calculated allowable pellet shrinkage with respect to fully loaded target temperatures along with partially loaded PIE data as a function of pellet heat generation. 


\subsubsection{Revision 3 calculation}

At the time of the revision 3 analysis, recent PIE data from the partially loaded target prototype had indicated a potential safety concern for the axial stresses and clearance in the fully loaded target design under second cycle irradiation swelling and thermal expansion conditions. The purpose of this analysis was then to perform best estimate computations of the axially-segmented temperatures and axial thermal expansion in the pellet stack region based on current PIE data. In addition, a special "cold case" is analyzed at the end of the second cycle (EOC-2), where the pellet stack is in contact with (while not applying pressure to) the inside surface of the target housing. These thermal data outputs were then input into a separate hand calculation that calculated a conservative estimate of the axial clearance and stresses.

The PIE dimensional data in Fig. 5.21 was available at the time of this revision, using averaged partially loaded target measurements of the diametrical shrinkage of the pellets to yield both a "best-estimate" and bounding curve fit for use as inputs.

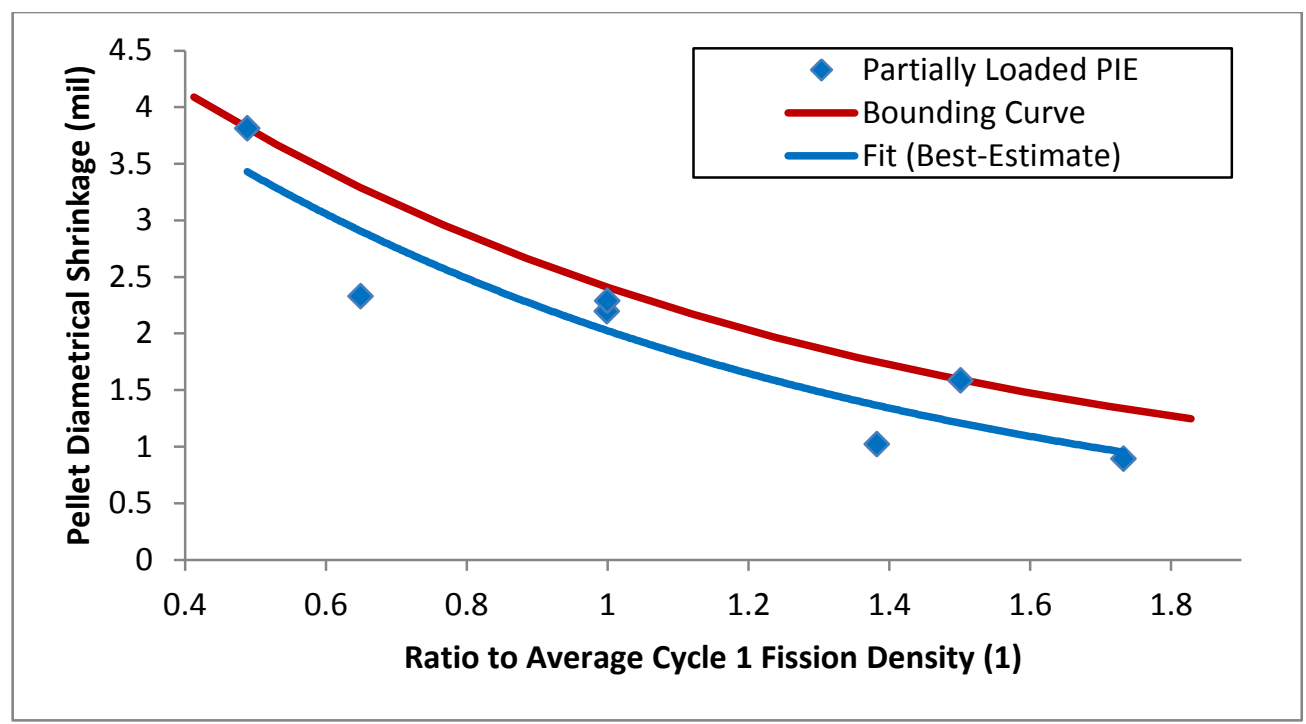

Fig. 5.21: PIE data and fitted curves for pellet shrinkage vs. fission density.

The cold case model concerns the case where the $\mathrm{NpO}_{2}$ pellets, in response to axial compression from the surrounding target components, deform to fill the radial gap between the pellet stack and adjacent target housing. Pressure applied by the pellets to the target housing is not credited in this model. The physical radial gap will thus be the RMS sum of the pellet and housing surface roughness values. For the cold case model, no structural mechanics equations are solved, instead only the temperature field is solved with a modified geometry to put the pellets in contact with the target housing inside surface.

Since previous assessments (revisions 0 through 2) provide a bounding estimate of the maximum pellet temperature with respect to this target design, the SB results from this case do not provide any new insights to the behavior of the target. However, renewed interest in the time- or burnup-dependence of the target temperatures and other behavior gave rise to confirm that end-of-cycle conditions were thermally limiting. Constant pellet temperatures over discrete material regions, as were reported in tables in the analyses for input to a separate calculation, are plotted in Fig. 5.22 below for discrete time steps in the $2^{\text {nd }}$ cycle, confirming that EOC- 2 is still the bounding estimate with regard to maximum and average pellet temperatures. However, taking into account the burnup-dependence of pellet dimensional behavior yields a more complex axial temperature profile than previously observed in fully loaded target models. As pellets diameters recover from maximum densification and swell outward, closing the radial gas gap, the maximum temperature location moves from the center of the pellet stack to the outer ends, where 
densification/shrinkage is still dominant. This creates a sinuous axial temperature curve at EOC-2 and an almost constant maximum temperature with respect to cycle time after day 5. Fig. 5.23 plots the raw COMSOL pellet temperature values, averaged temperatures by material region and a moving average of the temperatures as a function of axial position.

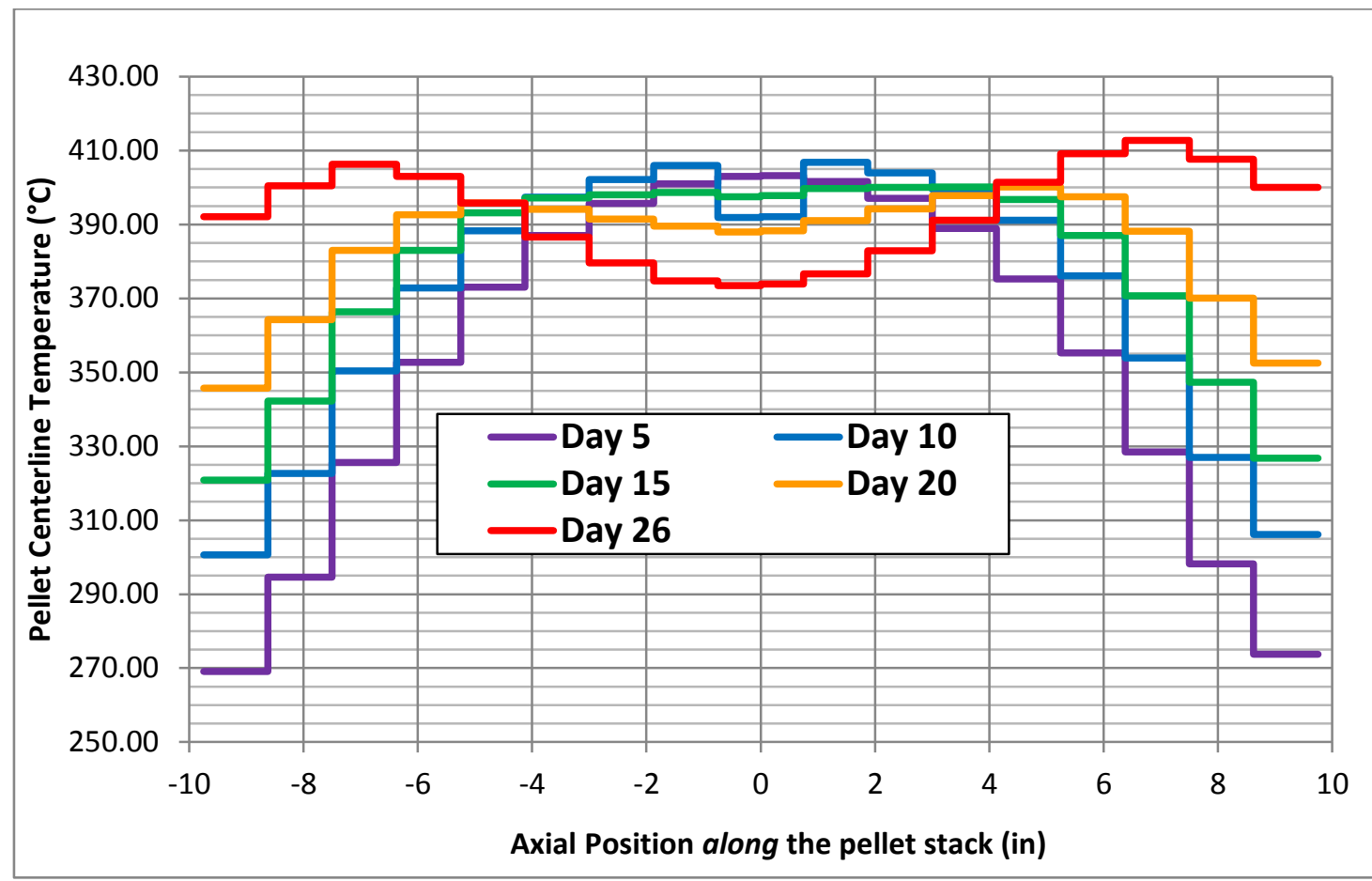

Fig. 5.22: Temperature profile along the pellet centerline at $100 \%$ power for $5,10,15,20$, and 26 days into the $2^{\text {nd }}$ cycle for VXF-3 position.

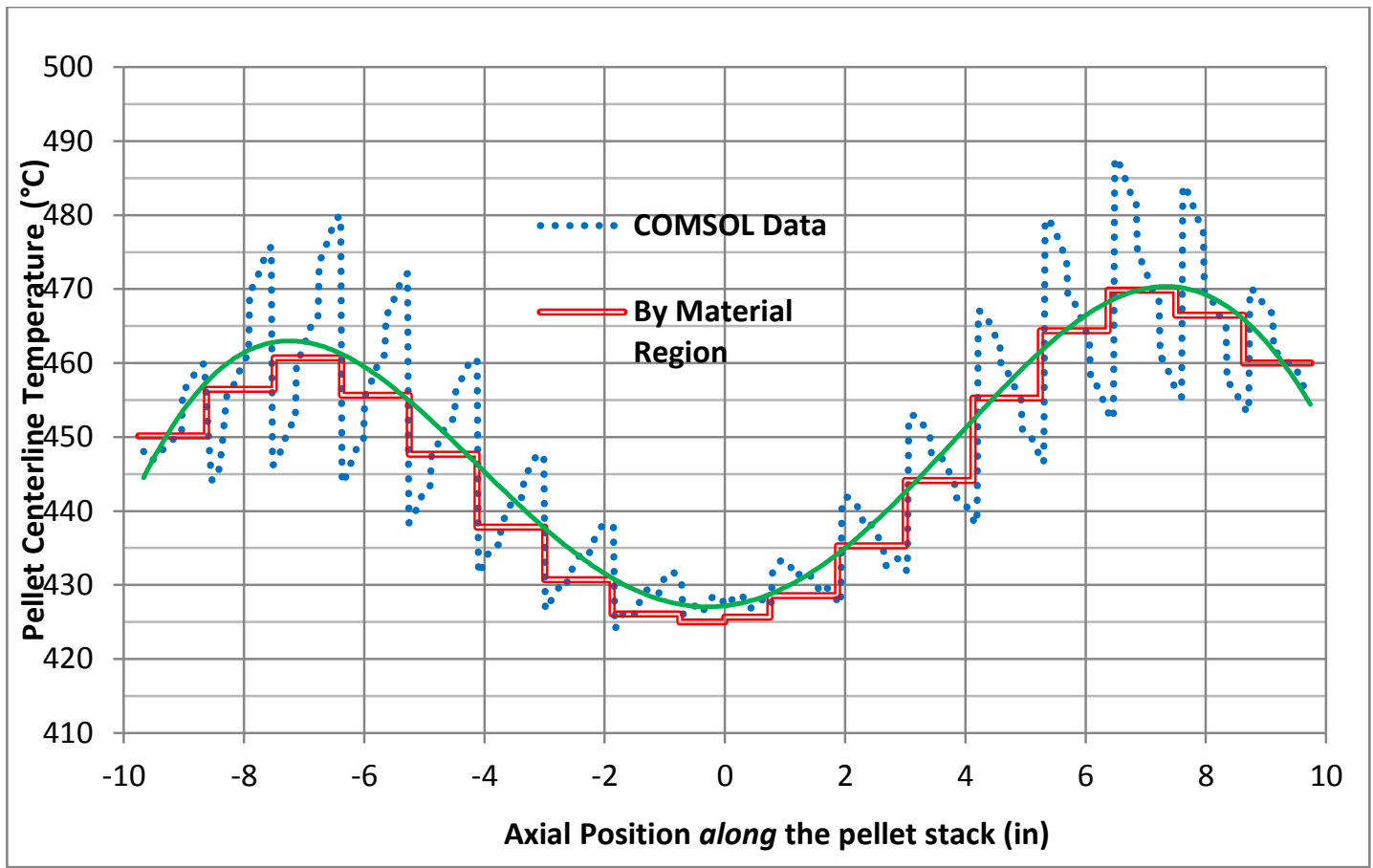

Fig. 5.23: Day 26 of $2^{\text {nd }}$ cycle at VXF-3 temperature profile along the pellet axial centerline at $130 \%$ power. 


\subsubsection{Revision 4 calculation}

The purpose of the revision 4 analyses was to extend the second cycle analyses in the VXF- 3 position, documented in Revision 3, to second cycle irradiation times in the VXF-15 position and the end of the first cycle in both positions. As in Revision 3, the purpose of Revision 4 was not to ensure that internal temperatures in the target do not exceed their melting temperature under safety-basis conditions, which was conservatively addressed in Revisions 0,1 , and 2 . The purpose of Revisions 3 and 4 is to provide data to address a potential structural failure in target cladding, a safety analysis which was completed in a subsequent calculation.

The concluding remarks on the burnup or time-dependent temperature behavior during the $2^{\text {nd }}$ irradiation cycle were expanded for these analyses. Plots of the running average of the pellet temperature along the axial centerline for five discrete times in the $2^{\text {nd }}$ cycle are shown in Fig. 5.24, and plotted along with the EOC-1 axial centerline pellet temperatures for VXF-3 and VXF-15 in Fig. 5.25. The same relationship is shown, with the maximum temperature moving to the outer ends of the pellet stack towards the EOC-2, in addition the EOC-1 maximum temperature is shown to be higher than those seen in the $2^{\text {nd }}$ cycle, including EOC-2. As expected, temperatures are higher in the VXF-15 position. Fig. 5.26 and Fig. 5.27 show the spatial temperature profile in the pellet stack for a distorted spatial scale for days $0,5,10,15,20$ and 26 into the $2^{\text {nd }}$ cycle, giving a much clearer image of pellet stack temperatures throughout the $2^{\text {nd }}$ cycle.

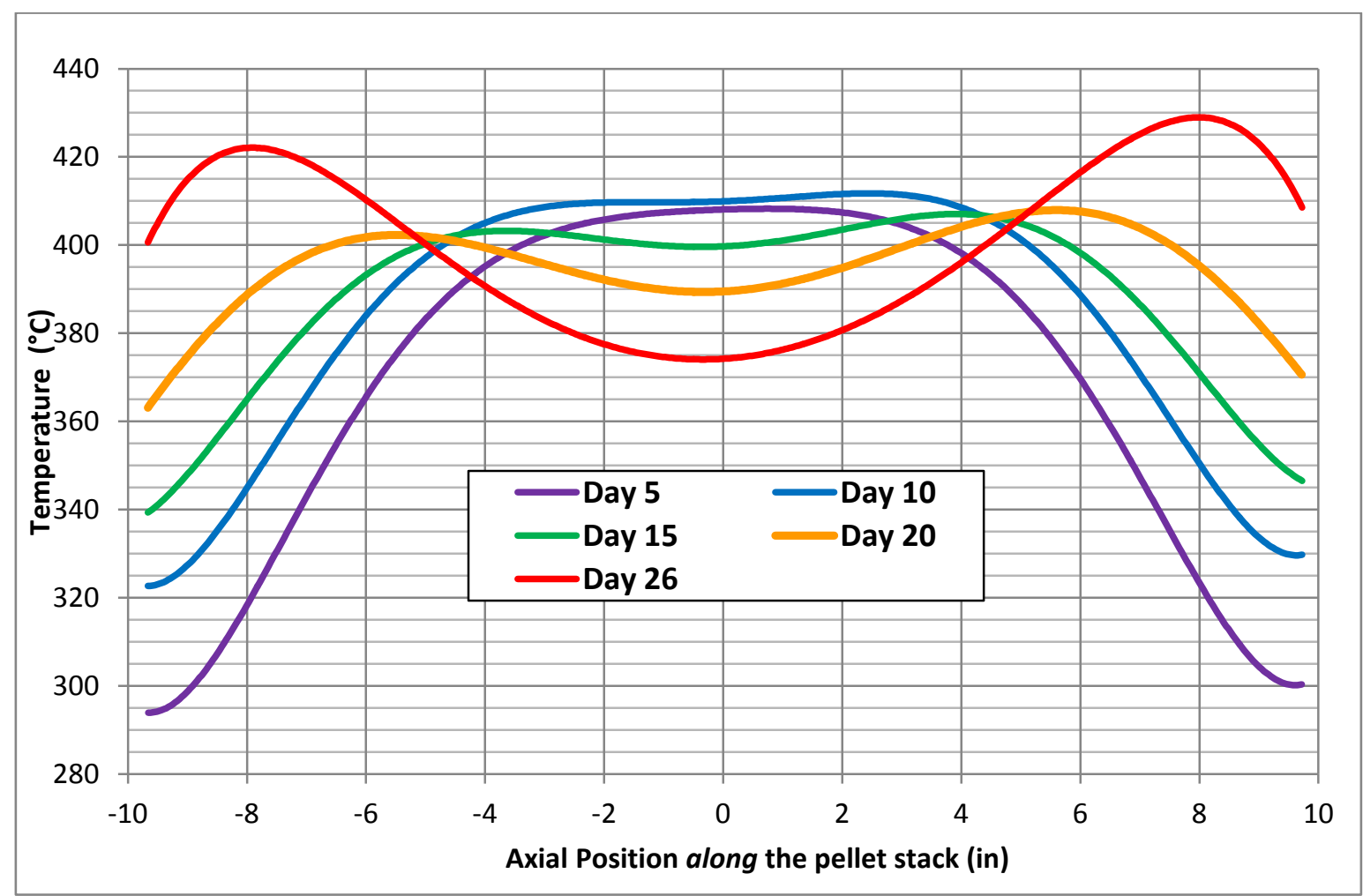

Fig. 5.24: COMSOL data-fitted temperature profiles along the pellet centerline at $100 \%$ power for $5,10,15$, 20 , and 26 days into the second cycle at position VXF-15. 


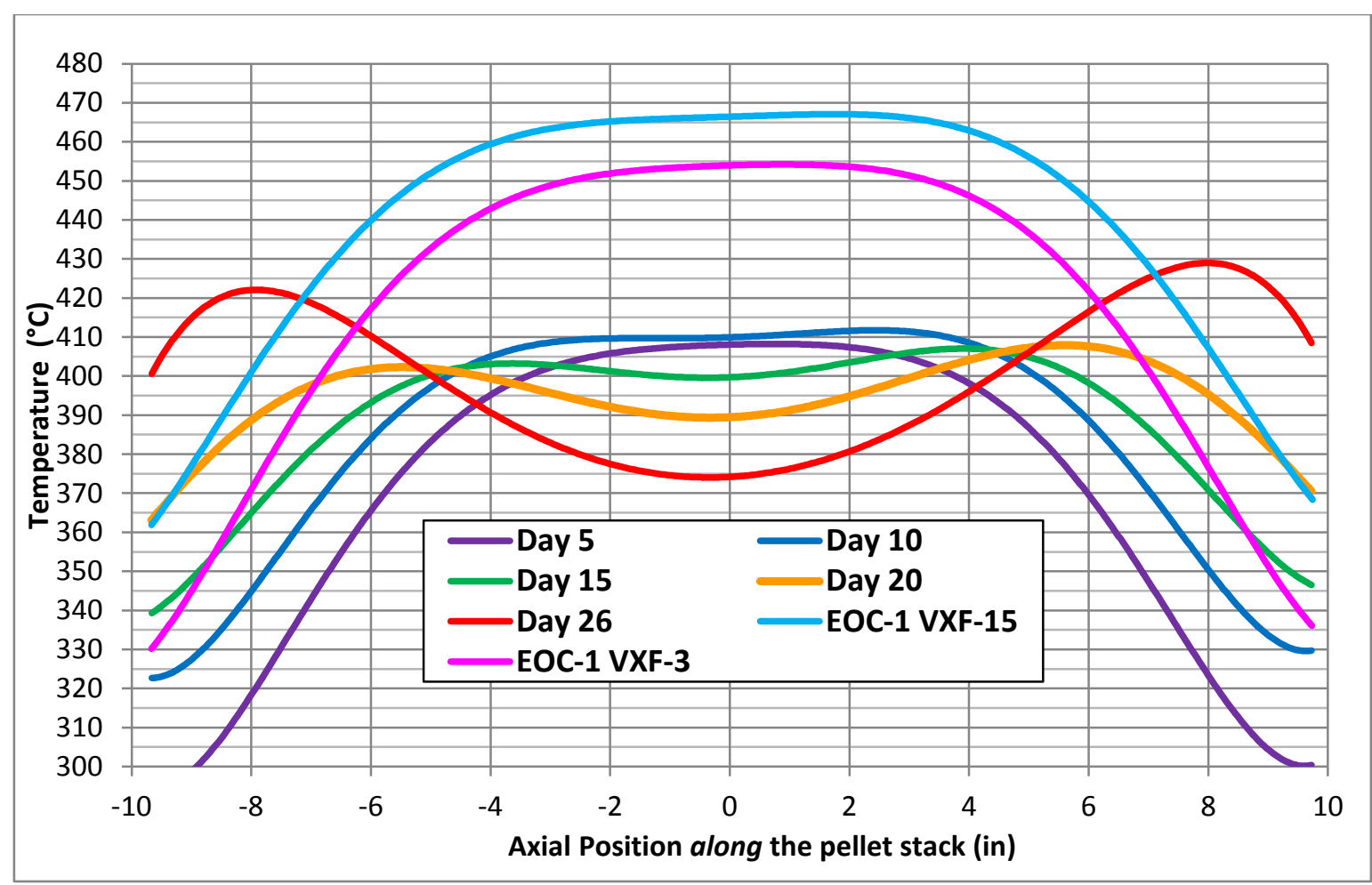

Fig. 5.25: COMSOL data-fitted pellet centerline temperature profiles at $100 \%$ power for second cycle times at VXF15 as well as EOC-1 for positions VXF-3 and VXF-15.

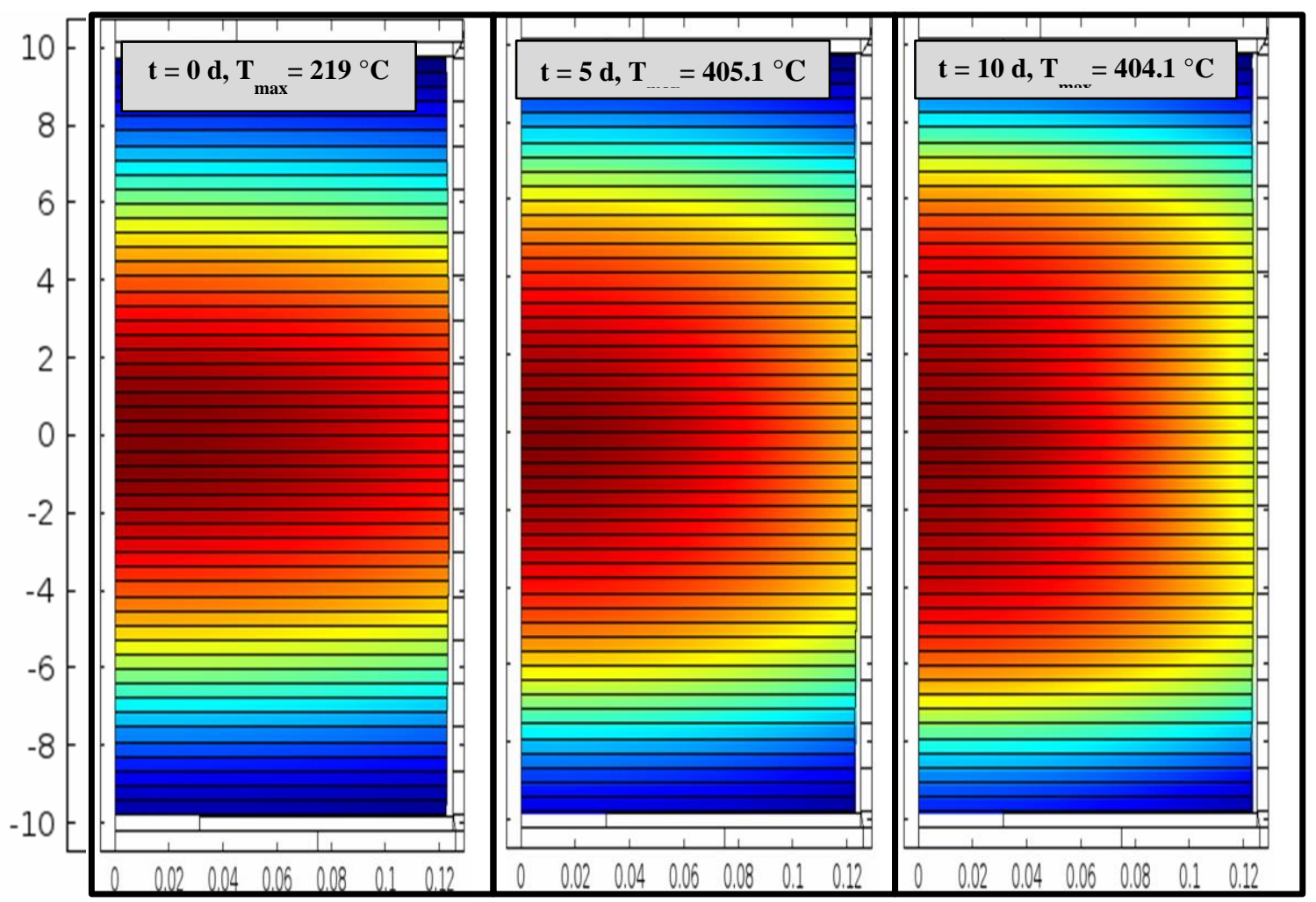

Fig. 5.26: Pellet stack temperature profiles for day 0,5 , and 10 into the $2^{\text {nd }}$ cycle, not to same scale. 


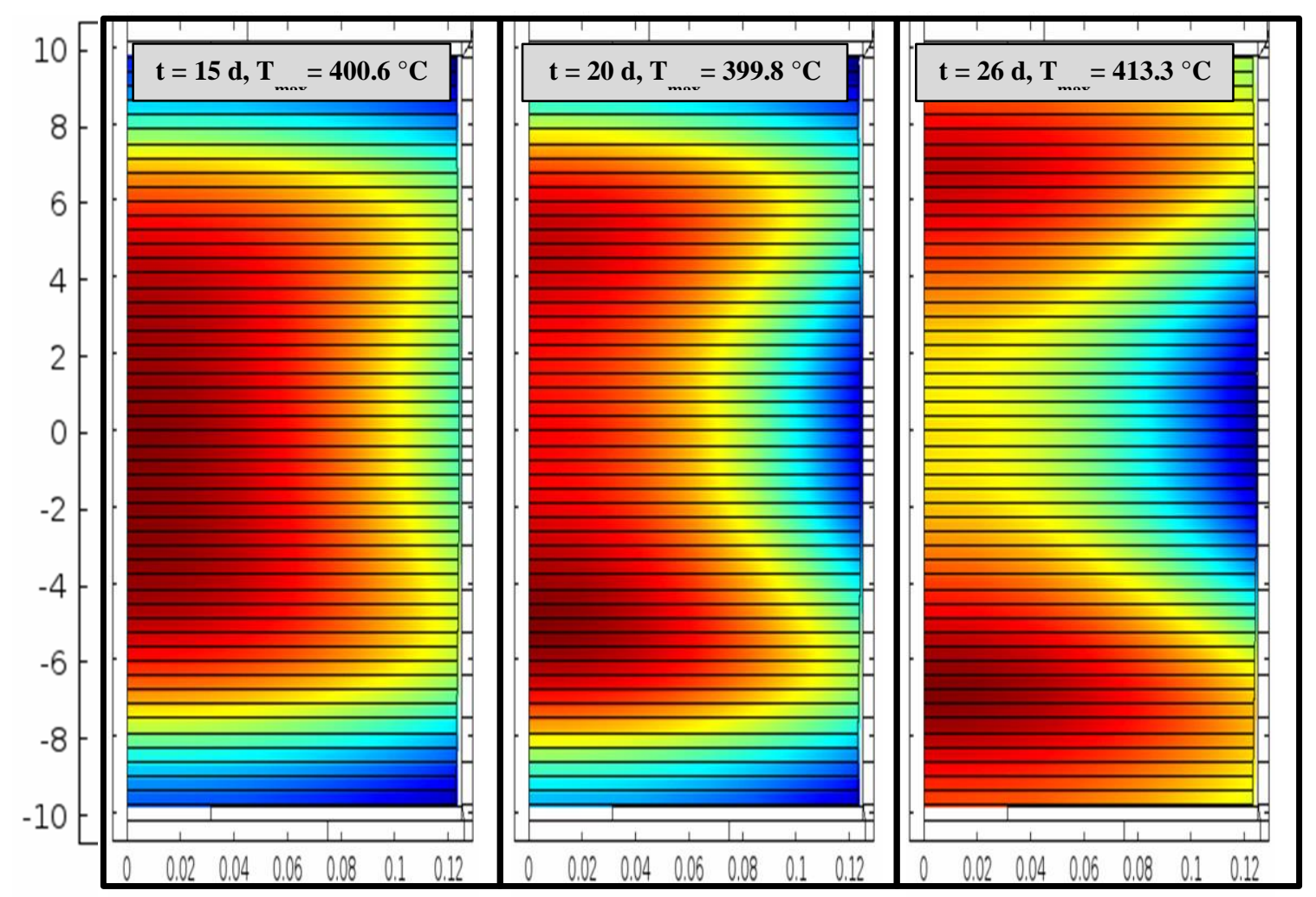

Fig. 5.27: Pellet stack temperature profiles for day 15,20 and 26 into the $2^{\text {nd }}$ cycle, not to same scale.

A mesh refinement study was performed for the revision 4 analysis that is now briefly discussed. The study was performed at $130 \%$ power, EOC- 2 for both the best estimate and cold case models to demonstrate the increased convergence for the latter model method (where structural mechanics equations are not included and the nonlinear coupling at the pellet/housing gap does not negatively impact convergence).

The number of mesh elements in the pellet/housing region was roughly doubled at each convergence step and an error estimate was made from two post-processing results: 1) pellet centerline average temperature, and 2) the maximum pellet centerline temperature. The individual error estimates were defined as:

$$
e^{T}=\frac{\Delta T}{3}
$$

And the square root of the product of the errors was used as a final error "norm". The error norm is plotted against the reciprocal of the mesh number in the log-log plot in Fig. 5.28. The increased rate of convergence and reduced error in the cold case model can be clearly seen. More specifically, the finite element order of convergence approximately doubles and is a better comparison to the theoretical slope value of 4 for smooth convergence with a $2^{\text {nd }}$ order basis function (quadratic). 


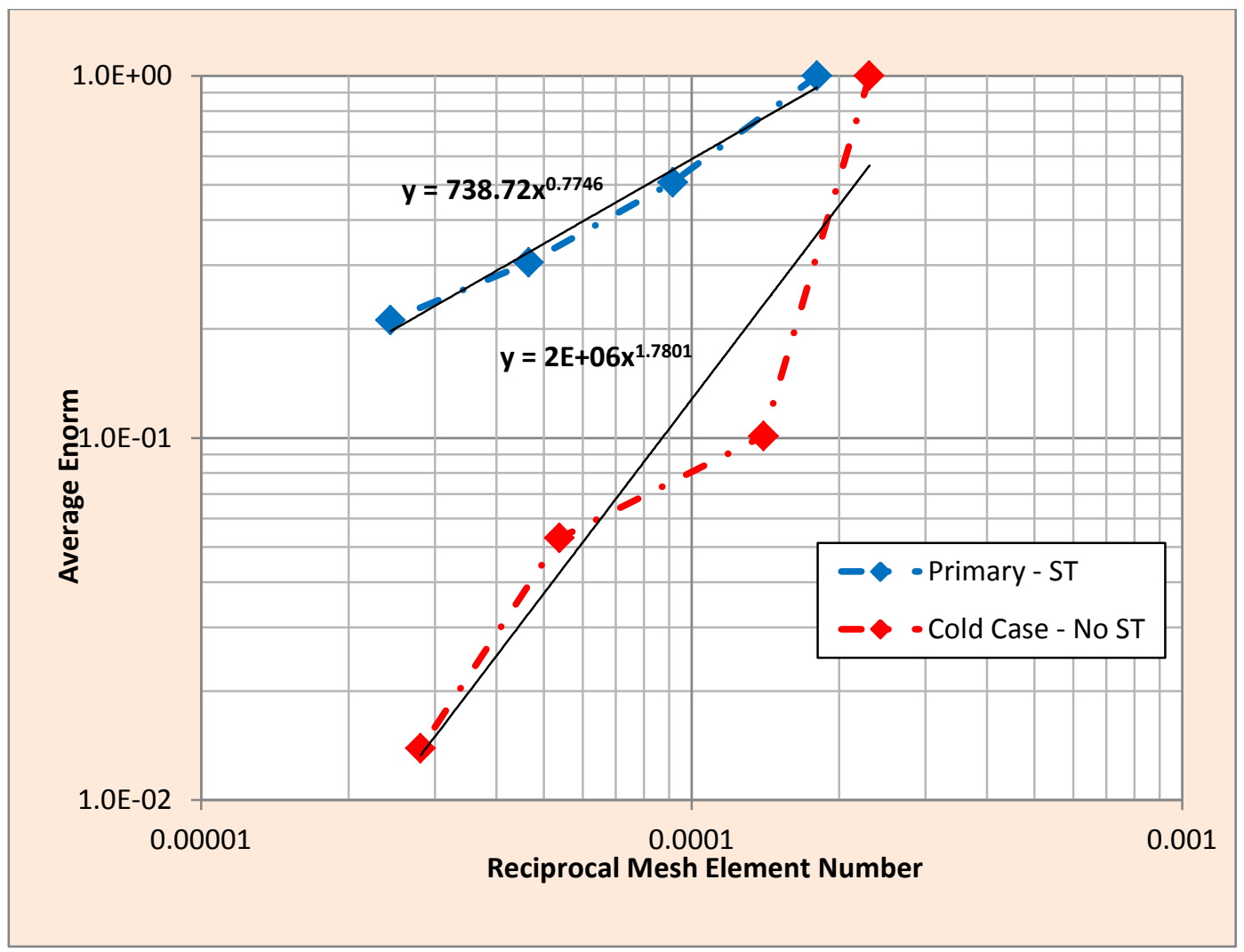

Fig. 5.28: Mesh refinement for best estimate (primary) and cold case (no structural mechanics) models for the fully loaded target. 


\section{PRODUCTION MODEL}

The production model in COMSOL extends the analysis to three irradiation cycles and makes use of the most up-to-date PIE data, material property inputs, and modeling methodology. The fully coupled thermo-mechanical equations are solved over the entire domain, significantly increasing the degrees of freedom required for a solution, in addition to several other improvements in the computational methodology of the model. In addition, a significantly expanded solution space is covered using this model, given the updated inputs, including each of the seven target holder pins in position VXF-15 and pin 1 in VXF-3, as well as 10 discrete time steps for each of all 3 cycles of irradiation. This detailed solution space allows the verification of "pin 1" at the irradiation end of cycles to be the limiting safety cases for the production target.

There are three primary cases solved for this model, each designed for its own purpose. The "bestestimate" case uses the inputs and methodology designed to solve for conditions in the range of the expected nominal behavior, with a subcase for $50 \%$ coolant flow conditions. The thermally limiting safety basis (TLB) is designed to maximize temperatures in the target, specifically the pellet stack, in order to conservatively satisfy the $130 \%$ overpower case with regard to melting temperatures. The structurally limiting safety basis (SLB) is designed to maximize stresses in the target, with subcases for optimizing radial stresses on the cladding from the pellets and to optimize axial stresses on the target from aggregate swelling of the pellet stack.

\subsection{INPUTS AND METHODOLOGY}

\subsubsection{Pellet properties}

PIE dimensional data in the form of pre- and post-irradiation measurements of the pellets' diameter and length for six fully loaded targets was available and documented for this model. These targets were irradiated for either 1 ( 2 targets) or 2 (4 targets) cycles, in either the hottest (4 targets) or coldest (2 targets) positions in the holder, and in either the ISVXF-15 (2 targets) or ISVXF-3 (4 targets) positions in the permanent beryllium reflector. This data was processed in MATLAB in order to assess a statistical trend.

A curve was fitted to the volumetric swelling data as a function of burnup or fission density, following previous guidance on $\mathrm{UO}_{2}$ oxide/cermet pellets for the functional form:

$$
\text { Vol.Swell. }(B U)=\frac{\Delta V}{V_{0}}=a * 1 e-20 * B U+c\left(e^{-b * 1 e-20 * B U}-1\right)
$$

where

$$
\begin{array}{lll}
\mathrm{a}, \mathrm{b}, \mathrm{c} & = & \text { fit parameters }, \\
\mathrm{BU} & = & \text { burnup or accumulated fission density }\left(\text { fissions } / \mathrm{cm}^{3}\right), \text { and } \\
\frac{\Delta V}{V_{0}} & =\quad \text { change in pellet volume }(\%) .
\end{array}
$$

From this fit, predictive confidence intervals of $95 \%$ were created based on non-simultaneous observation, and these were fitted with fifth degree polynomials to create upper and lower bounds to the dimensional behavior of the pellets under irradiation. The original curve fit was determined the "bestestimate" fit. Fig. 6.1 shows the spread of the data vs the upper and lower bounds as a function of fission density: 


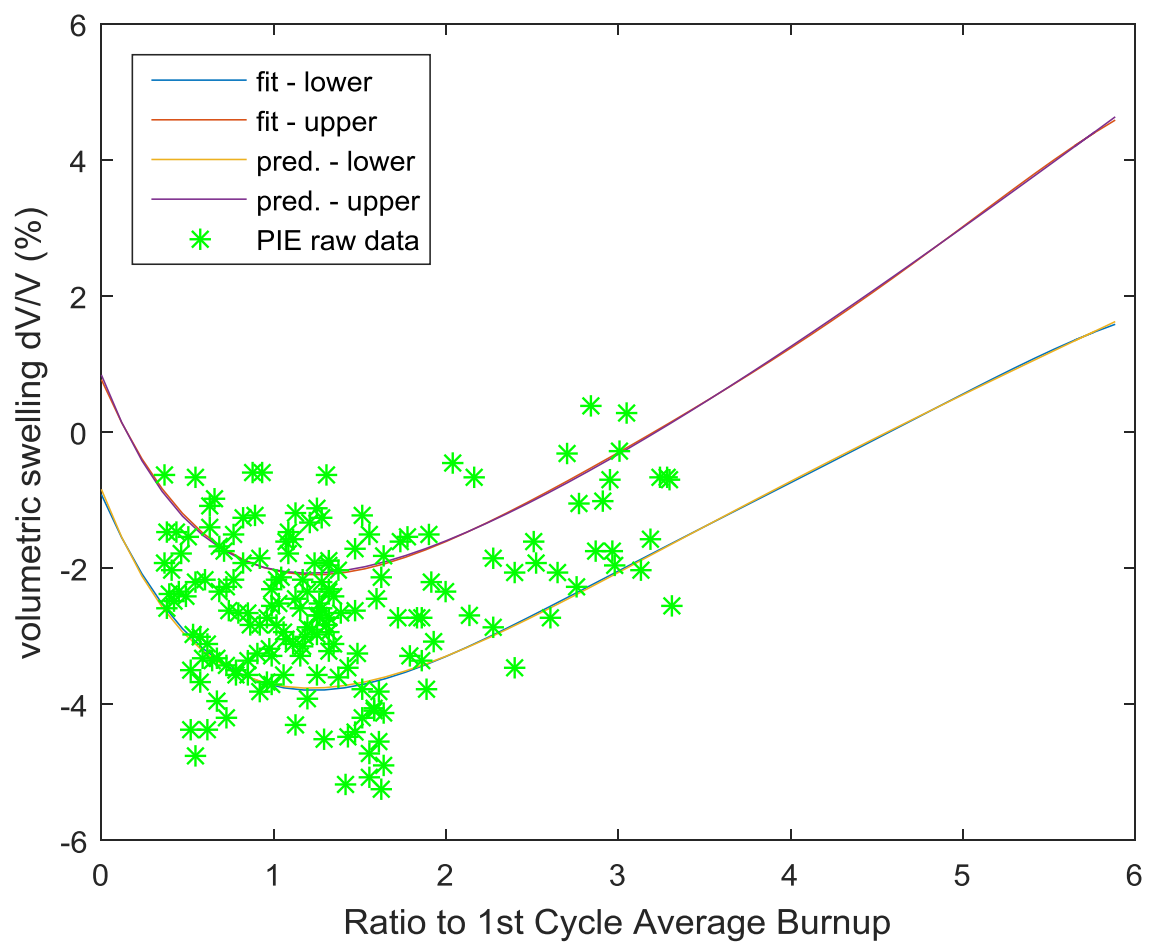

Fig. 6.1: Non-simultaneous observation confidence intervals and their curve fits along with the raw PIE data.

In order to input the volumetric swelling effect into COMSOL, it was determined that incorporating it under the thermal expansion coefficient was most effective. It is useful to recall the original definition of the linear thermal expansion coefficient as a factor of the volumetric expansion coefficient:

$$
\frac{V(T)}{V_{0}}=\left(1+\alpha_{V} \Delta T\right)=\left(1+\alpha_{L} \Delta T\right)^{3}=1+3 \alpha_{L} \Delta T+\cdots \gg \alpha_{L} \cong \frac{\alpha_{V}}{3}
$$

Now define the modified linear "thermal" expansion as a variable alpha_L that is no longer only expansion due to thermal effects but also fission density (FD)-dependent irradiation effects:

$$
\alpha_{\text {modified }}=\alpha_{L}(T)+\frac{1}{3} \frac{d V}{V}(F D(z)) \frac{1}{\left(T-T_{\text {ref }}\right)}
$$

Updated thermal expansion measurement results for $\mathrm{NpO}_{2} / \mathrm{Al}$ pellets heat-treated at $1200{ }^{\circ} \mathrm{C}$ were also available, which were fit to a $4^{\text {th }}$ degree polynomial to determine a temperature-dependent thermal expansion coefficient in the secant form. This polynomial was then input into COMSOL to recreate the measurement results and compare to the experiment, thus verifying the correct implementation, as shown in the Fig. 6.2 below where the raw data, averaged data and COMSOL probe results are plotted against each other as a function of temperature. 


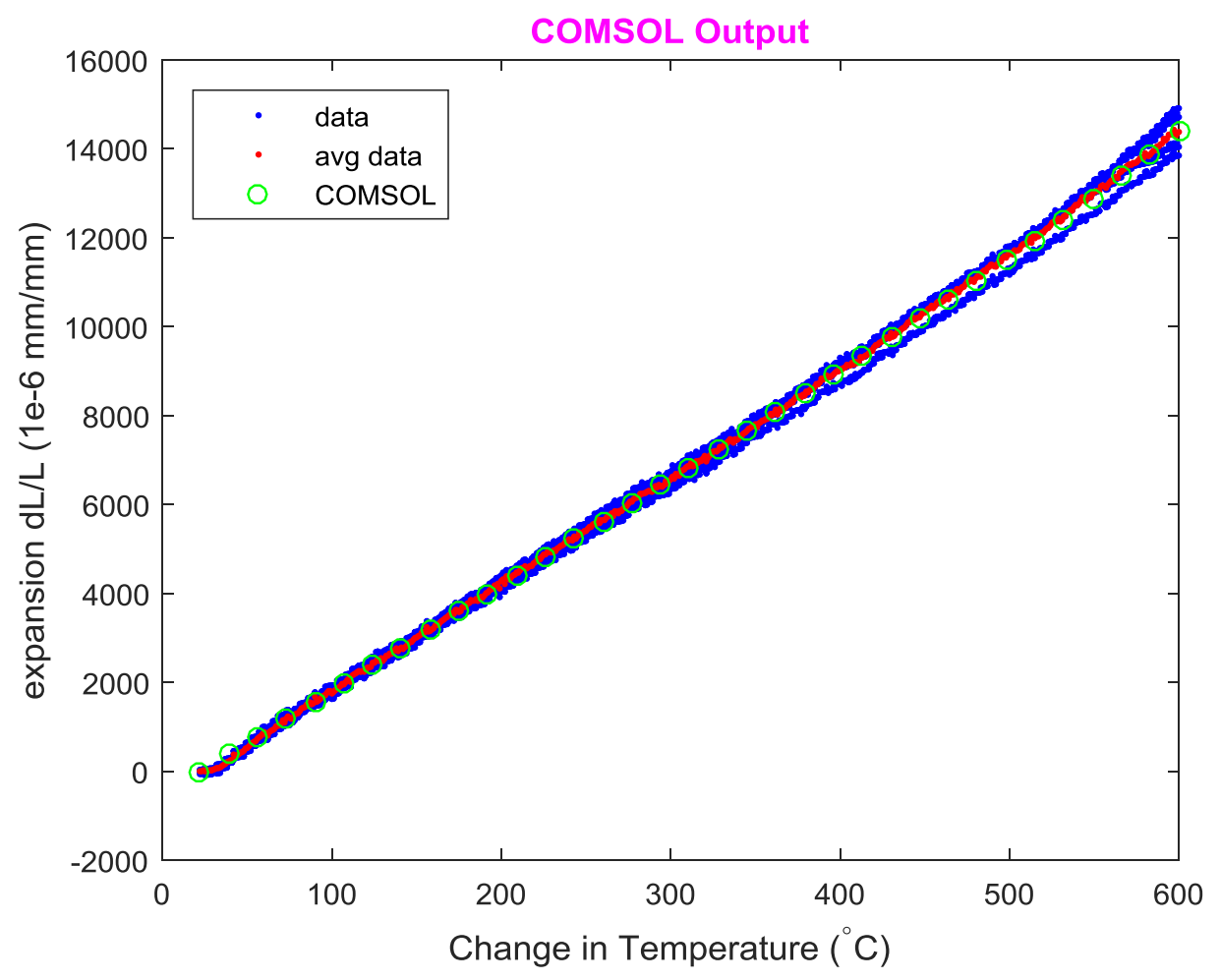

Fig. 6.2: Thermal expansion measurement data, averaged data, and the COMSOL probe results.

Other updated properties included the fission gas release fractions, which were set at a constant value during cycles 1 and 2, and increased to another constant during cycle 3 . Measurements of the hydrostatically collapsed fabrication gas gap between the pellet stack and housing tube were also made available in order to estimate bounding and best-estimate values.

\subsubsection{Structurally Limiting Basis Methods}

The methodology to create a conservative assurance of adequate target cooling was well-explored prior to this model however the methodology to assess structural integrity in the target was not as well developed. In addition to using 130\% overpower conditions, a bounding Poisson's ratio, best-estimate fabrication gap, and the bounding volumetric swelling curve in the direction of maximum swelling, several other changes were made in order to make this assessment sufficiently conservative.

The first case run is an intermediary step, using the above inputs except for the best-estimate swelling curve (which is conservative for this use), to calculate a temperature profile for the target that is saved for a later subcase. The subcase to assess radial stresses on the cladding from the pellet is denoted SLB-1 and uses the documented tensile yield strength of the cladding material as a safety limit, with observations that the yield strength of the material increases under irradiation [47]. In addition, the inside cylindrical surface of the housing tube was made rigid, not allowed to deform under pressure or axially expand, in order to maximize stress onto the cladding. Finally, documented failure tests of the target specified a minimum elongation of the target itself which was set as a prescribed limit on the target and bounding internal components like the weld support tube.

The subcase utilized to conservatively assess axial stresses in the target is denoted SLB-2 and uses as its safety limit a minimal tensile failure force from the aforementioned destructive target tests. A major 
conservative assumption desired is to limit the radial expansion of the pellets due to thermal expansion and irradiation swelling to only meet the target cladding inside surface, thereafter letting expansion due to these effects be exhibited only in the axial direction. Therefore, a limiting expansion variable is defined, that is the linear expansion variable that would cause the diameter of the pellet to increase to the collapsed diameter of the housing:

$$
\alpha_{\text {lim }}=\frac{\left[\frac{D_{\text {housing }}}{D_{\text {pellet }}}-1\right]}{\Delta T}
$$

The diametrical expansion variable is then set as the minimum of the nominal expansion and this limiting expansion value, thus not allowing the pellet to expand into the housing due to only thermal or irradiation effects.

It is now useful to examine the expanded volume in a pellet between a nominal state and the limited state where the pellet is just in radial contact with the housing. First in terms of the linear "thermal" expansion coefficient, then in terms of the utilized modified coefficients including a new coefficient to be applied to linear expansion in the axial direction:

$$
V(T, F D)=V_{0}\left(1+\alpha_{L} \Delta T\right)^{3}=V_{0}\left(1+\alpha_{l i m} \Delta T\right)^{2}\left(1+\alpha_{z m o d} \Delta T\right)
$$

In order to conserve volume expansion due to thermal and irradiation effects, these must be equal. Now solve for the new coefficient using the above equation where it is the only unknown:

$$
\alpha_{z \bmod }=\frac{\left[\frac{\left(1+\alpha_{L} \Delta T\right)^{3}}{\left(1+\alpha_{\lim } \Delta T\right)^{2}}-1\right]}{\Delta T}
$$

And the axial linear expansion coefficient is defined as either the modified coefficient or the nominal, depending on how much expansion has occurred.

$$
\alpha_{\text {axial }}=\left\{\begin{array}{cc}
\alpha_{L}>\alpha_{\text {lim }} & \alpha_{\text {zmod }} \\
\alpha_{L}<\alpha_{\text {lim }} & \alpha_{L}
\end{array}\right.
$$

Using these terms yields anisotropic expansion that will only allow the diameter of the pellets to expand to a certain diameter, followed then by only axial expansion. Due to this assumption, any solution to the temperature field values would be unrealistic and artificial, thus only the solid mechanics equations are solved for subcase SLB-2 and the temperature field is input from the previous intermediary solution using SLB inputs with otherwise default methodology.

\subsection{PRODUCTION MODEL GEOMETRY}

The geometry of the production model target is an extension of the target designed for the prototypical targets, where a pellet stack is contained within an aluminum housing tube, as shown in Fig. 6.3. Similar features to the prototypical targets include: dummy pellets at either end of the pellet stack, a top end cap (TEC) with a large helium plenum and threaded top for HFIR operations removal, a bottom end cap (BEC) with a swage joint, spacer tubes at either end of the target (UST and LST), a support tube (WBT) for the E-beam weld, and welds at either end to attach the end caps. Expansion spacer assemblies of SST316 were added on either end of the pin each consisting of a roll pin that slides into a sleeve under axial compression, designed to create greater axial clearance in the event of axial stresses in the target due 
to pellet stack swelling, as a result spacer tube lengths decreased. In addition, the nominal pellet length increased by a few mils.

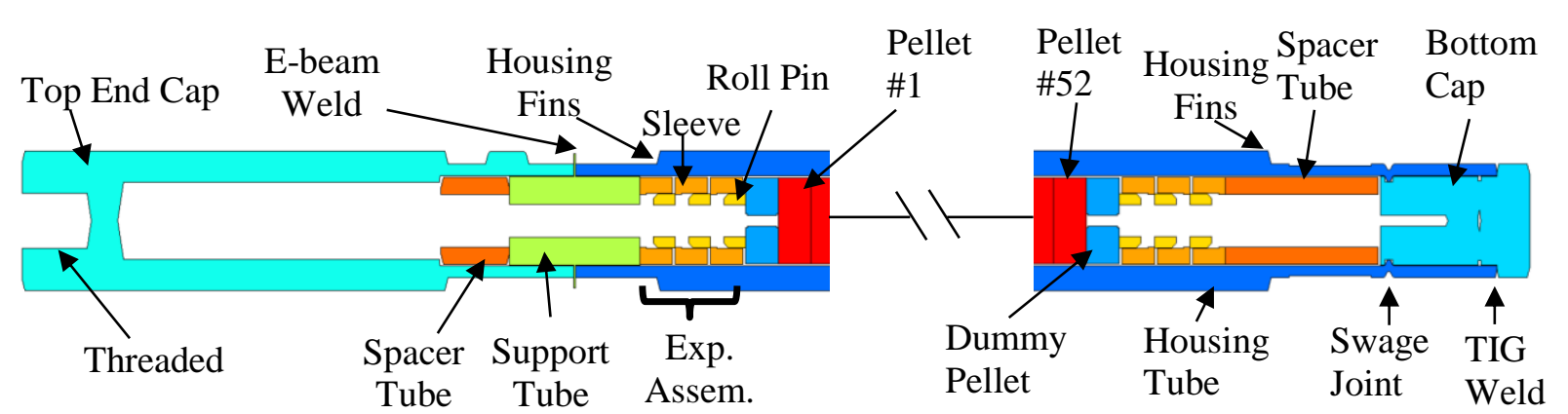

Fig. 6.3 : Representation of production model target pin components.

\subsection{PRODUCTION MESH}

A total of five mesh cases were designed in analyzing this problem. These 5 cases are designated (1) extra coarse, (2) normal, (3) finer, (4) extra fine, and (5) extremely fine. All 5 mesh cases are similarly formed and differ primarily by the selection of their free mesh size types as defined by COMSOL predefined settings which are sometimes custom adjusted (in terms of minimum and maximum element sizes, or ratio for element growth) in order to optimize the mesh ratios in the side gap (best at a pellet/housing ratio of 2 or greater). These free mesh size settings include four boundary size settings on the pellet sides, housing inside surface, and pellet tops (applying to each pellet top surface) as well as the universal domain size setting. The boundary settings are calibrated for fluid dynamics (a finer mesh category to allow for more exact solutions in these domains of high interest) at Coarser on the housing tube sides and Normal on the pellet sides for the normal $\left(2^{\text {nd }}\right)$ case mesh level, as an example. The universal domain free mesh size is calibrated for general physics at a Normal setting for the normal case. The pellet boundaries are at finer mesh settings than the adjacent housing surface due to the guidance on the stable convergence for non-linear contact pairs.

The mesh is designed so that the pellet mesh is the dominate control feature of the mesh design. This was done after preliminary analysis revealed that the predominate temperature change in the problem occurs in and around the pellet, with all other temperature features extending out beyond the pellet requiring less detail than within the pellet.

An extensive mesh-density evaluation of this problem was performed early in the study and revealed that the extra coarse mesh with linear finite-element basis function was sufficient to analyze this problem's time-dependent values provided that a quadratic finite-element basis function was also exercised with the extremely fine-mesh to confirm extra coarse mesh values at the times yielding safety basis values, EOC-1 and EOC-3. Therefore, the results corresponding to mesh cases 2, 3, and 4 are not documented herein. Only the first and last mesh case (extra coarse and extremely fine) results are directly documented in the analysis, and as a result will be more closely examined in this section. Should it become necessary to examine time-dependent results for finer meshes, the mesh-case designs were retained in the model for that potential purpose.

The pellet and adjacent housing domain mesh have the highest impact on the solution and are shown below for all 5 mesh cases in Fig. 6.4 through Fig. 6.6. Note that the mesh density is refined near the cylinder radius edge as recommended by the COMSOL documentation for contact-pair problems, with a desired ratio of 2 to 1 for the adjacent cladding surface mesh density, as well as on the top surfaces of each pellet which is evident for the finer meshes. This is a noted improvement from previous models that 
did not control the mesh as closely in this manner. The housing is chosen as the source boundary as it is both the stiffer and concave-shaped surface under contact, the destination boundary (pellet radial surface) is then more finely meshed as a result.

Each individual domain is meshed separately. Attention is paid between domains that are combined as a union and those domains that are left separately to be combined as an assembly during the geometry creation process. If an assembly is used to form the geometry, adjacent mesh surfaces are not imprinted automatically. The domains outside the pellet stack/housing regions experience less change with increasing mesh fineness as they are governed by a general physics mesh calibration, instead of a fluid dynamics calibration for the surface settings. Fig. 6.7 shows the mesh in the WBT, housing and upper expansion spacer regions and Fig. 6.8 shows the mesh for the BEC, LST, and lower expansion spacer regions.

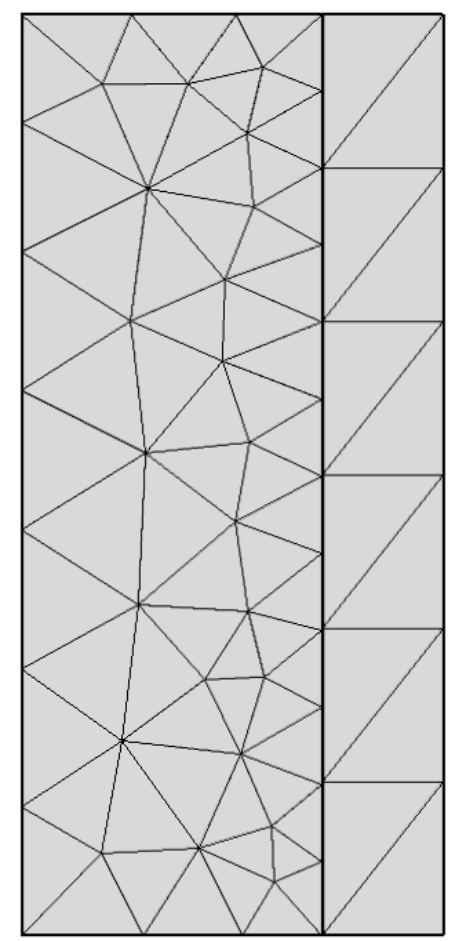

Fig. 6.4 : Extra coarse mesh in the pellet/cladding region. 

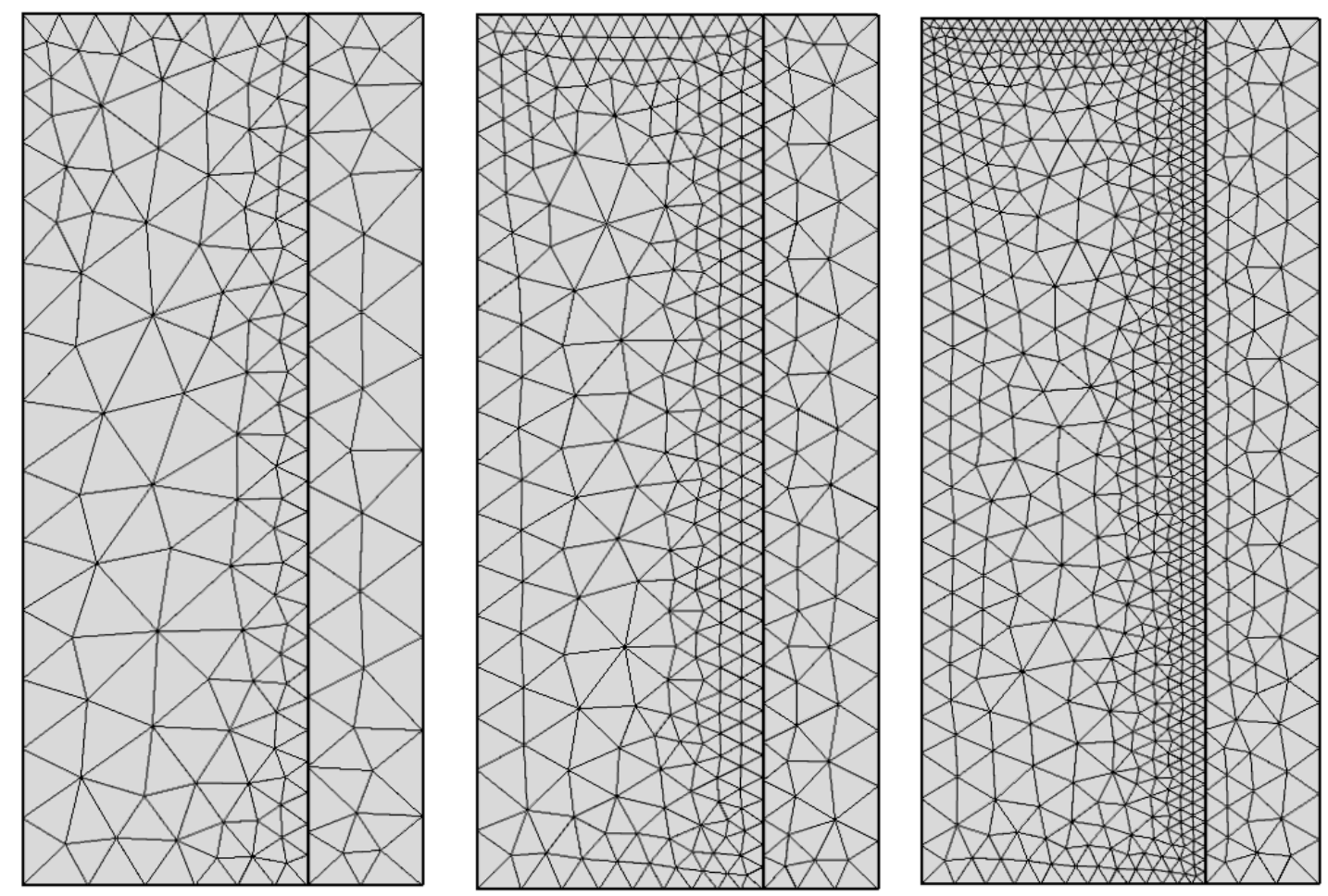

Fig. 6.5 : Normal, finer and extra fine meshes in the pellet/cladding region.

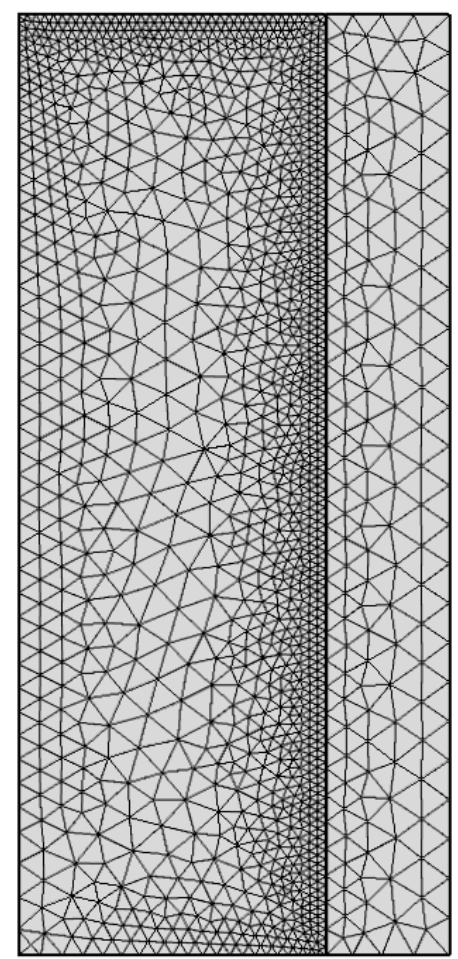

Fig. 6.6: Extremely fine mesh in the pellet/cladding region. 

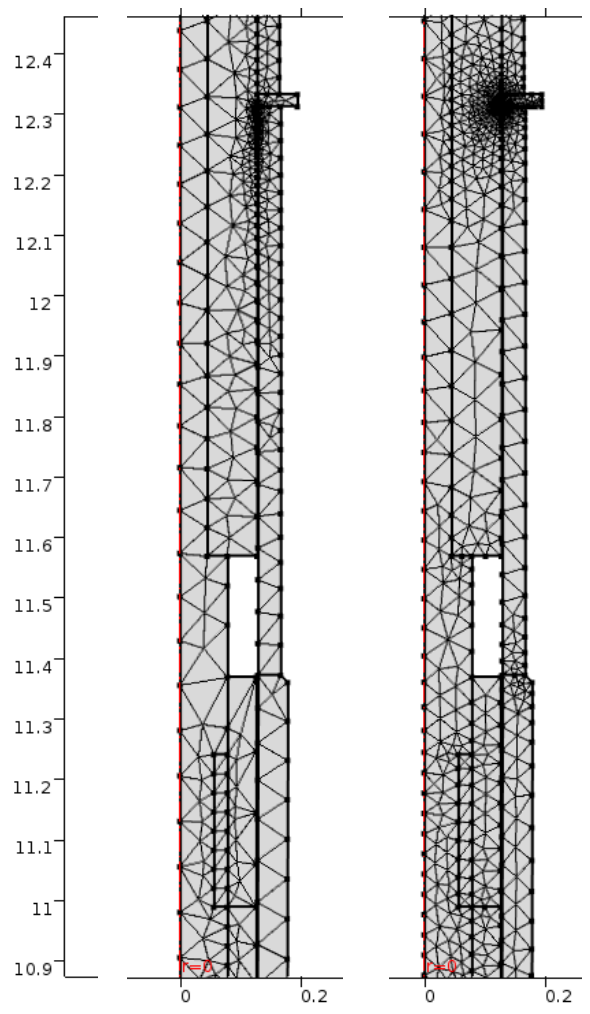

Fig. 6.7: Extra coarse and extremely fine meshes in the upper region near the WBT.

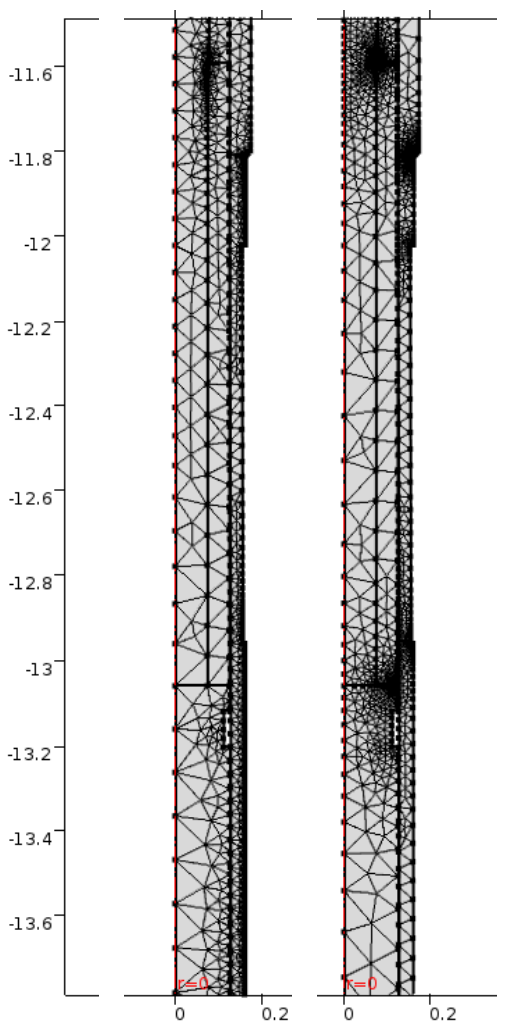

Fig. 6.8: Extra coarse and extremely fine meshes in the lower region near the BEC, LST, lower expansion spacers and housing. 


\subsection{ANALYSES AND DISCUSSION}

In the previous fully loaded target analyses, three of the five revisions addressed the maximum target temperatures with respect to the melting temperature and the final two revisions supported the assessment of target axial stresses with axially-dependent thermal data. The analyses for the production model address the bounding temperatures and provide supported axially-dependent thermal data in one assessment, while also providing an assessment of the structural integrity of the target (in terms of the axial stresses among other features).

There are four different model cases analyzed: 1) DB case at steady-state $100 \%$ flow, or "best-estimate" 2) DB case at steady-state $50 \%$ flow, and 3) TLB case at $130 \%$ overpower conditions, and 4) SLB case at 130\% overpower conditions Case 2 and 3 are run for the hot pin (or Pin 1) in position VXF-15, and for the DB case at $100 \%$ flow (also referred to as the "best-estimate" model) the model is run for all 7 pins in position VXF-15 and pin 1 in position VXF-3. The SLB case is run only for EOC-3, where maximum irradiation swelling leads the limiting conditions for structural integrity.

\subsubsection{Best-estimate Analyses}

The best-estimate case is analyzed for all irradiation pins, all seven positions in the holder in position VXF-15 and the hot pin (pin 1) in position VXF-3 which is referred to as a "Pin 8". All eight pins are analyzed over the course of 3 cycles, at 10 discrete time periods $(0,1,3,5,10,15,20,22,24$, and 26 days into each irradiation cycles). Fig. 6.9 below provides a summary of the analyses for the eight pins with their maximum target temperatures plotted against irradiation days into the cycle, where Pin 1 of VXF-15 has the highest temperatures over the 3 cycles, Pin 8 (or pin 1 of VXF-3) has the second highest, and the highest temperature pins (1, 2, 3, and 8) have their maximum temperatures at EOC-1.

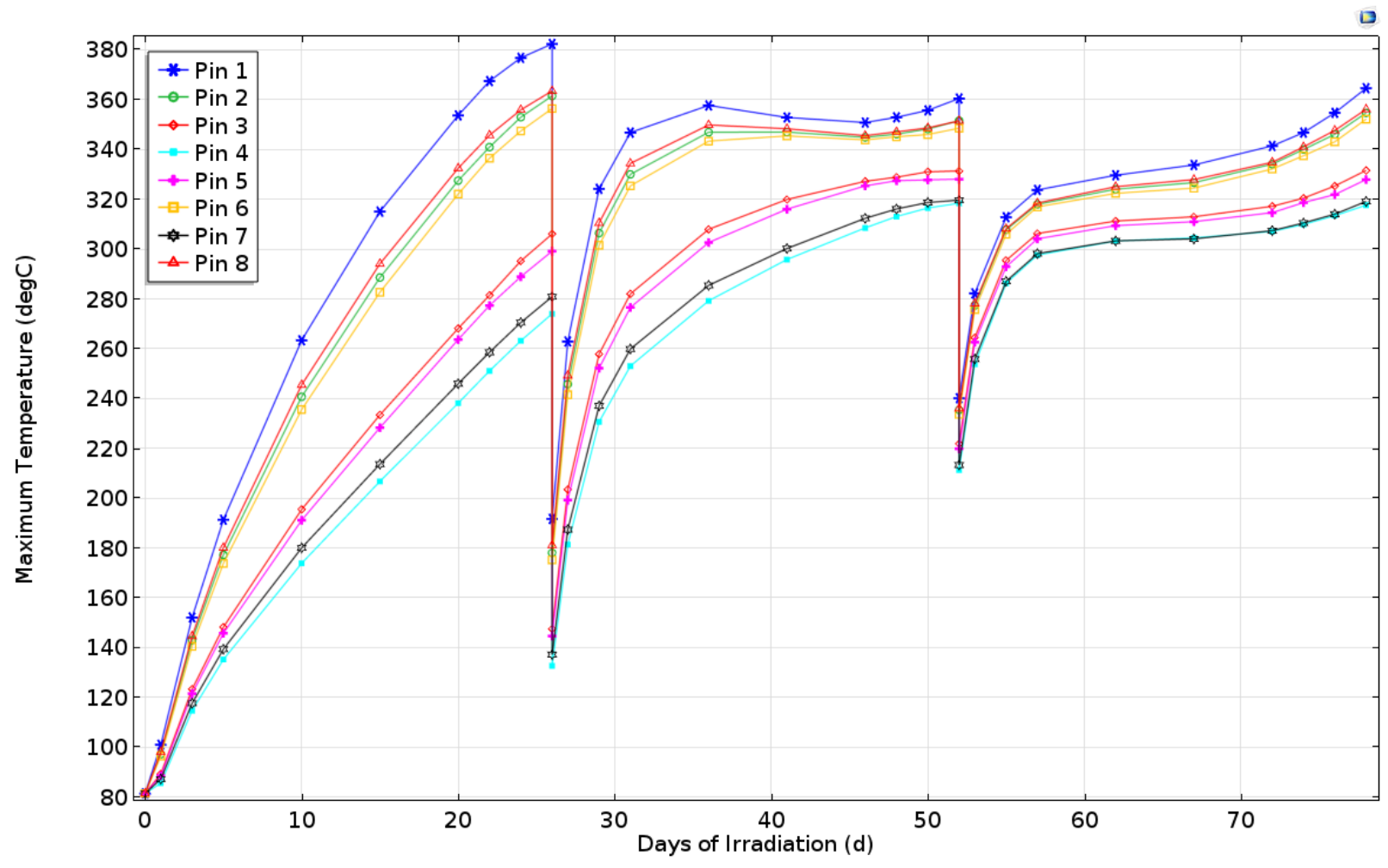

Fig. 6.9: Maximum target temperatures over 3 irradiation cycles ( 78 days) for all 7 pins in $\mathrm{VXF}-15$ and pin 1 in VXF-3 ("Pin 8"). 
Fig. 6.10 shows the target side pressure for pin 1 over 3 cycles as a function of irradiation days, where the peak pressure occurs at EOC-3. Fig. 6.11 shows the temperature profiles in the VXF-15 pin $1 \mathrm{NpO}_{2} / \mathrm{Al}$ pellet stack on a 2-D R-Z section (spatially not-to-scale) for the EOC-1, 2, and 3, while Fig. 6.12 shows the effect of irradiation-induced swelling/densification in the pellet/housing gap at the end of each cycle. Fig. 6.13 through Fig. 6.15 show the pellet centerline temperature profiles for cycles 1, 2, and 3, respectively at ten discrete time steps in each cycle. Fig. 6.16 and Fig. 6.17 show pellet side temperature and pressures, respectively, for cycle 3 at ten discrete time steps in the cycle. Altogether, the figures show the similar dynamic previously observed where due to higher burnups in the center of the pellet stack linear swelling begins to close the gap and the maximum temperature regions move to the "outer ends" where the gap is larger. During cycle 3, contact is made with the pellet housing at around day 5 and pellet temperatures are reduced as a result.

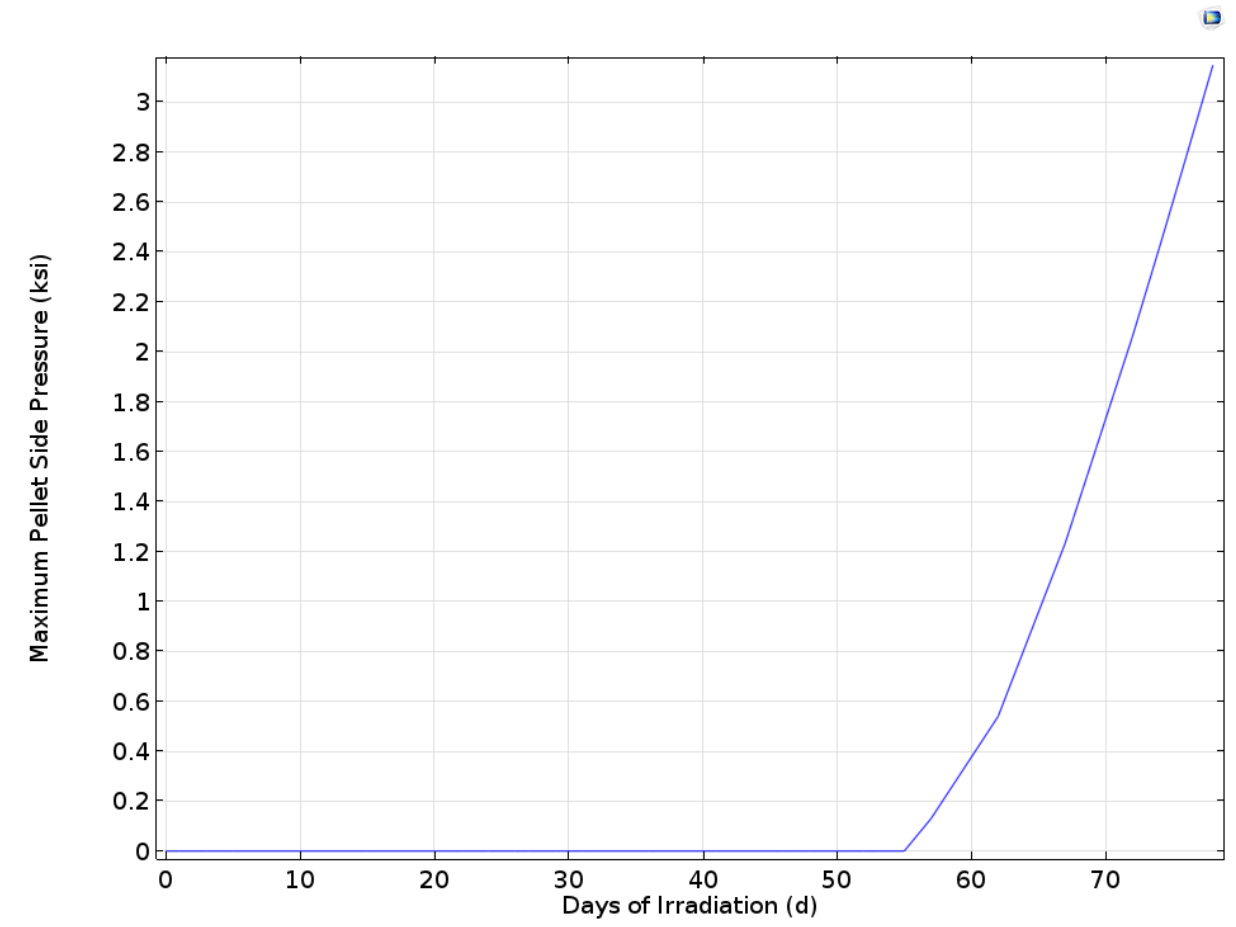

Fig. 6.10: Maximum side pressure over 3 irradiation cycles ( 78 days) for pin 1 in VXF-15. 


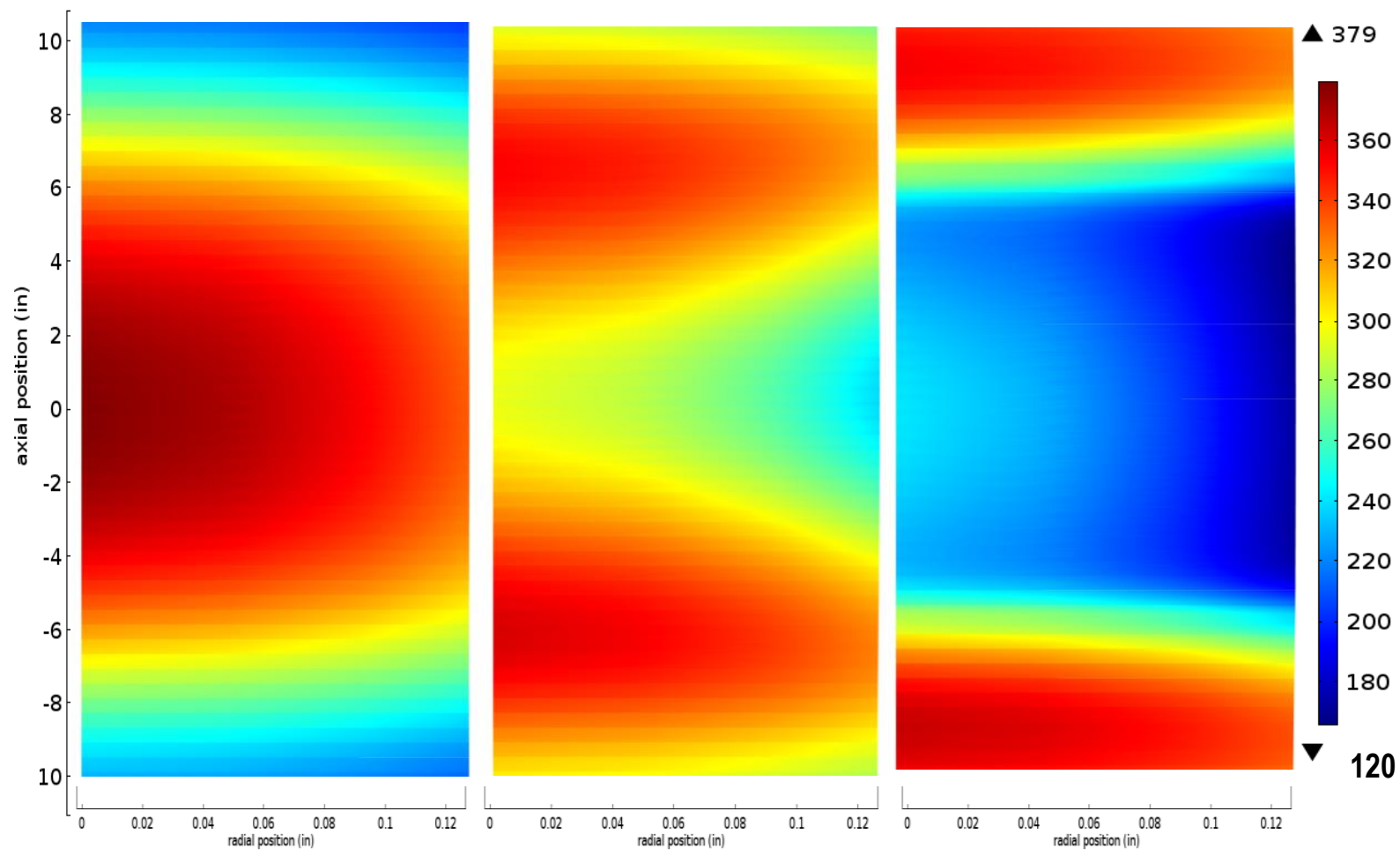

Fig. 6.11: 2-D R-Z (distorted) VXF-15 pin 1 pellet temperature profiles $\left({ }^{\circ} \mathrm{C}\right)$ for EOC-1, 2 , and 3.
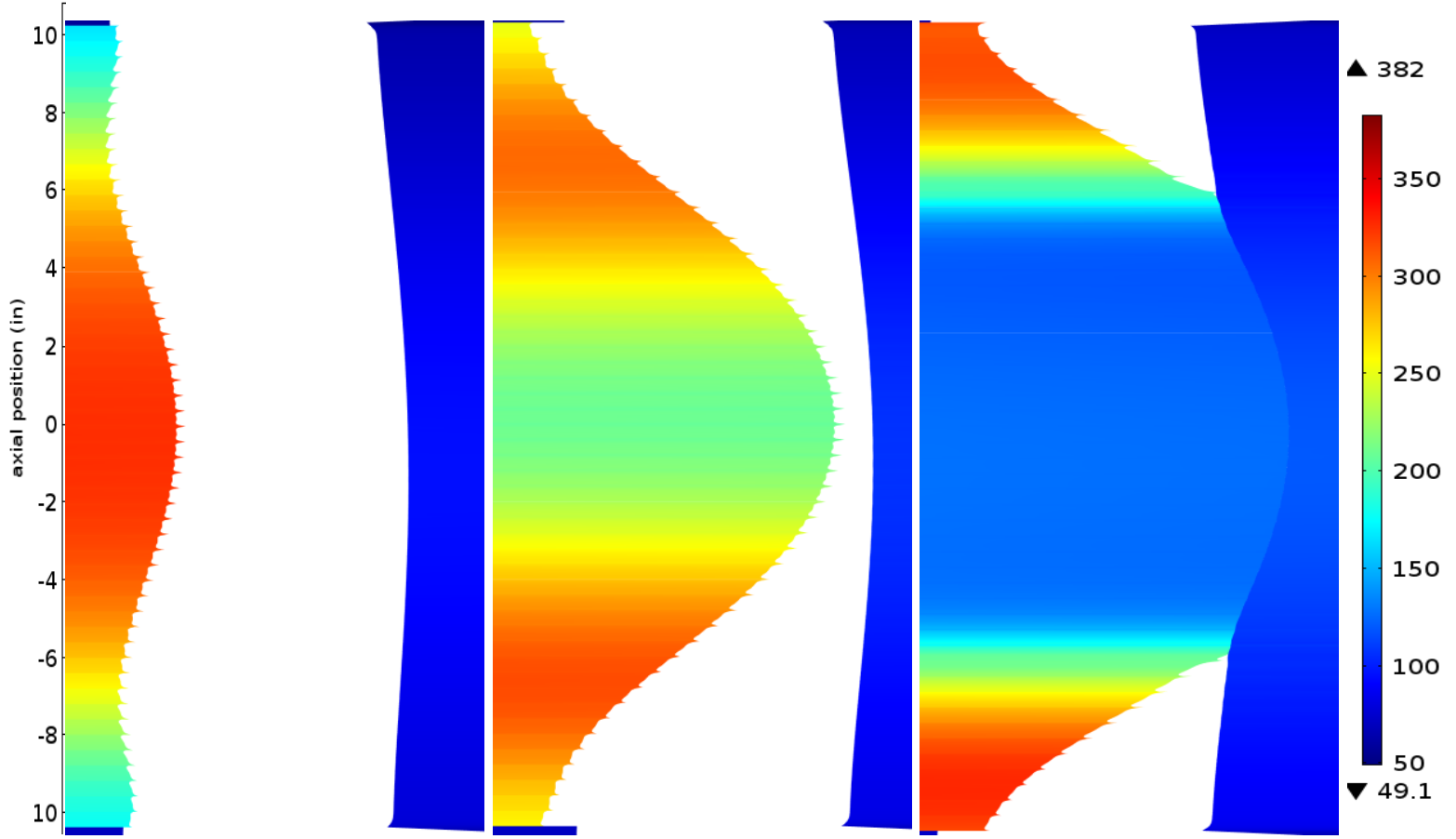

Fig. 6.12: 2-D R-Z (distorted) VXF-15 pin 1 pellet temperature profiles $\left({ }^{\circ} \mathrm{C}\right)$ showing radial gap for EOC-1, 2 , and 3 where gap width shown is approximately 1 mil. 


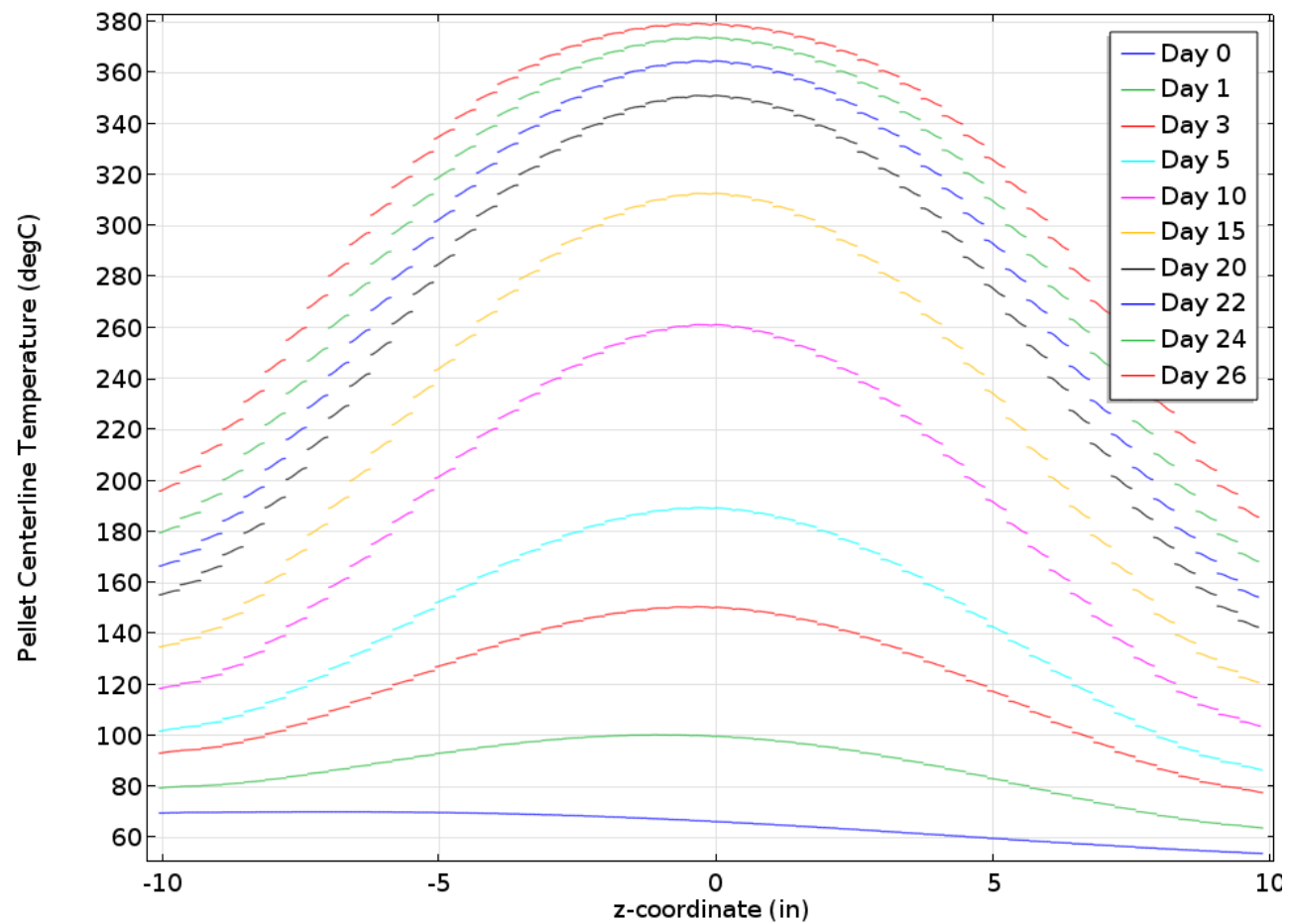

Fig. 6.13: Pin 1, cycle 1 pellet centerline temperatures as a function of axial position.

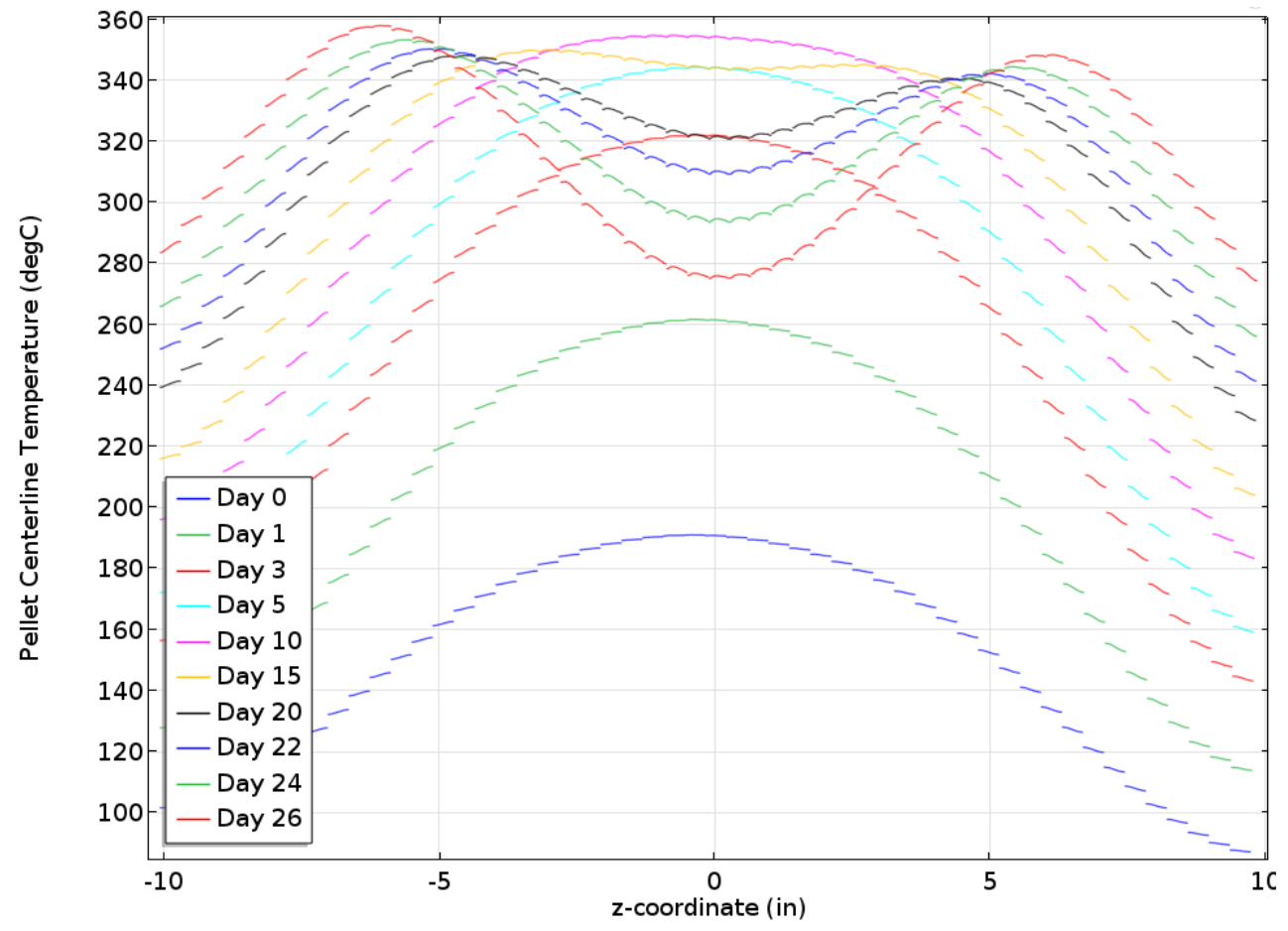

Fig. 6.14: Pin 1, cycle 2 pellet centerline temperatures as a function of axial position. 


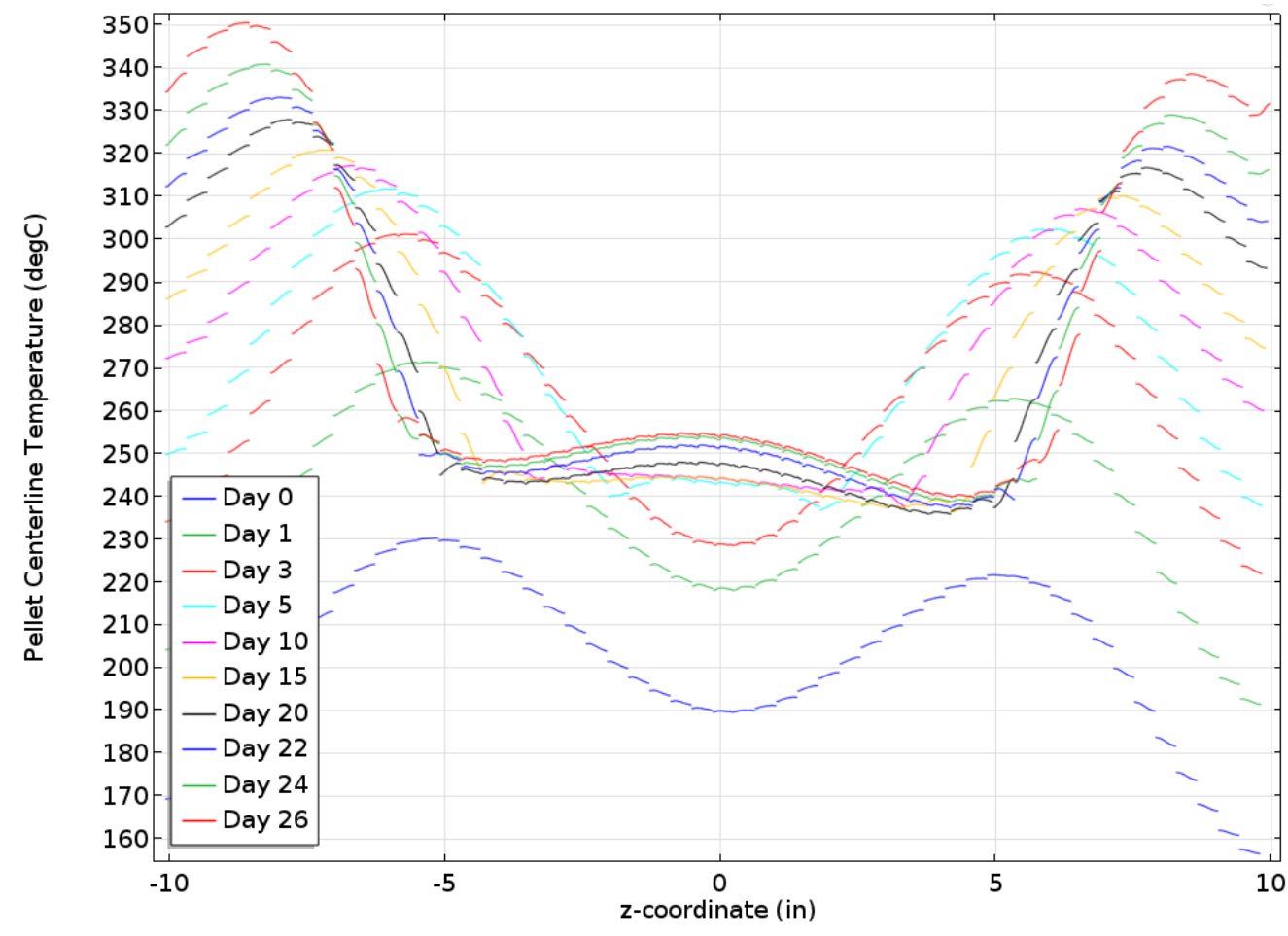

Fig. 6.15: Pin 1, cycle 3 pellet centerline temperatures as a function of axial position.

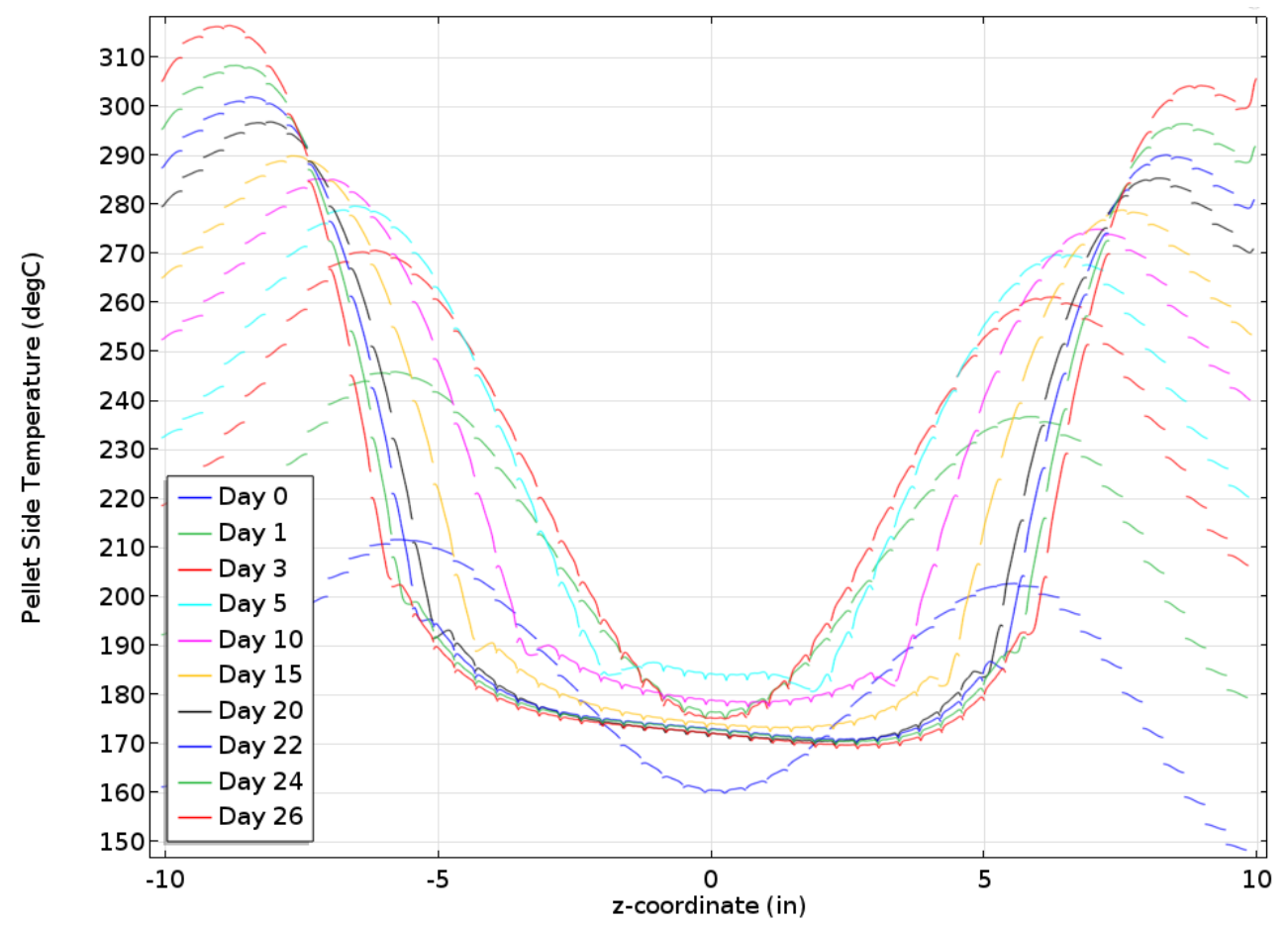

Fig. 6.16: Pin 1, cycle 3 pellet side temperatures as a function of axial position. 


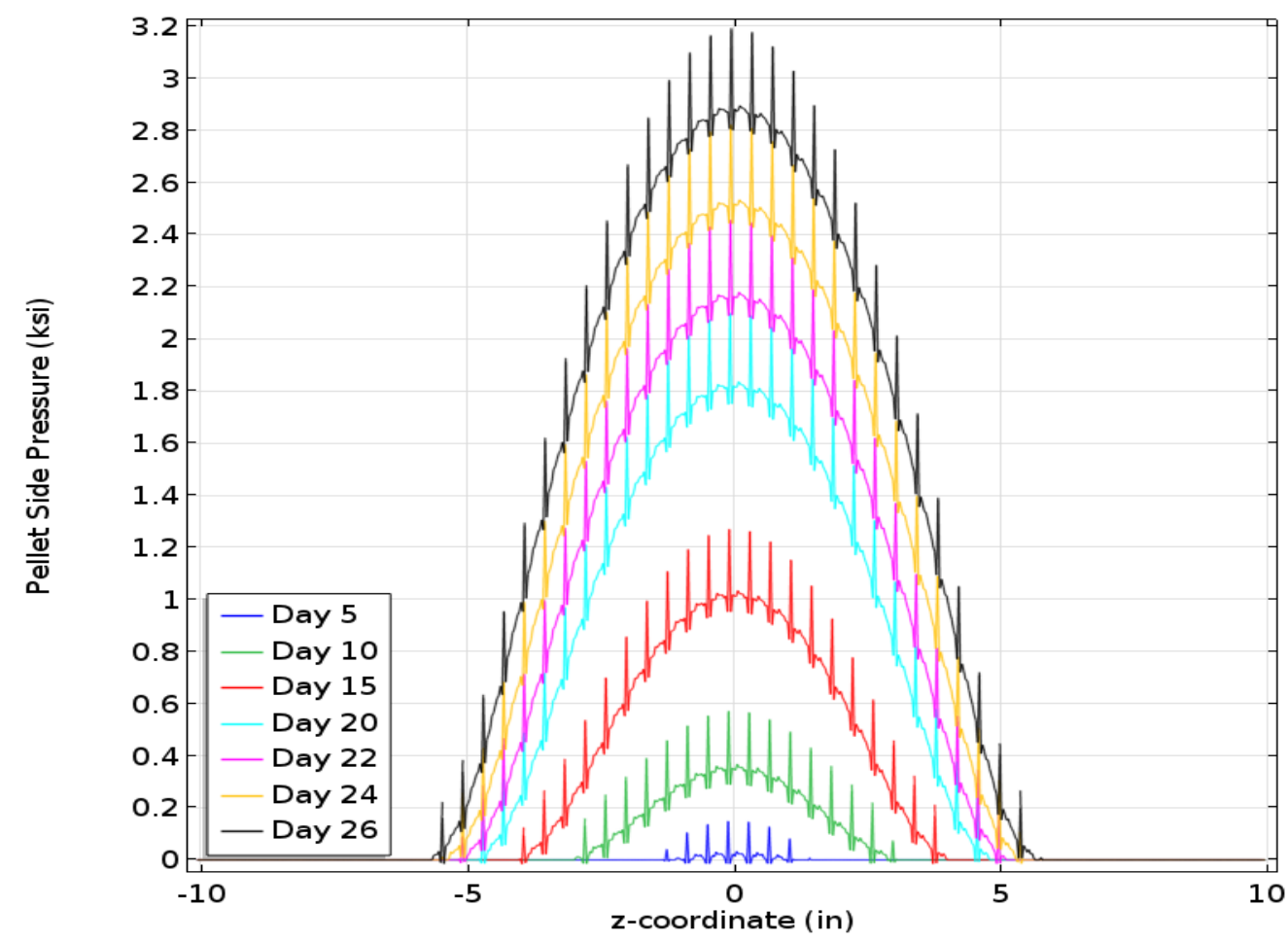

Fig. 6.17: Pin 1, cycle 3 pellet side pressures as a function of axial position.

\subsubsection{Thermally Limiting Safety-Basis}

As previously noted, the TLB yields the highest pellet temperature and the minimum safety factor for the calculation. The TLB case is analyzed for the VXF-15 hot pin only over 3 cycles, as the best-estimate case analyses of all pins establishes that Pin 1 is the "hottest" pin and most important for thermal safety analyses. Fig. 6.18 shows the maximum pellet temperatures in material regions 5611-5619 where lower numbers denote pellets closer to the horizontal midplane. Fig. 6.19 shows the von Mises stress profile in the center pellet at EOC-2 and 3 for a rotated 3-D view, with 100x deformation included. At EOC-2, the pellet expected hourglass shape is clearly shown. By EOC-3 internal strains have clearly risen as the pellet makes side contact with the cladding and, as a result, expansion is expressed as axial elongation, making it more difficult to observe the characteristic hourglass shape. In addition, peak stresses in the pellet have moved from the pellet "corners" to the pellet radial side. 


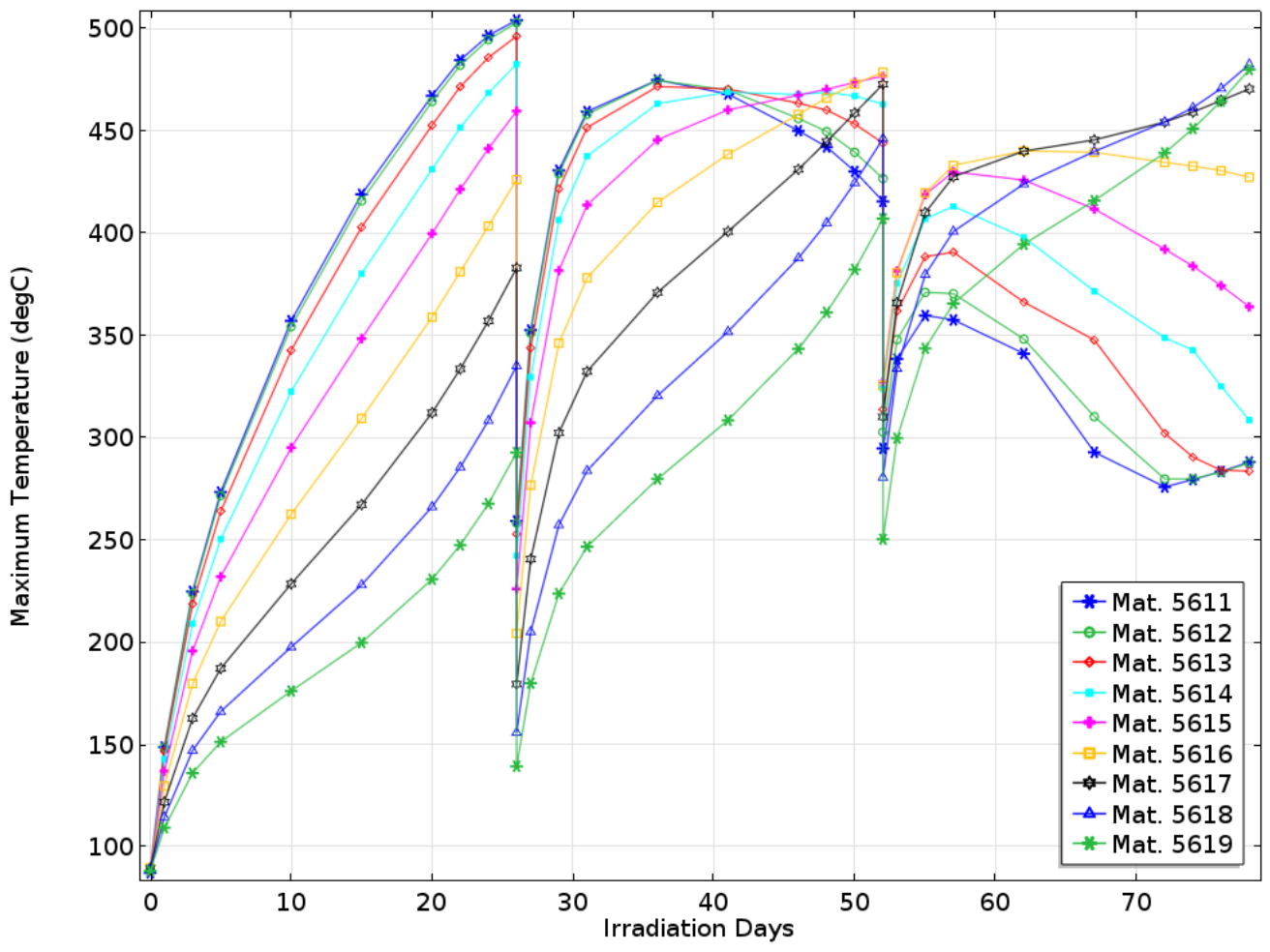

Fig. 6.18: Pin 1 maximum material region temperatures as a function of irradiation days over 3 cycles.
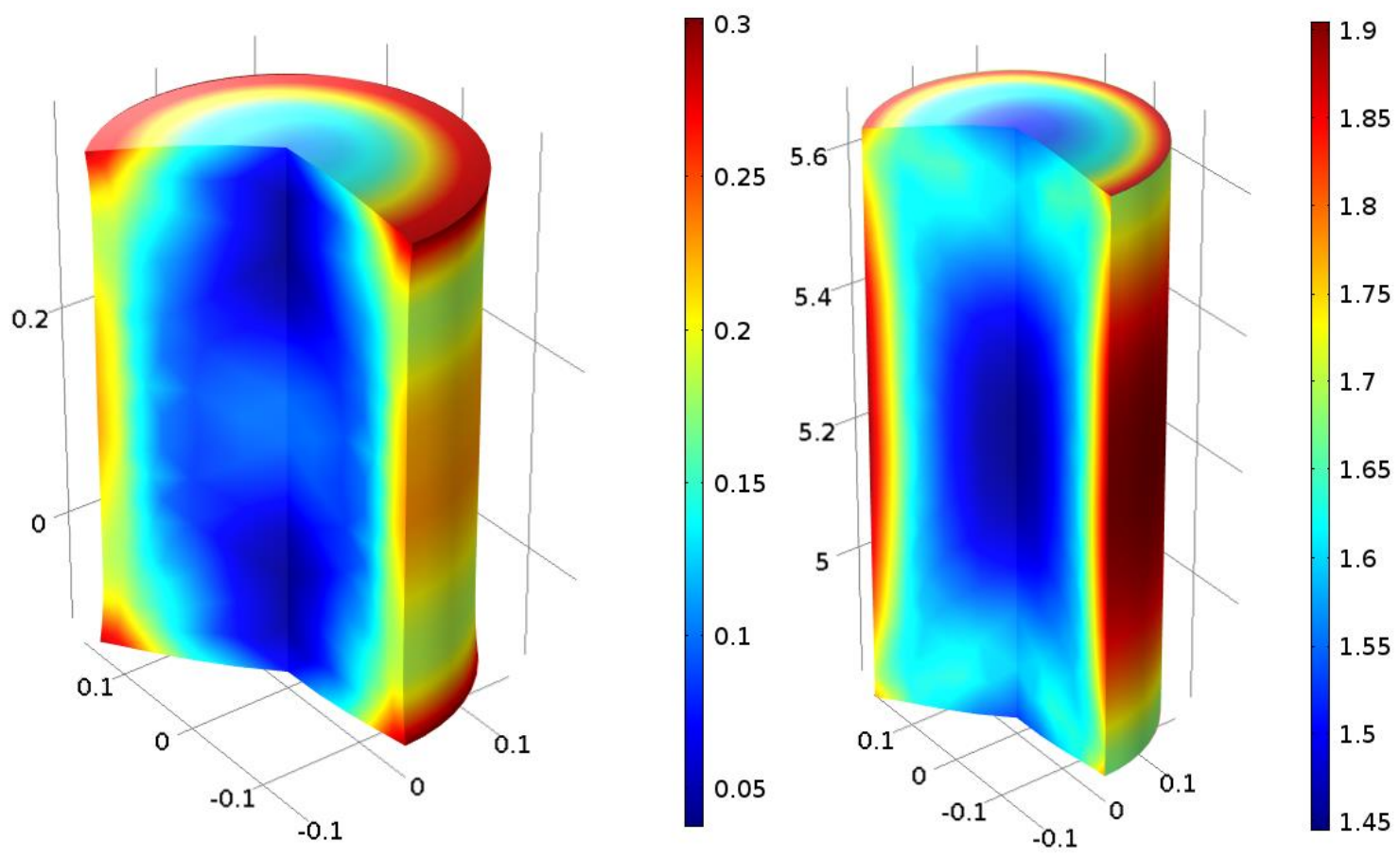

Fig. 6.19: 3-D center pellet von Mises stress profile at TLB EOC-2 and 3 with 100x deformation. 


\subsubsection{Design-Basis 50\% Flow}

The worst-case steady-state flow reduction of $50 \%$ is analyzed at DB or normal reactor operating conditions per EG-6 [48]. As the best-estimate case analyses of all pins establishes that Pin 1 is the "hottest" pin and most important for thermal safety analyses, the DB 50\% flow case only analyzes the VXF-15 pin 1 conditions for 3 cycles.

The bulk temperature and target surface temperature profiles as a function of distance into the coolant flow (starting from the top of the target) are shown in Fig. 6.20 and Fig. 6.21 at EOC-3 for both the DB $50 \%$ flow case as well as the DB 100\% flow (or best-estimate) case and TLB case. The end of the third cycle is the time period of highest steady-state coolant and target surface temperatures as the highest heat generation rates occur in this cycle. Although the highest target surface and bulk temperatures occur in the DB at 50\% flow case, the TLB results remain the bounding safety factor for coolant burnout as they are at $130 \%$ overpower conditions which includes a reduced inlet coolant pressure of 343 psig (from nominal at $468 \mathrm{psig}$ ) that, with pressure drop, yields a lower water saturation temperature of $391.7^{\circ} \mathrm{F}$ (from nominal at $431.7^{\circ} \mathrm{F}$ ) [49].

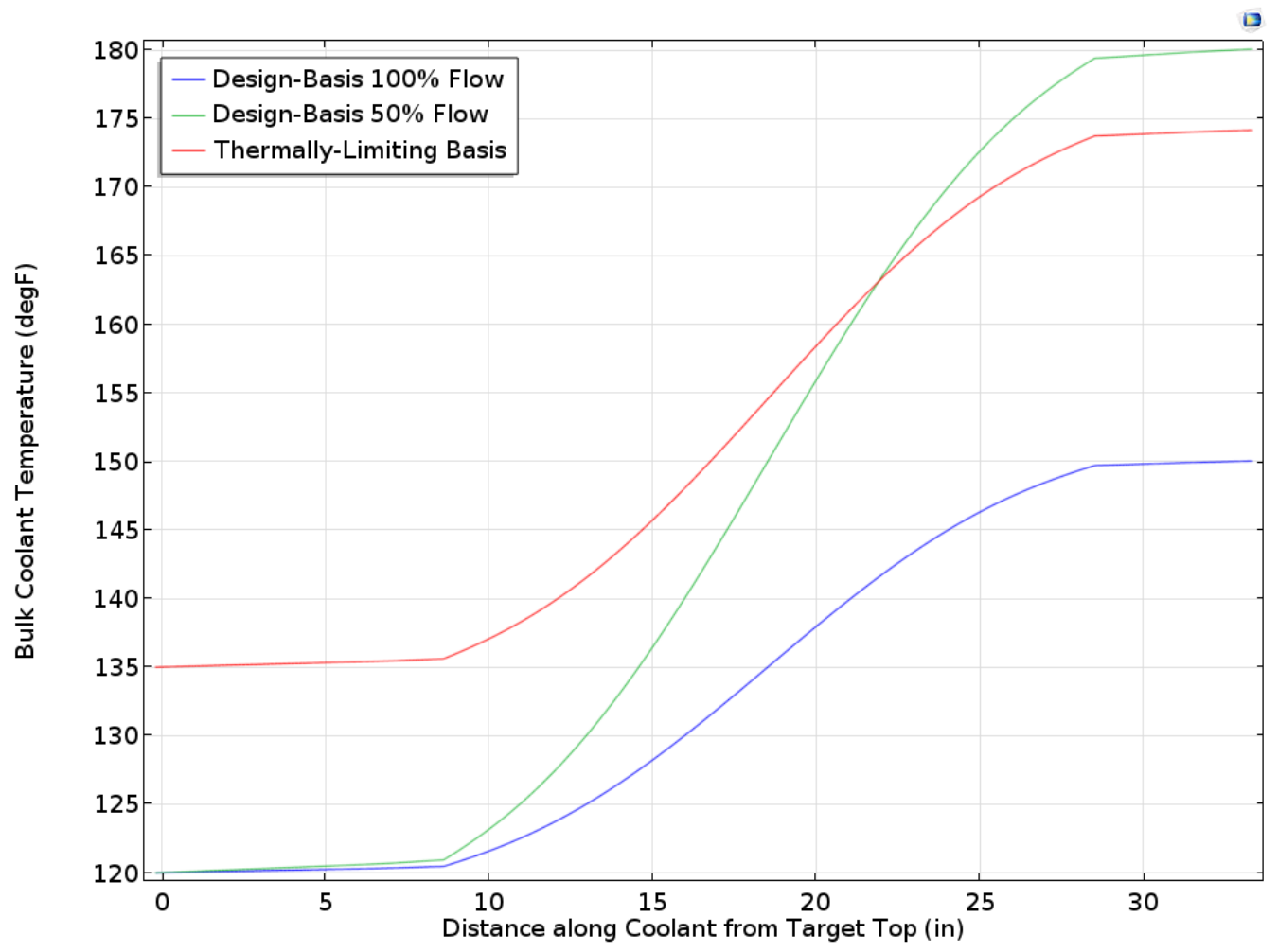

Fig. 6.20: EOC-3 bulk coolant temperature as a function of axial position for all cases. 


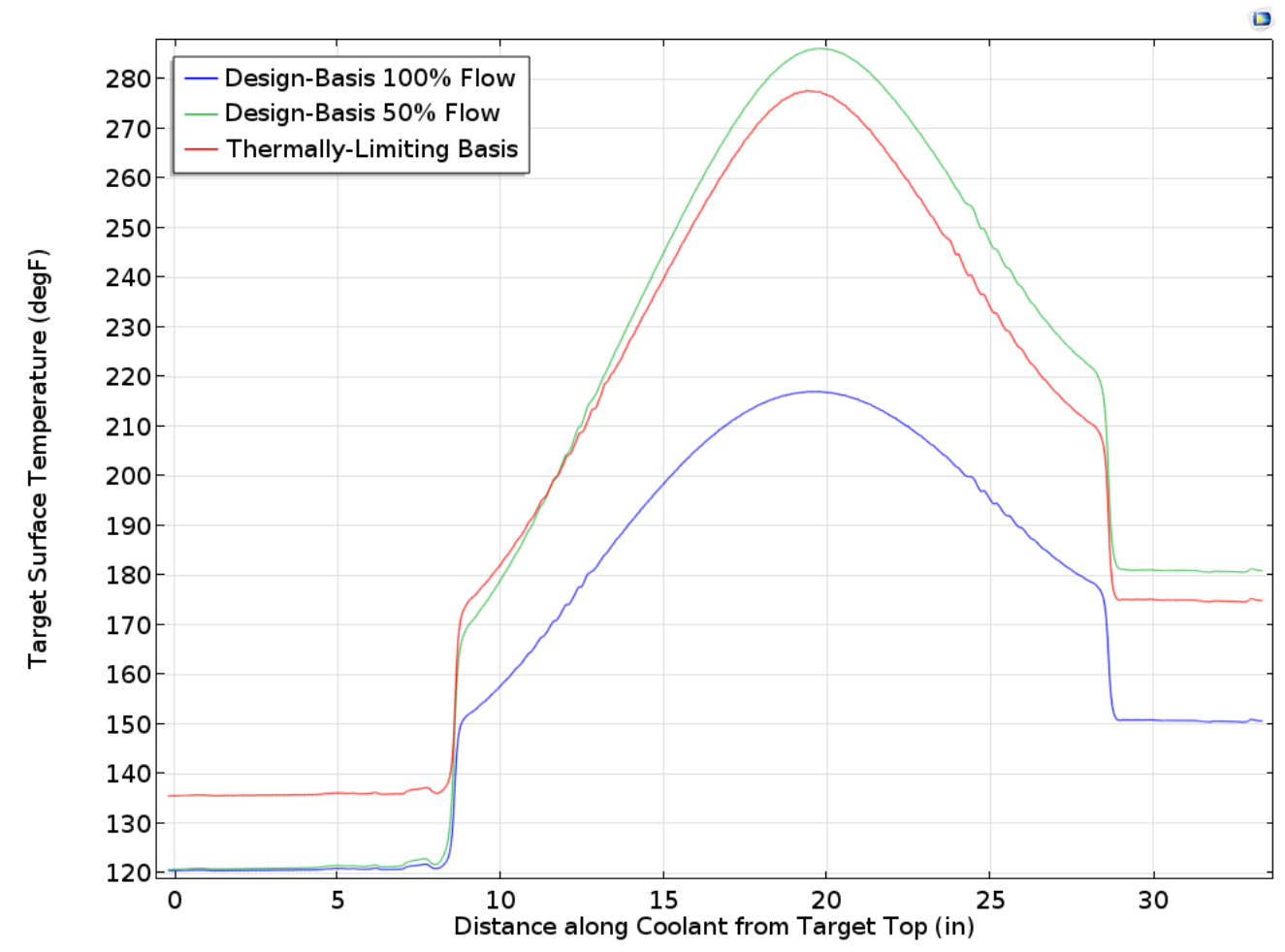

Fig. 6.21: EOC-3 target surface temperature as a function of axial position for all cases.

\subsubsection{Structurally Limiting Safety-Basis}

The SLB conditions previously described are only analyzed at EOC-3, for the two primary cases that serve to maximize either radial or axial stresses/forces in the target and are denoted SLB-1 and SLB-2, respectively. The reason for this limited solution space is that the structurally limiting conditions, as confirmed by analysis of the previous case results, are driven by the pellet volume swelling under irradiation, which is at its maximum at the highest burnup at EOC-3.

For both cases, the resulting stresses/forces were within their safety limits, as later described in the following section. The "hot pellet" or center pellet stress profile at EOC-3 is shown for a 3-D rotation of $225^{\circ}$ for the TLB case (previously shown in Fig. 6.19), SLB-1 and SLB-2 cases in Fig. 6.23. The axial elongation due to pellet side contact previously noted in Fig. 6.19 is extended even further for the SLB cases, where pellet volumetric swelling is significantly increased. For the SLB-1 case, side stresses approximately triple and the pellet deforms upward. For the SLB-2 case stresses maxima are in the center of the target, since for this case axial compression occurs on the pellet stack and expansion into the cladding side wall is minimized. The stress maxima in the pellet stack are higher for the SLB-1 case, however average stress profiles are closer between SLB-1 and SLB-2 where the stress of axial compression is spread throughout the entire pellet stack, as shown in the distorted 3-D stress plots in Fig. 6.24 where stress minima for SLB-2 are higher than for SLB-1.

It is important to note the changing scales (on the right of each plot) in Fig. 6.22 and Fig. 6.24, which if unnoticed could lead to misleading interpretations of the results. These plots are therefore best used for comparing differing behavioral trends in the different cases, and only cautiously for comparisons of magnitude. 

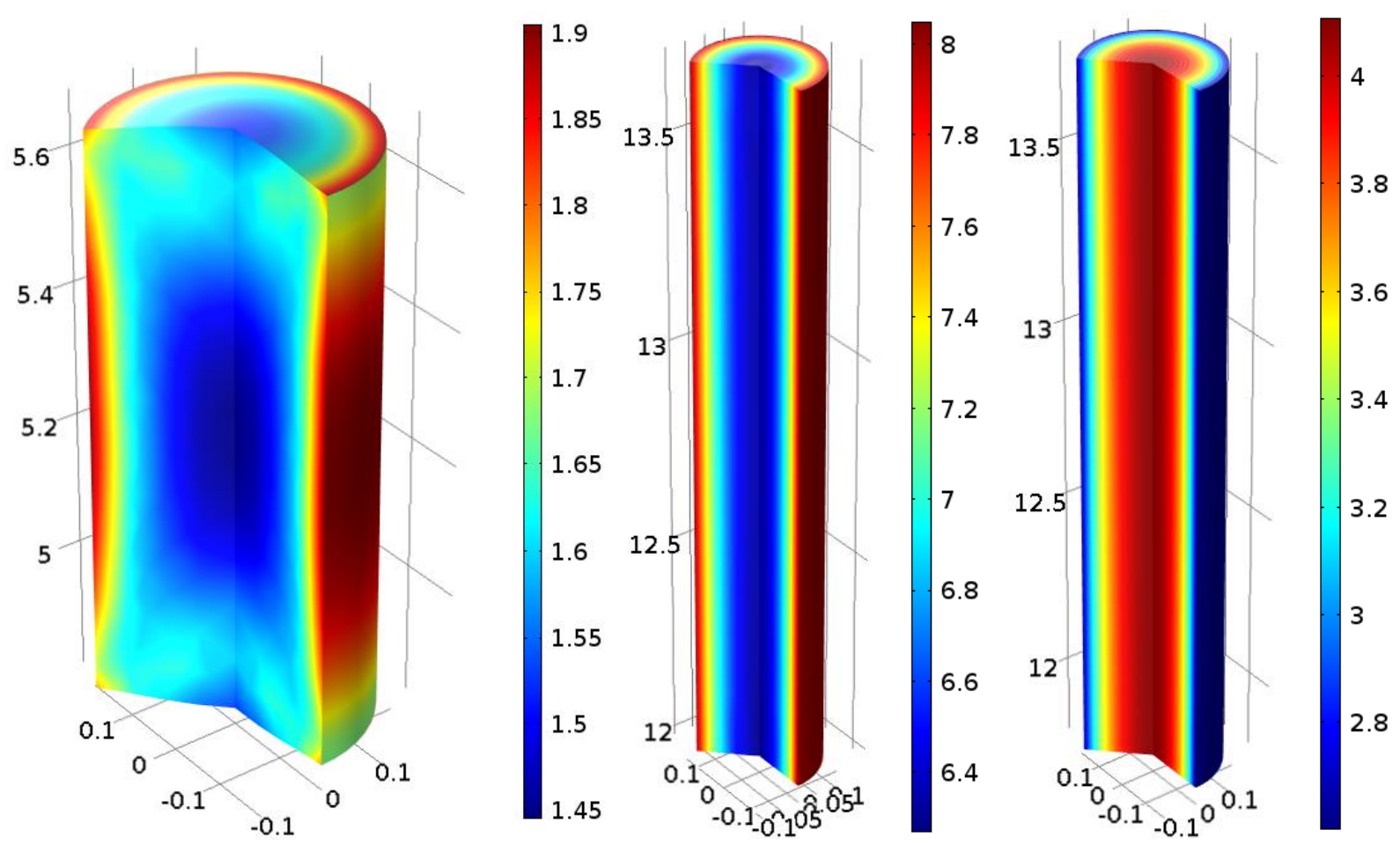

Fig. 6.23: 3-D center pellet von Mises stress profile at EOC-3 for TLB, SLB-1 and SLB-2 cases with 100x deformation.

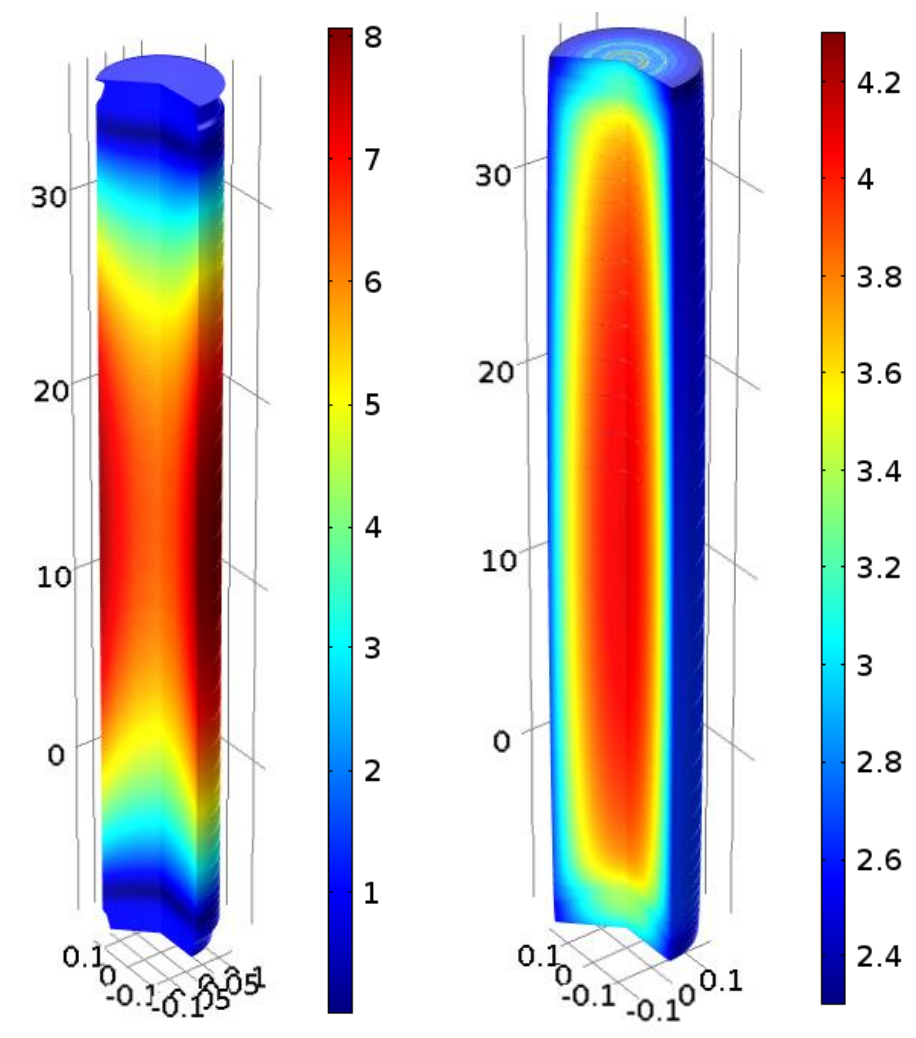

Fig. 6.24: 3-D pellet stack von Mises stress profile at EOC-3 for SLB-1 and SLB-2 cases with 100x deformation and 20x distortion in $\mathrm{R}$ direction. 


\subsubsection{Summary of Production Target Analyses}

A summary of the limiting parameter results for each case and identification of the case which yields the lowest safety factor ratio are given in Table 6.1 below. The primary safety limits of interest over the entire 3 cycle irradiation period are: 1) the maximum target temperature, 2) the maximum side/radial pressure on the cladding wall by the $\mathrm{NpO}_{2} / \mathrm{Al}$ pellets, 3) the maximum estimate of the force on the target axially, 4) the maximum target surface temperature, and 5) the maximum local linear cladding strain due to single pellet expansion. The axial clearance was also included, since many cases did not put any load on the target axially. The maximum target temperature typically occurs at end-of-cycle 1 (EOC-1), with other temperature local maxima occurring at EOC-2, EOC-3 and around day 10 into cycle 2. The maximum target stress/strains and target surface temperatures occur at the EOC-3.

The lower two rows of the table show the safety limits and minimum safety factors (ratio of safety limit to analyzed value), where the value that yields the minimum safety factor for each parameter is highlighted in bold in the upper portion of the table. In order to satisfy structural integrity of the target, the side pressure safety limit will be set to the tensile yield strength of the cladding material Al-6061-t4 at $21 \mathrm{ksi}$ [50] and the axial force safety limit of the target will be set to $659.675 \mathrm{lb}$-f as taken from the minimum of failure tests documented in Attachments 3 through 6 of [26]. Tests have shown that the yield strength of 6061 grade aluminum increases under irradiation [47].

A special case where the hydrostatic collapse of the target causes the cladding to surround each pellet individually - a concern raised from PIE gamma scans of the irradiated targets - is considered here. To address this, the local strain maxima for each pellet, conservatively allowing no diametrical strain to occur against the adjacent housing, are considered for this case. The unirradiated failure strain for clad material 6061-t4 is 22\%. Under irradiation, the failure elongation decreases and tests [47] for 6061-t6 showed a decrease from $15 \%$ to $9-5 \%$ (from 50 to $150{ }^{\circ} \mathrm{C}$ ). Considering that the $\mathrm{T} 4$ temper has a greater unirradiated elongation than the T6 temper, that temperatures in the housing are below $150{ }^{\circ} \mathrm{C}$, and that neutron fluence in the reference case were on the order of $10^{27} \mathrm{n} / \mathrm{m}^{2}$-s which is two orders of magnitude greater than those expected over 3 cycles $\left(\sim 10^{24}-10^{25}\right)$ the $5 \%$ elongation failure is likely an overly conservative estimate. Taking the middle ground between 50 and $150{ }^{\circ} \mathrm{C}$ loss of elongations and the ratio of the greater elongation for T4 to T6, a better still conservative estimate is given as $\sim 10.27 \%$. In addition, this conservatively assumes that no elastic compression of the pellets will occur, that is the pellets are expanding and incompressible. The saturation temperature of water at reactor pressures is used for the surface temperature limit, as previously described in section 6.4.3.

The minimum safety factor comes from the pellet melting temperature shown in bold, where the calculated maximum temperature for the TLB case at EOC-3 is approximately $150{ }^{\circ} \mathrm{C}$ below the melting temperature. Fig. 6.25 and Fig. 6.26 show a parametric sweep case of the power factor at EOC-3 for the three primary cases (no rigid surface is set for SLB), where the TLB is shown to be constricting for maximum target temperatures, the SLB for target side pressure and the BE between the two cases.

It is worthwhile to note that although for case SLB-2 no radial expansion due to thermal or irradiation effects is allowed to occur past the cladding side wall, some significant side pressure still occurs. This is due to elastic axial compression of the pellet stack that causes a transverse strain into the side wall, a result of the calculated stress/strain equations in COMSOL that are not easily adjusted. 
Table 6.1: Summary of safety limit results for the production target analyses.

\begin{tabular}{|l|cccccc|}
\hline Model Case & $\mathbf{T}_{\max }\left({ }^{\circ} \mathbf{C}\right)$ & $\mathbf{P}_{\text {max-side }}(\mathbf{k s i})$ & $\begin{array}{c}\boldsymbol{\delta}_{\text {min- }} \\
\text { axial }\end{array}(\mathbf{m i l s})$ & $\mathbf{F}_{\text {max-axial }}(\mathbf{l b f})$ & $\mathbf{T}_{\text {max-surf }}\left({ }^{\circ} \mathbf{F}\right)$ & $\boldsymbol{\varepsilon}_{\text {max-local }}$ \\
\hline DB at 100\% flow & 382.40 & 3.30 & 115.45 & 0 & $213.45^{\mathrm{a}}$ & $3.79 \%$ \\
DB at 50\% flow & 403.91 & 3.10 & 116.83 & 0 & $281.79^{\mathrm{a}}$ & $4.05 \%$ \\
TLB & 494.95 & 1.86 & 158.34 & 0 & $270.49^{\mathrm{b}}$ & $2.74 \%$ \\
SLB-1 & 308.93 & 8.50 & 41.28 & 49.31 & $268.00^{\mathrm{b}}$ & $\mathbf{5 . 6 2 \%}$ \\
SLB-2 & 404.87 & 3.50 & 0 & 253.65 & $268.00^{\mathrm{b}}$ & $\mathbf{5 . 7 2 \%}$ \\
\hline Safety Limit & 650 & 21 & N/A & 659.675 & $392^{\mathrm{a}}-432^{\mathrm{b}}$ & $10.27 \%$ \\
Safety Factor & $\mathbf{1 . 3 1}$ & 2.47 & N/A & 2.60 & 1.59 & 1.79 \\
\hline
\end{tabular}

Note a: Model cases with note "a" use a DB inlet pressure and thus surface saturation temperature of $\sim 432^{\circ} \mathrm{F}$.

Note b: Model cases with note " $\mathrm{b}$ " use a DB inlet pressure and thus surface saturation temperature of $\sim 392^{\circ} \mathrm{F}$.

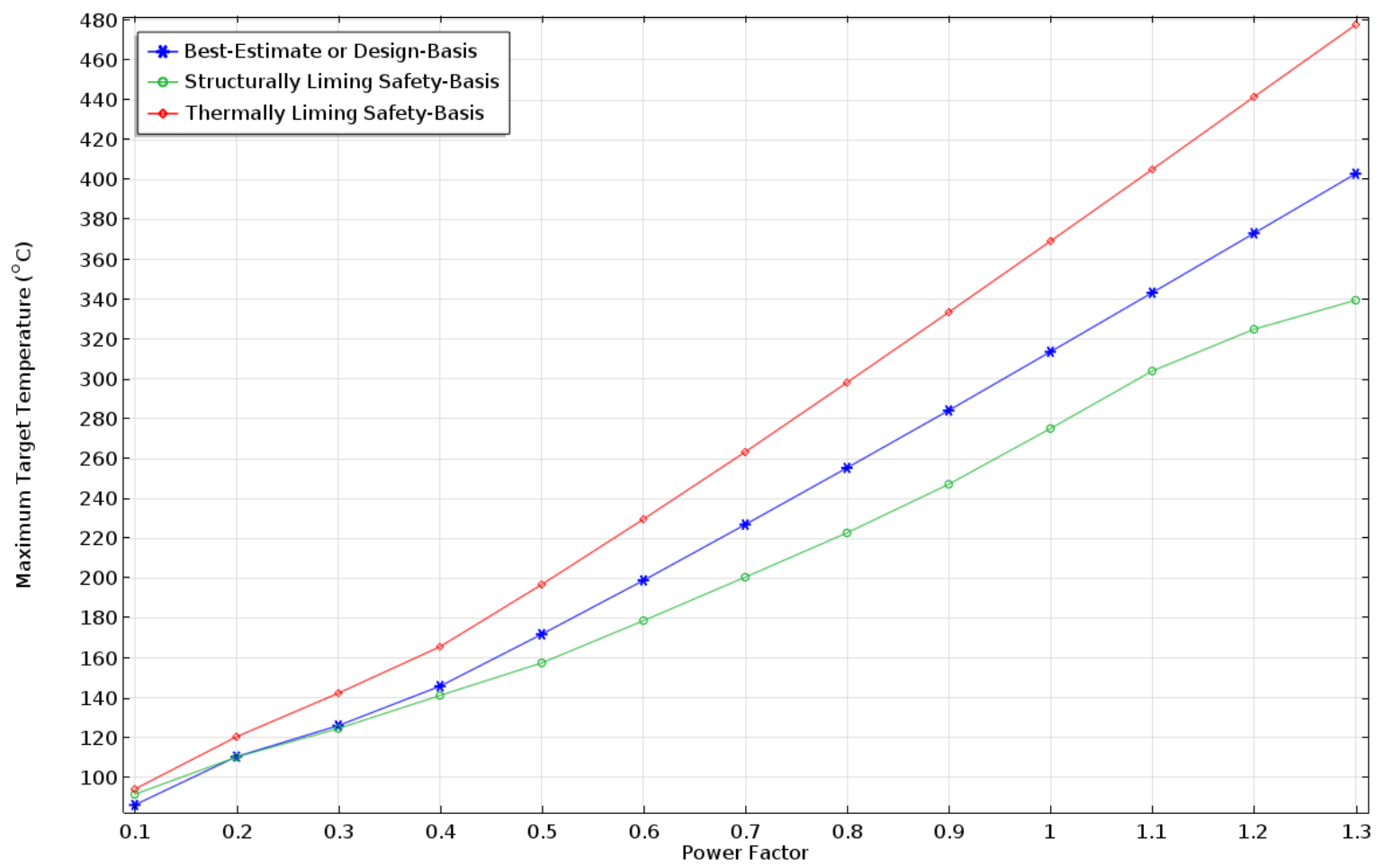

Fig. 6.25: EOC-3 maximum target temperature as a function of the power/volume factor for the BE, SLB, and TLB cases. 


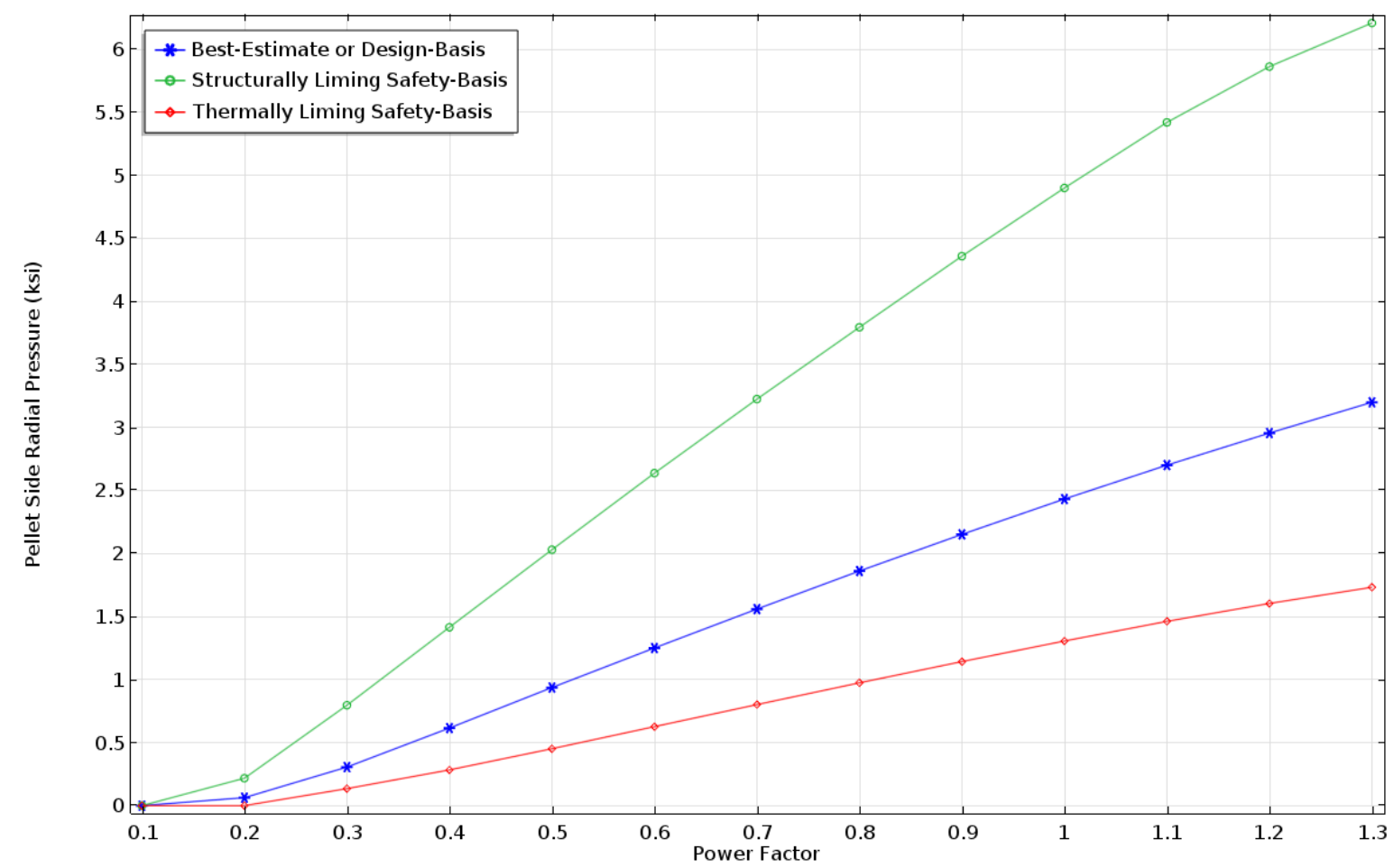

Fig. 6.26: EOC-3 pellet radial side pressure as a function of the power/volume factor for the BE, SLB, and TLB cases.

\subsubsection{Mesh Refinement Study}

Mesh refinement studies were performed for both the best-estimate and TLB cases that will now be discussed. The TLB study was performed at EOC-1 and the best-estimate study was performed at $100 \%$ flow EOC-3 in order to assess a sufficient variety of the solution space.

The number of mesh elements in the pellet/housing region was roughly doubled at each convergence step and an error estimate was made from three post-processing results: 1) the net energy balance loss in the pellets (energy generated minus energy removal), 2) the maximum pellet centerline temperature, and 3) the maximum pellet side pressure (for EOC-3 study) or minimum axial clearance (for EOC-1). The individual error estimates were defined in the equation below, where e is the error norm, $\mathrm{T}$ is the parameter of interest, $\mathrm{k}$ is the element order or basis, and $\mathrm{h} / 2$ denotes the doubling of the mesh number:

$$
e^{h / 2}=\frac{\Delta T^{h / 2}}{2^{2 k}-1}
$$

The final error "norm" is defined as the p-norm of the three individual estimates:

$$
\left\|e^{h / 2}\right\|=\left(\prod_{i=1}^{3} e_{i}^{h / 2}\right)^{1 / 3}
$$

There are some limitations to this error norm estimation method, in that its derivation assumes equal size mesh elements, which is not true for this refinement study, and that it assumes doubling of the mesh number for each refinement step, which is approximately true for this refinement study. The error norm is plotted against the reciprocal of the mesh number in log-log scaling in Fig. 6.27 and Fig. 6.28 using the 
error norm based on an average of all three parameters and the maximum temperature, respectively. Each plot contains refinement curves using linear $(\mathrm{k}=1)$ and quadratic $(\mathrm{k}=2)$ basis elements as well as EOC-1 and EOC-3 inputs. The refinement study for the higher basis quadratic elements have both lower error norms and an increased convergence "slope". The EOC-1 and EOC-3 refinement studies exhibit very similar convergence slopes and error values.

The error norm estimate using only the maximum temperature shows a clear increased convergence slope compared to the 3-parameter averaged error norm, possibly due to the increased role of non-linear physics in the other two parameters. The convergence slopes for all refinement studies fall short of the theoretical values of 2 (for linear basis) and 4 (for quadratic basis), where a value of $\sim 0.85-1.54$ is observed for the linear basis studies and $\sim 1.28-2.92$ is observed for the quadratic basis studies. This is likely due to the non-linear thermo-mechanical feedbacks and complexity of the model, as well as the limitations in this refinement study previously mentioned. Comparing the convergence slopes to those in the revision 4 analysis of the fully loaded target model, there is a considerable increase in the convergence slope likely due to improved methodology in the production model (including augmented Lagrangian contact instead of penalty factor, more detailed meshing control, etc.). For reference, the local convergence slope would be determined as follows, where $\mathrm{M}$ is the number of mesh elements:

$$
\text { slope }=\frac{\log \left(e^{h / M} / e_{e^{h / 2 M}}\right)}{\log (2)}
$$

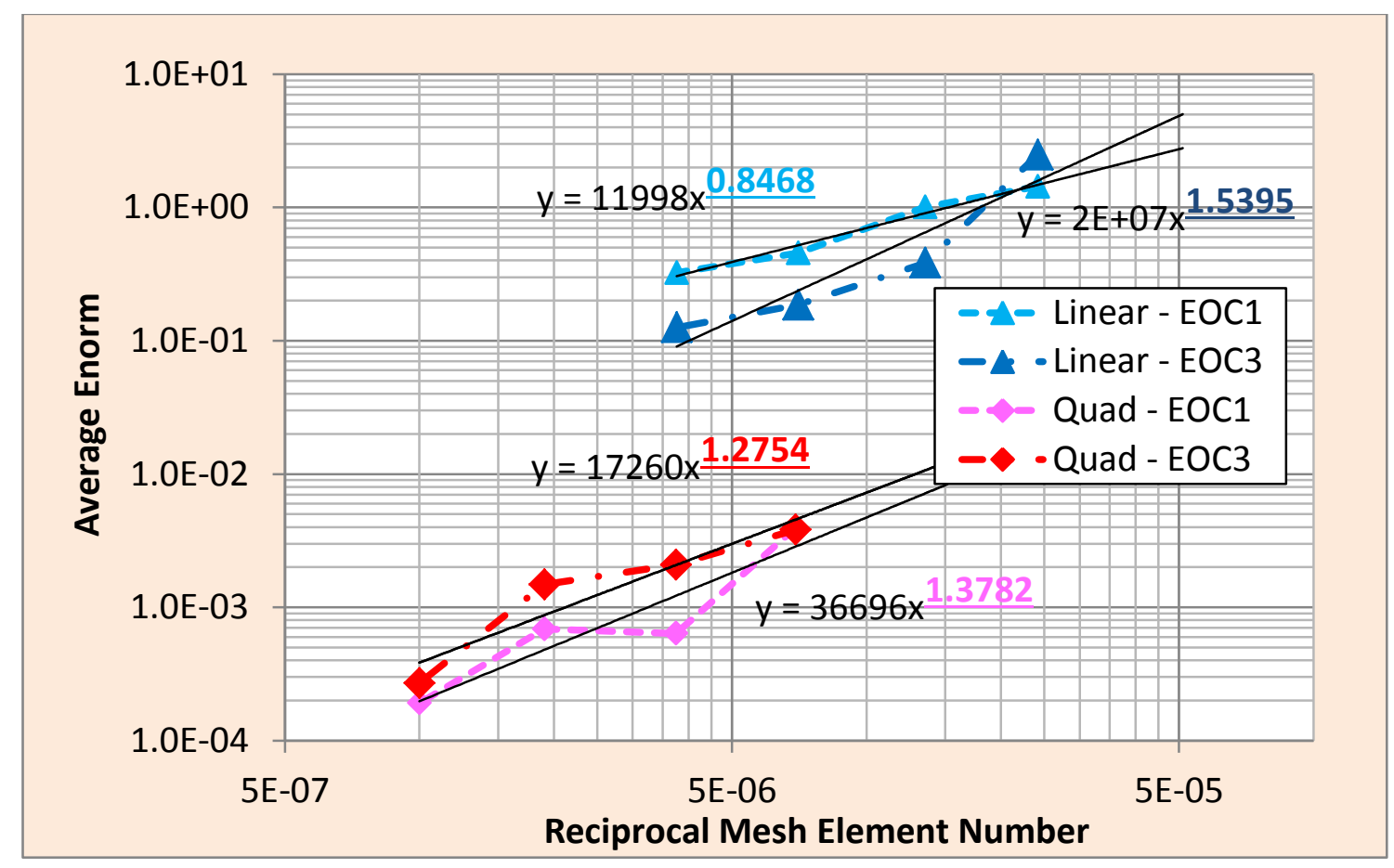

Fig. 6.27: Mesh refinement results for EOC1/EOC3 and linear/quadratic bases using an averaged error norm. 


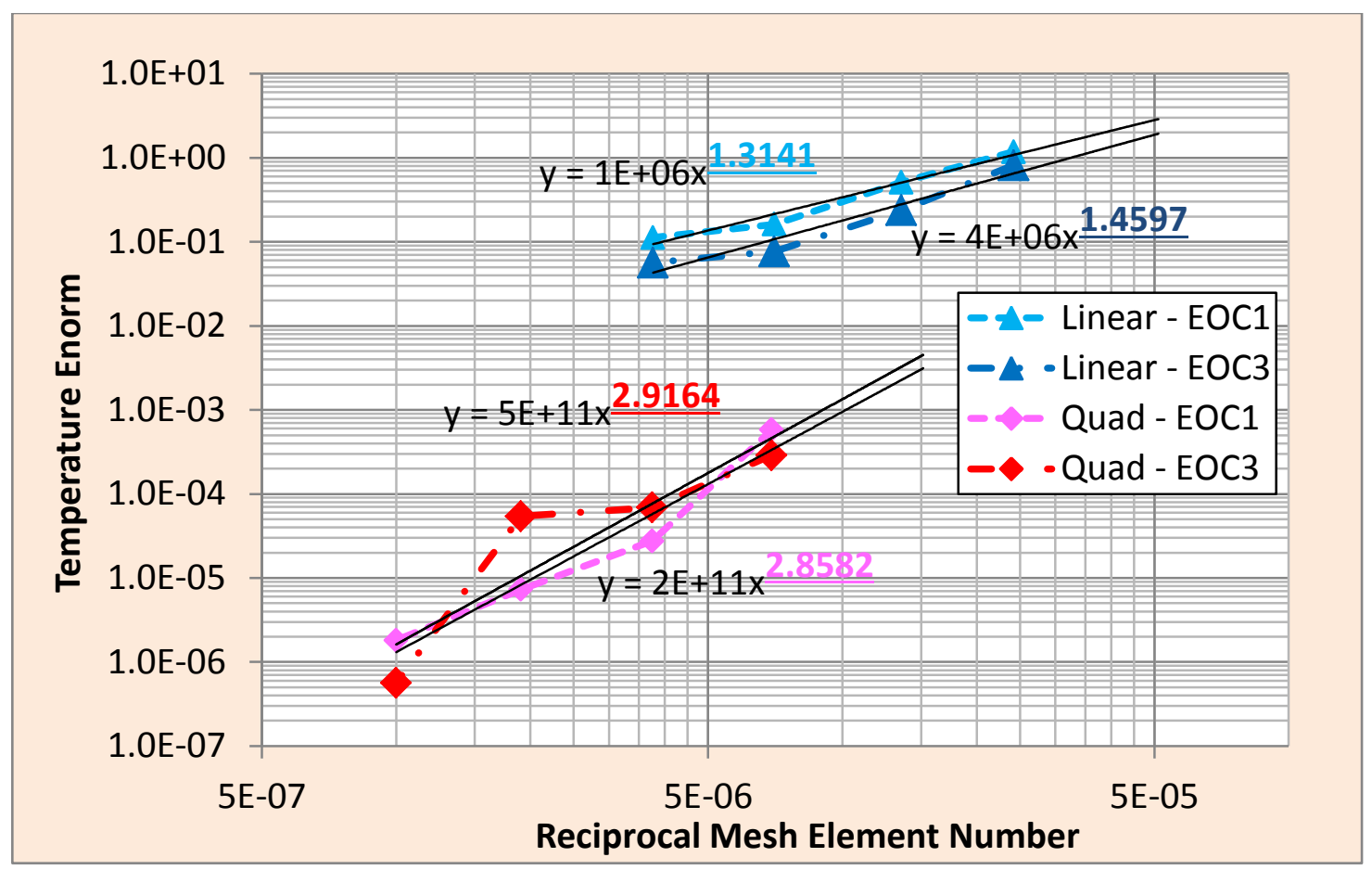

Fig. 6.28: Mesh refinement results for EOC1/EOC3 and linear/quadratic bases using the maximum temperature error norm. 



\section{SUMMARY AND CONCLUSIONS}

A summary of the changing solution scope for the five models detailed in this report is shown in Table 7.1. Each model uses strongly coupled, non-linear thermo-mechanical equations to simulate the steadystate behavior of a specific experiment design and each model's results are used successfully to qualify the irradiation of a ${ }^{238} \mathrm{Pu}$ production target at the HFIR. Detailed summaries of each of the five models, their solution scopes and results are given below.

Table 7.1: Summary of solution scopes for all models

\begin{tabular}{|c|c|c|c|c|c|c|c|}
\hline Model & $\begin{array}{c}\text { Parametric } \\
\text { Sweep }\end{array}$ & $\begin{array}{c}\text { Pellet } \\
\text { Heat- } \\
\text { Treatments }\end{array}$ & $\begin{array}{c}\text { Solution } \\
\text { Search }\end{array}$ & $\begin{array}{c}\text { Pellet } \\
\text { Swelling }\end{array}$ & $\begin{array}{c}\text { Time } \\
\text { Steps }\end{array}$ & Positions & Limiting fields \\
\hline $\begin{array}{c}\text { Bare Pellet } \\
\text { Reduced- } \\
\text { Length }\end{array}$ & Yes & $800{ }^{\circ} \mathrm{C}$ & No & None & 2 & 3 & $\mathrm{~T}_{\max }, \mathrm{T}_{\text {surf }}$ \\
$\begin{array}{c}\text { Partially } \\
\text { Loaded }\end{array}$ & No & $800{ }^{\circ} \mathrm{C}$ & No & Constant & 1 & 1 & $\mathrm{~T}_{\max }, \mathrm{T}_{\text {surf }}$ \\
$\begin{array}{c}\text { Fully } \\
\text { Loaded }\end{array}$ & Yes & $1200{ }^{\circ} \mathrm{C}$, & Yes & Constants & 2 & 1 & $\mathrm{~T}_{\max }, \mathrm{T}_{\text {surf }}$ \\
Production & Yes & $1200{ }^{\circ} \mathrm{C}$ & Yes & $\begin{array}{c}\text { Constants/2 } \\
\text { Functions }\end{array}$ & $2 / 7$ & 2 & $\mathrm{~T}_{\max }, \mathrm{T}_{\text {surf }}$ \\
\hline
\end{tabular}

The initial single pellet steady-state thermal analysis was the "bare pellet" model, where significant pellet shrinkage or densification was not expected to occur, or only to occur at very early irradiation times that could not be observed or have an impact on the limiting safety conditions. This initial analysis first considered the worst case horizontal midplane position at EOC-1, followed by an analysis at two specific positions for EOC-2, identifying an expected 1.1 mil cold fabrication gap as acceptable for irradiation.

After PIE revealed significant shrinkage (and therefore opening of the pellet/housing gap), a new target employing a shortened pellet intended to only require axial heat transfer due to a target spring (densification therefore not a consideration) was designed as the reduced-length pellet capsule. This model was considered at EOC-2 and showed acceptable maximum temperatures for a 2 mil shrinkage and 7 mil fabrication gap.

Each non-prototypical model employed parametric sweeps of the heating power factor to aid convergence, constant terms for characterization of the cold side gap, and although the reduced-length pellet was irradiated for $800{ }^{\circ} \mathrm{C}, 900{ }^{\circ} \mathrm{C}$, and $1200{ }^{\circ} \mathrm{C}$ heat-treatment pellets, only the $800{ }^{\circ} \mathrm{C}$ heat-treated pellet was considered for both models (conservatively). Together, these non-prototypical models allowed for the initial irradiation tests of single pellet capsule designs necessary to collect PIE data and fabrication experience.

The first prototypical model was for the partially loaded target design, including 8 pellets, and the geometry dimensions were reduced from 3-D to 2-D R-Z in order to save computation resources. Because of the reduced margins and unavailable PIE data from the reduced-length tests, two heattreatments at $900{ }^{\circ} \mathrm{C}$ and $1200{ }^{\circ} \mathrm{C}$ were considered, each analyzed using a manual solution search for varying bounding shrinkage and fabrication gaps at EOC-1 and EOC-2. As a result of these analyses and the received PIE data, the target with $1200{ }^{\circ} \mathrm{C}$ heat-treatment pellets was chosen for irradiation. 
The second prototypical target model was for the fully loaded target, containing 52 pellets, and underwent several revisions to its solution scope for evolving results from the incoming PIE data. At first, the same manual solution search method was employed for EOC-1 analysis, analyzed at two different positions VXF-15 and a lower flux location VXF-3. For the EOC-2 analysis, it became necessary to credit the time or burnup-dependent behavior of pellet densification/swelling observed in partially loaded target PIE, using an automated solution search method that found the maximum allowable shrinkage for a range of pellet heat generation rates at EOC-2 conditions. This method, plotted alongside current PIE data at the time, allowed for the irradiation of $2^{\text {nd }}$ cycle targets. As pellet swelling (or densification recovery) was observed, the potential for aggregated pellet stack expansion to place axial force on the target became a concern. As a result, time-dependent analysis in cycle 2 were completed with two swelling curves and, in addition to further confirming acceptable temperature maxima and revealing target time-dependent behavior, supplied axial temperatures for a separate calculation of axial target stresses.

The production model was then created, as the potential for 3 cycles of irradiation with acceptable isotopic quality was realized and the design updated for greater axial clearance, with thermo-mechanical modeling enabled over the entire target domain as opposed to only the pellets and their surrounding components. A large wealth of PIE data from fully loaded target irradiations allowed three curves (a bestestimate and two bounding fits) for dimensional irradiation behavior to characterize the 7 pins of the VXF-15 holder and pin 1 of VXF-3 for 3 cycles of irradiation for 10 time steps in each cycle. The model cases addressed structural as well as thermal limitations, confirming pin 1of VXF-15 as the limiting pellet and reaffirming the target maximum temperature as the limiting safety parameter. This model allowed for the safe irradiation over 3 cycles as well as detailed characterization of the target behavior under irradiation. 


\section{REFERENCES}

[1] Wham, R.M., "The ${ }^{238}$ Pu Supply Project,” Nuclear Energy Technology for Space, February 2016.

[2] Wham, R.M., DePaoli, D.W., Hobbs, R.W., "Reestablishing the Supply of Plutonium-238, 2015 ANS Winter Meeting and Nuclear Technology Expo," Washington, D.C., November 2015.

[3] Hurt, C.J., Wham, R.M., Hobbs, R.W., et. al., "Plutonium-238 Production Target Design Studies, "Institute of Nuclear Materials Management 55th Annual Meeting, Atlanta, GA, July 2014.

[4] Hurt, C.J., Freels, J.D., Griffin, F.P., et. al., "Safety Analysis Models for the Irradiation of 237Np Targets at the High Flux Isotope Reactor," Nuclear and Emerging Technologies for Space 2015 (NETS), Albuquerque, NM, February 2015.

[5] Freels, J.D., Jain, P.K., Hobbs, R.W., "Design and Nuclear-Safety Related Simulations of BarePellet Test Irradiations for the Production of Pu-238 in the High Flux Isotope Reactor using COMSOL," COMSOL Conference 2012, Boston, MA, October 2012.

[6] Freels, J.D., COMSOL Thermal-Structure Interaction Simulations of NpO2 Bare-Pellet Test Capsules in HFIR, C-HFIR-2012-017/R1, September 2012.

[7] Freels, J.D., Thermal-Structure Interaction Simulation of Reduced-Length NpO2 Bare-Pellets During HFIR Irradiation Using COMSOL, C-HFIR-2012-036/R0, December 2012.

[8] Hurt, C.J., Freels, J.D., COMSOL Thermal-Structure Interaction Simulations of NpO2 PartiallyLoaded Targets in HFIR, C-HFIR-2013-007/R0, April 2013.

[9] Hurt, C.J., COMSOL Thermal-Structure Interaction Simulations of NpO2 Fully-Loaded Targets in HFIR, C-HFIR-2013-029/R4, August 2014.

[10] Hurt, C.J., Thermo-Mechanical Safety Analysis of a Pu-238 Fully-Loaded Target Assembly for up to Three Irradiation Cycles in HFIR using COMSOL Multiphysics v5.1, C-HFIR-2015-033/R0, June 2016.

[11] Hobbs, R.W., Irradiation of Fully Loaded Np237 Targets in the HFIR ISVXF Positions, RRD EABD-HFIR-2013-005/R3, August 2014.

[12] Oak Ridge National Laboratory, HFIR Updated Safety Analysis Report, Revision 14, Chapter 4.4 Thermal and Hydraulic Design and Chapter 15, ORNL/HFIR/USAR/2344, October 2014.

[13] Griffin, F.P., RELAP5 Transient Analyses of Pu-238 Fully-Loaded Targets, C-HFIR-2013-030/R0, September 2013.

[14] Chandler, D., Activation and Heat Generation Calculations to Support Pu-238 Fully Loaded Target Irradiations in Inner Small VXFs for up to Three Cycles, C-HFIR-2015-014/R0, September 2015.

[15] Chandler, D., "Neutronics Simulations of 237Np Targets to Support Safety-Basis and 238Pu Production Assessment Efforts at the High Flux Isotope Reactor," Nuclear and Emerging Technologies for Space 2015 (NETS), Albuquerque, NM, February 2015.

[16] Chandler, D., "Development of an Efficient Approach to Perform Neutronics Simulations for Plutonium-238 Production,” PHYSOR Conference 2016, Sun Valley, Idaho May 2016. 
[17] Hobbs, R.W., Chandler, D., Hurt, C.J., et. al., "Potential Improvements to 238Pu Production Targets for the High Flux Isotope Reactor," ANS Winter Meeting 2015, Washington, DC, November 2015.

[18] COMSOL Multiphysics® v. 5.2. www.comsol.com. COMSOL AB, Stockholm, Sweden.

[19] Hoffman, G.L., Rest, J., Snelgrove, J.L., "Irradiation Behavior of Uranium Oxide - Aluminum Dispersion Fuel," 1996 International Meeting for Reduced Enrichment for Research and Test Reactors, Seoul, Korea, October 7-10, 1996.

[20] Assmann, H., Stehle, H., "Thermal and in-reactor densification of UO2: Mechanisms and experimental results," Nuclear Engineering and Design, Volume 48, Issue 1, June 1978, p49-67.

[21] Yanagisawa, K., "Fuel Densification and Swelling: Relationship Between Burn-Up Induced Axial and Radial Fuel Dimensional Changes," Nuclear Engineering and Design, 96 (1986), p11-10

[22] Meyer, R.O. The Analysis of Fuel Densification - Aluminum Dispersion Fuel, Office of Nuclear Regulatory Commission, NUREG-0085, Washington, D.C., July 1976.

[23] Hobbs, R.W., Analysis of Fully Loaded Np237 Target Krypton and Xenon Fission Gas Release Data to Support Third Cycle of Irradiation of Fully Loaded Np237 Target Capsules, C-HFIR-2016008/R0, May 2016.

[24] Owens, R.S., Thermal Conductivity Measurements of Neptunium/Aluminum Cermet Pellets, ORNL Pu-238 Technology Demonstration Project, July 2012.

[25] Owens, R.S., Thermal Expansion Measurements of Neptunium/Aluminum Cermet Pellets, ORNL $\mathrm{Pu}-238$ Technology Demonstration Project, October 2015.

[26] R.W. Hobbs, Evaluation of Axial Stresses in the Fully Loaded Np237 Targets During the 2nd Cycle of Irradiation, C-HFIR-2014-008/R2, September 2014.

[27] Bohler, R., Welland, M.J., et. al, "Revisiting the melting temperature of NpO2 and the challenges associated with high temperature actinide compound measurements," Journal of Applied Physics, Vol. 111, 113501, 2012.

[28] United States National Institute of Standards and Technology, "NIST Chemistry Webbook", http://webbook.nist.gov/chemistry/, 2005.

[29] Madhusudana, C.V., Thermal Contact Conductance, Springer-Verlag, ISBN 0-387-94534-2, 1995.

[30] Garimella, S., Interface Contact Resistance, ME-505 Guest Lecture, Professor Suresh Garimella, Purdue University, September 2005 (a companion to Reference [29]).

[31] Lambert, M.A., Fletcher, L.S., "Thermal Contact Conductance of Spherical Rough Metals,” ASME J. Heat Transfer, Vol. 119, pp. 684-690, 1997.

[32] Antonetti, V.W., White, T.D., Simmons, R.E., "An Approximate Thermal Contact Conductance Correlation," ASME $28^{\text {th }}$ National Heat Transfer Conference, Minneapolis, MN, HTD-Vol. 170, pp.35-42 1991. 
[33] Bahrami, M., et. al., "Review of Thermal Joint Resistance Models for Nonconforming Rough Surfaces," Applied Mechanical Reviews, Vol. 59, pp. 1-12, January 2006.

[34] Lambert, M.A., Fletcher, L.S., "Thermal Contact Conductance of Non-Flat, Rough, Metallic Coated Metals," ASME J. Heat Transfer, Vol. 124, pp. 405-412, June 2002.

[35] Brokaw, R.S., Approximate Formulas for Viscosity and Thermal Conductivity for Gas Mixtures, NASA TN D-2502, November 1964.

[36] TPMD, Thermo-physical Properties of Matter Database, https://cindasdata.com/Applications/TPMD/, ORNL Library web access.

[37] Ullman, A., et. al., "Thermal Accommodation Coefficients of Inert Gases on Stainless Steel and $\mathrm{UO}_{2}$," Journal of Nuclear Materials, Vol. 51, p277-279, 1974.

[38] Thomas, L.B., Loyalka, S.K., "Determination of Thermal Accommodation Coefficients of Inert Gases on a Surface of Vitreous $\mathrm{UO}_{2}$ at $\sim 35^{\circ} \mathrm{C}$," Nuclear Technology, Vol. 59, 1, p63-69, 1982.

[39] Hall, R.O.A., Martin, D.G., "The Evaluation of Temperature Jump Distances and Thermal Accommodation Coefficients from Measurements of the Thermal Conductivity of $\mathrm{UO}_{2}$ Packed Sphere Beds," Nuclear Engineering and Design, Vol. 101, 3, p249-258, 1987.

[40] Rohsenow, W.M., et al., Handbook of Heat Transfer Fundamentals, 2nd edition, McGraw-Hill Book Co., 1985.

[41] Wikipedia data page on Noble gases, http://en.wikipedia.org/wiki/Noble_gas_(data_page), Ultimately referenced to Encyclopedia Britannica and attached to Reference.

[42] Bondi, A., van der Waals Volumes and Radii, The Journal of Physical Chemistry, 68 3, p441-451, 1964.

[43] Van Atta, C.M., "Vacuum Science and Engineering," 1st Edition, McGraw-Hill, Inc., p440-441, 1965.

[44] Hirschfelder, J., Curtiss, C., Bird, R., Molecular Theory of Gases and Liquids, 1st Edition, John Wiley \& Sons, Inc., New York, p1110, 1954.

[45] Incrupera, F.P., DeWitt, D.P., Fundamentals of Heat and Mass Transfer, 5th edition, John Wiley \& Sons, 2002

[46] J. C. Griess et al., Effect of Heat Flux on the Corrosion of Aluminum by Water. Part III. Final 49 Report on Tests Relative to the High-Flux Isotope Reactor, ORNL-3230, December 1961.

[47] K. Farrell, R.T. King, "Tensile properties of Neutron-Irradiated 6061 Aluminum Alloy in Annealed and Precipitation-Hardened Conditions," Effects of Radiation on Structural Materials, ASTM STP 683, J.A. Sprague and D. Kramer, Eds., American Society for Testing and Materials, p440-449, 1979.

[48] Experiment Review Questionnaire: In-Vessel Experiments, EG-6, Revision 1, April 2007.

[49] Schmidt, F.W., Henderson, R.E., Wolgemuth, C.H., Introduction to Thermal Sciences: Thermodynamics, Fluid Dynamics, Heat Transfer, $2^{\text {nd }}$ edition, John Wiley and Sons, Inc., 1993. 
[50] MatWeb: Material Property Data, http://www.matweb.com.

[51] NIST, NIST Reference Fluid Thermodynamic and Transport Properties - REFPROP, NIST Standard Reference Database 23, Version 8.0, April 2007. 